\title{
A Review on the Thermal Hazards of the Lithium-Ion Battery and the Corresponding Countermeasures
}

\author{
Dongxu Ouyang ${ }^{1}$, Mingyi Chen ${ }^{2} \mathbb{D}$, Que Huang ${ }^{3}$, Jingwen Weng ${ }^{1}$, Zhi Wang ${ }^{1}$ and \\ Jian Wang ${ }^{1, *(1)}$ \\ 1 State Key Laboratory of Fire Science, University of Science and Technology of China, Hefei 230026, China; \\ ouyang11@mail.ustc.edu.cn (D.O.); wengjw@mail.ustc.edu.cn (J.W.); ustc14wz@mail.ustc.edu.cn (Z.W.) \\ 2 School of Environment and Safety Engineering, Jiangsu University, Zhenjiang 212013, China; \\ chenmy@ujs.edu.cn \\ 3 School of Environment and Safety Engineering, North University of China, Taiyuan 030051, China; \\ que.huang@nuc.edu.cn \\ * Correspondence: wangj@ustc.edu.cn
}

Received: 28 April 2019; Accepted: 12 June 2019; Published: 18 June 2019

\begin{abstract}
As one of the most promising new energy sources, the lithium-ion battery (LIB) and its associated safety concerns have attracted great research interest. Herein, a comprehensive review on the thermal hazards of LIBs and the corresponding countermeasures is provided. In general, the thermal hazards of the LIB can be caused or aggravated by several factors including physical, electrical and thermal factors, manufacturing defect and even battery aging. Due to the activity and combustibility of traditional battery components, they usually possess a relatively high thermal hazard and a series of side reactions between electrodes and electrolytes may occur under abusive conditions, which would further lead to the thermal failure of LIBs. Besides, the thermal hazards generally manifest as the thermal runaway behaviors such as high-temperature, ejection, combustion, explosion and toxic gases for a single battery, and it can even evolve to thermal failure propagation within a battery pack. To decrease these hazards, some countermeasures are reviewed including the application of safety devices, fire-retardant additives, battery management systems, hazard warnings and firefighting should a hazard occur.
\end{abstract}

Keywords: lithium-ion battery; thermal hazard; management and countermeasures

\section{Introduction}

In light of the steadily increasing energy demands and the consensus regarding the reduction of pollution, humans have paid great attention to the development of new energy such as solar energy, wind energy, tidal energy, lithium-ion battery (LIB) and fuel cell [1-5]. Advantages including high energy density, less pollution, stable performance and long-life cycle compared to many alternatives have made LIBs the dominant power sources for electrical applications [6,7]. Especially, with the approaching era of electric vehicles (EVs), it is foreseeable that the use of LIB will be more common in the future.

However, behind the boom, there exist challenges that must be faced. As a result of the high energy density of LIBs, they are sensitive to abusive conditions such as high temperature, crashing, overcharge, over-discharge and short-circuit, etc. [8-10]. Moreover, the typical components of a battery, e.g., plastic packing, separator and electrolyte are combustible. Thereby, the accidents induced by LIBs are frequently reported and can occur in a range of applications from mobile telephones, to EVs and even airplanes [11-14]. Especially with the increasing energy density, e.g., the popularity of $\mathrm{LiNi}_{0.8} \mathrm{Mn}_{0.1} \mathrm{Co}_{0.1}$ (NMC811), the problems will be exacerbated $[15,16]$. The abusive conditions 
described above will destroy the original stable structure of battery, which triggers chain reactions inside battery and eventually leads to thermal runaway. Among, thermal runaway of a battery typically manifests as high temperature, gas ejection, violent combustion and even explosion, which will lead to catastrophic results.

Regarding the thermal hazards of the LIB, much research has been directed toward enhancing the inherent safety of battery and improving the thermal management to prevent thermal failure. For the former, it mainly focuses on enhancing the fire-retardant performance of battery components including the cathode, anode, electrolyte, additives and separator [17-27]. As for the latter, it includes the inclusion of battery safety devices, thermal management of LIBs during usage, thermal hazards warning and firefighting should a hazard occur. The thermal management of the LIB can usually be categorized into several types including air, liquid and phase change material (PCM) based systems [28-33]. Prior to the occurrence of a thermal hazard, LIBs are prone to experiencing evident increases in temperature and may also release representative gases such as $\mathrm{CO}, \mathrm{H}_{2}$ and $\mathrm{SO}_{2}$. Therefore, battery safety devices such as vents can be used to terminate the deterioration of failure, meanwhile a temperature sensor or gas sensor can also be applied to warn to the hazard [34-37]. Finally, if the thermal hazards are accompanied by severe combustion, it is necessary to fight the fire to impede its progression. Until now, researchers have paid great attention to firefighting methods and extinguishers so that the flame or combustion of the LIB can be extinguished effectively [38-41].

Although much work has been done on the thermal hazards of the LIB, comprehensive summaries on the thermal hazards of batteries involving battery components, a single battery and a battery pack are scarce. Besides, most researchers focus on the thermal management of battery during normal usage, countermeasures that suppress the thermal hazard require further study. The current work provides a comprehensive review on the thermal hazards of battery, and related thermal hazard prevention techniques. The Section 1 partially summarizes the safety-related LIB incidents that have occurred in recent years. The Section 2 is regarding the common causes of battery thermal hazard and the respective mechanism. The Section 3 demonstrates the thermal hazards of the LIB, involving typical battery components, a single battery and a battery pack. It is worthy to be noted that the influence of low-pressure environment and cathode chemistry on the thermal hazard is also involved. The Section 4 is concerning how to prevent the thermal hazard of a battery and improve its safety which can be divided into inherent safety methods and extra countermeasures.

\section{Safety-Related Incidents Involving Lithium-Ion Batteries}

Table 1 lists several representative incidents of LIB failure in recent years which can be divided into three main types including mobile telephone, EV and airplane [13,42-44]. With regard to safety-related battery incidents in mobile telephones, it is apparent that nearly all mainstream mobile telephones have experienced such incidents, e.g., Apple, Samsung and Huawei. Take the Samsung Note 7 as an example, it was released on 3 August 2016, and then its first reported explosion was on August 24, 2016. In the end, quantities of incidents forced Samsung to recall all Note 7 devices around the world on 2 September 2016. This greatly damaged consumer confidence in Samsung, and ultimately resulted in a sharp decrease in its market share and a loss of 17 billion dollars. The root reason of Note 7 incidents was attributed to the battery fault, i.e., Samsung adopted an excessively thin separator to increase the energy density of battery that substantially increased the possibility of the battery short-circuiting. Similar faults also occurred in the other failed batteries. For EVs, most safety-related battery incidents appeared under the conditions of crashing, charging, discharging and self-ignition, which subsequently led to the short-circuit of batteries. Although the failure rate of EV is approximately $1 / 10,000$, which is much lower than that of traditional vehicles (7.6/10,000 [45]), this issue still significantly hinders the development of EVs. In the case of incidents on airplanes, these usually resulted from the failure of passengers' electronic equipment where the battery caught fire, filled the cabin with smoke and led to catastrophic results. These accidents forced civil aviation bureaus around the world to take strict administration regarding portable electronics. Research revealed that battery failures in airplanes 
were generally the results of battery fault, aircraft vibration, pressure change and temperature change, which subsequently induced short-circuiting of the batteries.

Table 1. Selected incidents of lithium-ion battery failure in recent years.

\begin{tabular}{|c|c|c|c|c|}
\hline Classification & No. & Date & Location & Accident Reply \\
\hline \multirow{8}{*}{ Mobile telephone } & 1 & 2016.8 .24 & Korea & The first explosion of a Note 7 in the world [46] \\
\hline & 2 & 2016.9.18 & China & The first explosion of a Note 7 in China [46] \\
\hline & 3 & 2016.10.10 & China & An iPhone 7 exploded and hurt the user [47] \\
\hline & 4 & 2016.10 .14 & China & A Huawei P9 exploded during charging [48] \\
\hline & 5 & 2016.10.17 & Australia & An iPhone 7 caught fire which then, burned a car [49] \\
\hline & 6 & 2018.1.9 & Switzerland & $\begin{array}{l}\text { An iPhone exploded when replacing the battery, which caused an } \\
\text { injury and seven poisonings [50] }\end{array}$ \\
\hline & 7 & 2018.1.10 & Spain & An iPhone exploded which caused thick smoke inside the store [50] \\
\hline & 8 & 2018.12.30 & America & An iPhone XS Max self-ignited and burned the user [51] \\
\hline \multirow{8}{*}{ EV } & 1 & 2016.1 .1 & Norway & A Tesla Model S caught fire during charging [52] \\
\hline & 2 & 2016.5.14 & China & An EV bus caught fire because of battery pack short-circuit [52] \\
\hline & 3 & 2016.9 .7 & Netherlands & $\begin{array}{l}\text { A Tesla Model S crashed to a tree which caused the battery to catch fire, } \\
\text { resulting in the death of the driver [52] }\end{array}$ \\
\hline & 4 & 2017.1.15 & China & An EV bus self-ignited during driving [53] \\
\hline & 5 & 2017.2.19 & China & A Tesla Model X caught fire after crashing [53] \\
\hline & 6 & 2017.5.1 & China & An EV bus self-ignited during charging [53] \\
\hline & 7 & 2018.3.24 & America & A Tesla Model S caught fire whilst stationary [54] \\
\hline & 8 & 2018.5.21 & China & An EV bus self-ignited during driving [54] \\
\hline \multirow{4}{*}{ Airplane } & 1 & 2010.9.3 & $\begin{array}{l}\text { The United } \\
\text { Arab Emirates }\end{array}$ & $\begin{array}{l}\text { A Boeing } 787 \text { crashed due to the battery catching fire, which caused } \\
\text { two deaths [55] }\end{array}$ \\
\hline & 2 & 2013.1.7 & America & $\begin{array}{l}\text { The battery pack caught fire and filled the cabin of a Boeing } 787 \text { with } \\
\text { smoke [56] }\end{array}$ \\
\hline & 3 & 2013.1.16 & Japan & $\begin{array}{l}\text { The battery pack caught fire during a Boeing } 787 \text { flight from } \\
\text { Yamaguchi-Ube to Tokyo [56] }\end{array}$ \\
\hline & 4 & 2014.4 & Australia & $\begin{array}{l}\text { A Boeing } 737 \text { caught fire due to the short-circuit of the battery inside a } \\
\text { trunk [57] }\end{array}$ \\
\hline
\end{tabular}

As known, it is essential for LIB to pass several compulsory test standards, e.g., UN R100, SAE-J2464, IEC-62133 and GB/T 31485 etc. before its application. Therefore, it must be queried, why do incidents involving batteries still occur sporadically, even if these batteries have passed the test standards? The answers can be attributed to two factors: (1) the inherent possibility of battery failure and (2) the abusive conditions associated with their practical use. Similar to certain other equipment, an inherent possibility of self-induced failure exists for LIBs even if the probability of this is very low. It some cases, the working circumstances of LIBs are very complex and certain abusive conditions such as external forces, high temperature, low temperature, overcharging, over-discharging, etc. are typically experienced. Under the effects of abusive conditions, the manifestation of the battery failure will be more severe. Furthermore, the abusive conditions associated with batteries can typically be categorized into physical, electrical, and thermal factors even manufacturing defect and battery aging, which are reviewed in the next section.

\section{The Causes of Thermal Hazards Associated with Lithium-Ion Batteries}

Generally, LIB possesses stable structure in which lithium ions transfer between the cathode and the anode during charging/discharging such that it can be regularly cycled considerable times. Whereas, the original stable-structure of the LIB will become damaged due to the effect of abusive factors, generating thermal hazard. The factors can be summarized as several main types: physical, electrical and thermal factors, as well as manufacturing defect and battery aging [14,58-62].

\subsection{Physical Factor}

The destructive deformation of battery caused by an applied force is a common feature of physical factor. Where, vehicle collision/crash and penetration of battery are the typical conditions for physical failure. Furthermore, the volume expansion of electrode materials and stress generation within battery may also lead to physical failure. 
As seen in Table 1, many safety-related incidents involving the batteries of EVs took place after deformation. It reveals that during an accident involving the vehicle, it is possible for a single battery or a battery pack to deform under the effect of an external force. The deformation of battery may result in dangerous consequences: (1) the electrodes can come into contact causing an internal short circuit and (2) the flammable electrolyte leaks which may induce a fire.

Penetration, another common physical phenomenon may occur if the battery is affected by sharp objects. It is generally listed in the test standards of the LIB, i.e., GB/T 31485-2015, SAE J2464-2009 etc., to trigger the internal short circuit. Compared with collision or crash, penetration may result in more severe consequences due to the severity of the internal short circuit. In this case, severe short-circuit of the battery will rapidly take place and then severe heat release, combustion and even explosion may occur.

As known, the compressive stress reached during lithiation and the tensile stress reached during delithiation are significant inside battery $[63,64]$. Such large stress cycling over extended lithiation/delithiation cycles will invariably lead to fatigue damage, leaving battery materials susceptible to fracture and pulverization. Moreover, traditional electrode materials, such as silicon and transition metal oxides, may result in extreme volume changes during operation and further result in fracturing, electrical conductivity loss and mechanical integrity [65].

\subsection{Electrical Factor}

External short circuit, overcharge and over-discharge are common conditions of electrical failure. Where, the external short circuit of battery occurs once electrodes with a voltage difference are connected by conductors. It usually results from the deformation of battery, water immersion, conductor aging, improper usage and long-time charging, etc. During an external short circuit, the battery is in a state of fast discharging and the discharging current may be much larger than that of normal condition. Hereafter, the battery undergoes a violent temperature rise which may lead to serious consequence.

As the open circuit voltage of battery is charged above the cut-off voltage, overcharge occurs. The failure of battery management system is the ordinary reason of overcharge so that the charging of battery will proceed continuously. As a result, the internal pressure of battery increases, the deformation of battery and leakage of electrolytes occur, and the performance of battery also significantly decreases. Besides, severe heat and gas generation can also be seen during overcharge process. Compared to normal charging process, the heat generation behavior during overcharge will be much greater as a result of the side reactions inside battery and the increased internal resistance. In addition, excessive loss of lithium ions at the cathode during overcharging will lead to structural collapse of the cathode and subsequent oxygen release. The released oxygen accelerates the decomposition of electrolyte, and thereafter, gases are generated. Consequently, the thermal hazard associated with an overcharged battery is greatly heightened compared to that of a normal battery due to the excessive energy stored in the overcharged battery.

Similarly, when the open circuit voltage of battery is discharged below the cut-off voltage, over-discharge occurs and the failure of battery management system is also a typical reason for over-discharge. Over-discharge causes an excessive loss of lithium ions on the anode which will destroy the stable structure of the anode and cause irreversible damage. Meanwhile, gases such as CO and $\mathrm{CO}_{2}$ can also be generated, resulting in battery swelling. Furthermore, over-discharge will cause the dissolution of copper collector. The dissolved copper migrates and deposits onto the surface of the anode, which will pierce the separator, causing a short circuit to form. Consistent with the other abusive conditions, substantial heat release also occurs upon over-discharge of the LIB.

\subsection{Thermal Factor}

Besides the overheating caused by physical or electrical factors, thermal failure can also be triggered by external high temperature and overheating. Thermal factor results in a fierce rise of battery temperature, the melting of separator, the decomposition of electrodes/electrolytes and numerous side 
reactions etc., and finally leads to battery thermal runaway. In other words, thermal abuse is the root cause of battery thermal runaway. It should be noted that both physical and electrical factors also ultimately cause thermal runaway. Further, it can be found that almost all the abusive conditions are accompanied with internal short circuit, i.e., an internal short circuit is the most common feature of thermal runaway. It occurs when the cathode and the anode contact with each other due to the failure of battery separator. Once the internal short circuit is triggered, the electrochemical energy stored inside the battery spontaneously releases, generating large amounts of heat.

\subsection{Manufacturing Defect and Aging}

Apart from the external factors, battery internal defect due to poor manufacturing, such as a low-quality separator, material contaminant, and improperly arranged constituents, can also cause battery failure and result in thermally hazardous conditions [66]. As stated in Section 2, the main cause of incidents in the Samsung Note 7 was a battery fault, in other words, Samsung adopted an excessively thin separator to increase the energy density of battery which raised the possibility of battery short circuit [67]. Mohanty et al. [68] undertook a systematic investigation on several plausible cathode defects such as agglomeration, pinholes, metal particle contamination and non-uniformity. The findings showed that cathode agglomeration aggravated the cycle efficiency and resulted in faster capacity fading. Electrode pinholes showed substantially lower discharge capacities compared to the baseline of electrodes. Metal particle contaminants had an extremely negative effect on performance, and the electrodes with severe non-uniform coatings showed poor cycle life. In summary, cathode material defects decrease battery performance and increase the risk of thermal hazard. In addition, a low-quality separator will reduce the efficiency of $\mathrm{Li}^{+}$passing through the separator and result in serious Li plating, which will further penetrate the separator and induce the internal short circuit [69]. The improper arrangement of constituents is also harmful to the operation of battery, deteriorates the heat generation and heat release, therefore decreases battery safety.

Finally, due to deterioration associated with battery aging, its thermal hazards will increase correspondingly. The aged battery will lose quantities of lithium and active materials [70,71]. Partially inactivated $\mathrm{Li}^{+}$will transfer to $\mathrm{Li}$ metal and deposit onto the surface of electrodes and even the separator to form Li plating. Upon the progression of battery aging, the degree of Li plating will increase gradually and subsequently, dendrite is generated. The dendrite may penetrate the separator and form a bridge between the electrodes, which will cause micro-shorting inside the battery and eventually lead to failure of the battery. At the same time, the thickness of the solid electrolyte interface (SEI) layer will gradually increase with the aging of the battery, which will lead to increases in the battery resistance, heat generation and thermal hazards.

To better understand the thermal hazards of LIBs, some aspects regarding typical battery components, a single battery and a battery pack will be reviewed. In addition, the influence of certain parameters such as low pressure and cathode chemistry are also considered.

\section{Thermal Hazards of Lithium-Ion Battery}

\subsection{Thermal Hazards of Typical Battery Components}

In general, a LIB is mainly composed of electrodes, electrolytes and a separator. The electrodes can further be divided into the cathode and the anode. The thermal hazard of the LIB usually results from the destructive reactions of battery components such as the decomposition of electrode/electrolyte, the reaction between electrodes, the reaction between electrode and electrolyte, etc. In order to gain a comprehensive understanding on the thermal hazards of the LIB, the hazards of typical battery components will be discussed following. 


\subsubsection{Thermal Hazards of the Electrolytes}

Due to its relatively high content and liquidity, the combustion behavior of electrolyte is quite complicated. According to previous research, the initial decomposition temperature of electrolyte is approximately $80^{\circ} \mathrm{C}[72,73]$, and large quantities of heat and gas are released, which easily lead to LIB leakage. In addition, the electrolyte will react with electrodes with the increasing temperature. At the meantime, leaked electrolyte will increase the liquid fire risk once ignition occurs. If the internal temperature of the LIB is higher, it will lead to a jet fire, and then noticeably accelerate the spread of fire.

Currently, among the commonly used commercial electrolytes, lithium salt is mainly used as lithium hexafluorophosphate $\left(\mathrm{LiPF}_{6}\right)$ or lithium tetrafluoroborate $\left(\mathrm{LiBF}_{4}\right)$. For the functional mechanism of the two kinds of lithium salts in electrolyte combustion process, Sloop et al. compared and analyzed the pyrolysis process of $\mathrm{LiPF}_{6}$ and phosphorus pentafluoride $\left(\mathrm{PF}_{5}\right)$ in ethylene carbonate/dimethyl carbonate (EC/DMC), and found that the products were almost the same [73]. Nagasubramanian et al. analyzed the thermal decomposition process of $\mathrm{LiPF}_{6}$ in methyl ethyl carbonate (EC/EMC), and then put forward the pyrolysis mechanism of the $\mathrm{LiPF}_{6}$ under high temperature [74-76]:

1. Lithium salt undergoes thermal decomposition to form $\mathrm{PF}_{5}$;

2. $\mathrm{PF}_{5}$ reacts with water to generate hydrogen fluoride (HF);

3. $\mathrm{PF}_{5}$ can also react with carbonate solution to form methyl fluoride $\left(\mathrm{CH}_{3} \mathrm{~F}\right)$ and other substances.

In addition, it is generally regarded that $\mathrm{LiBF}_{4}$ is superior to $\mathrm{LiPF}_{6}$ with respect to factors such as high-temperature performance, reaction characteristics with water and chemical stability $[77,78]$. However, the anion of $\mathrm{LiBF}_{4}$ is very small and it can be easily combined with lithium ions in solution, resulting in its weak ion transport ability. To overcome this weakness, researchers chelated lithium salt with oxygen to synthesize new large anionic lithium salts, such as lithium diethylborate (LiBOB) and lithium fluoroethylborate (LiDFOB) [79,80].

After a long period of development, some researchers believe that liquid electrolytes have inherent safety disadvantages. No matter how good the electrolyte additives and solutions are, they cannot prevent the formation of lithium dendrites. Therefore, researchers have started to develop solid-phase electrolytes [81-84].

\subsubsection{Thermal Hazards of the Electrodes}

Nowadays, lithium nickel manganese cobalt oxide (NMC) ternary positive electrode material is one of the most widely used cathode materials, with high capacity, low cost and relatively good safety, which has been vigorously promoted in the current power battery industry [85]. The researchers found that with the higher content of Ni element, the cost would be significantly reduced, and the specific capacity would be higher [86]. However, the battery cycle life and the stability of electrode and electrolyte would be lower. Therefore, it is important to study the effect of element content in the NMC ternary material. Ma et al. compared the thermal runaway behavior of various NMC cathode materials with electrolytes at high temperature by accelerating calorimeter (ARC), while the results showed that under different cut-off voltages, using a traditional carbonate solution as the electrolyte, with the increase of Ni content, the initial temperature corresponding to the reactions between electrode and electrolyte was reduced, i.e., the fire risk of the LIB increased [16]. The material used in previous research was a common NMC cathode, made from a hydroxide precursor system, with a powder particle size of about $10 \mu \mathrm{m}$. The surface was not coated or modified to improve the performance. On the basis of traditional polycrystalline NMC materials, new single-crystal NMC materials have been developed, which are expected to improve battery stability at elevated temperatures [87].

For positive electrode materials, the amount of lithium embedded will directly affect the amount of heat produced. The more lithium that is embedded, the less heat the whole LIB system will generate. If there is only the electrode material without electrolyte, almost no heat will be released [88] and the reactivity between positive materials and different electrolytes will also be different. Wang et al. analyzed the heat production from the reaction between cobalt acid lithium batteries and different 
electrolytes using a C80 micro-calorimeter, and the results showed that when compared with chain solvent, the annular solvent was more stable. Among the various chain carbonate solutions, DMC showed the highest reactivity, while diethyl carbonate (DEC) presented the lowest [89]. According to the above research, the heat production mechanism of positive electrode with electrolyte can be summarized as follows: The stability of electrode material will decrease and the temperature will increase, resulting in the decomposition of the positive electrode material and oxygen release during the charging process. The oxygen will react with the electrolyte and negative electrode leading to substantial heat release and gas generation, thus greatly increasing the risk of thermal failure.

For negative electrode materials, most of the commercial anode material is carbon such as graphite. On the anode surface, a layer of SEI would be formed during the first charge and discharge cycle. The SEI layer will not affect the lithium ion transport and can also prevent direct contact occurring between the anode and the electrolyte, which reduces the cycle performance. While the existence of the SEI will to some extent influence the capacity of LIBs, and its thermal stability under high temperature is poor. Barnett et al. investigated the graphite anode with organic electrolyte containing $\mathrm{LiPF}_{6}$ using ARC and differential scanning calorimetry (DSC), and the results indicated that the initial exothermal temperature of the system was about $80^{\circ} \mathrm{C}$, while the starting temperature of rapid heat production was about $150^{\circ} \mathrm{C}$, which was regarded as the thermal runaway temperature of the LIB. At the same time, other scholars have studied the pyrolysis of the SEI. With the increase of temperature, the initial structure of the SEI would be destroyed, thus losing its protective function, leading to the reaction between electrode and electrolyte and the release of heat [90-92].

\subsubsection{Thermal Hazards of the Separator}

At present, the LIB separator is commonly made of polyethylene (PE), polypropylene (PP) or their composite materials. However, because of their low thermal deformation temperature (PE: within $85^{\circ} \mathrm{C}$, PP: within $100{ }^{\circ} \mathrm{C}$ ) [93], the polyolefin separators will suffer severe thermal contraction when ambient temperature is relatively high, thus it is not suitable for the usage under high temperature environment. In order to meet the requirement of the complex working environment of the LIB, researchers have developed a variety of new composite separator materials and optimized their performance from the aspects such as preparation process improvement [94-96]. Among them, a new type of separator material obtained by the composite of polyaryl ether and thermoplastic resin has attracted extensive attention due to its superior ionic conductivity and high safety [97,98]. Zhong et al. developed a series of poly aryl ether materials, including poly aryl ether ketone (PPEK), poly aryl ether sulfone (PPES), poly (phthalazinone ether sulfone ketone) (PPESK) and so on. Their glass transition temperatures were over $260{ }^{\circ} \mathrm{C}$, and the $5 \%$ thermal weightlessness temperatures were close to $500{ }^{\circ} \mathrm{C}$. Upon analysis using an electrostatic spinning process, the poly aryl ether materials with polyvinylidene fluoride (PVDF) as a composite separator of a LIB showed excellent electrochemical performance and thermal stability $[99,100]$.

Although the high-temperature resistant separator can significantly improve the safety condition of the LIB, it cannot completely inhibit the occurrence of thermal hazard. According to the previous research, although the mass ratio of the separator is approximately $3 \%$, it can release up to $33 \%$ of heat in the combustion process, see Figure 1, indicating that the combustion characteristics of separator directly affect the fire risk of the LIB [76]. Therefore, the research and development of a new separator material with high thermal safety is essential.

\subsection{Thermal Hazards of a Single Battery and Battery Pack}

Due to the high energy density of the LIB and the inherent hazards of battery components described above, it is common for the LIB to experience thermal hazards especially under abusive conditions. For a single battery, the thermal hazards are generally exhibited as high-temperature, ejection, combustion, explosion and toxic gases during thermal runaway. As for a battery pack, thermal failure propagation within the pack can also be observed. 


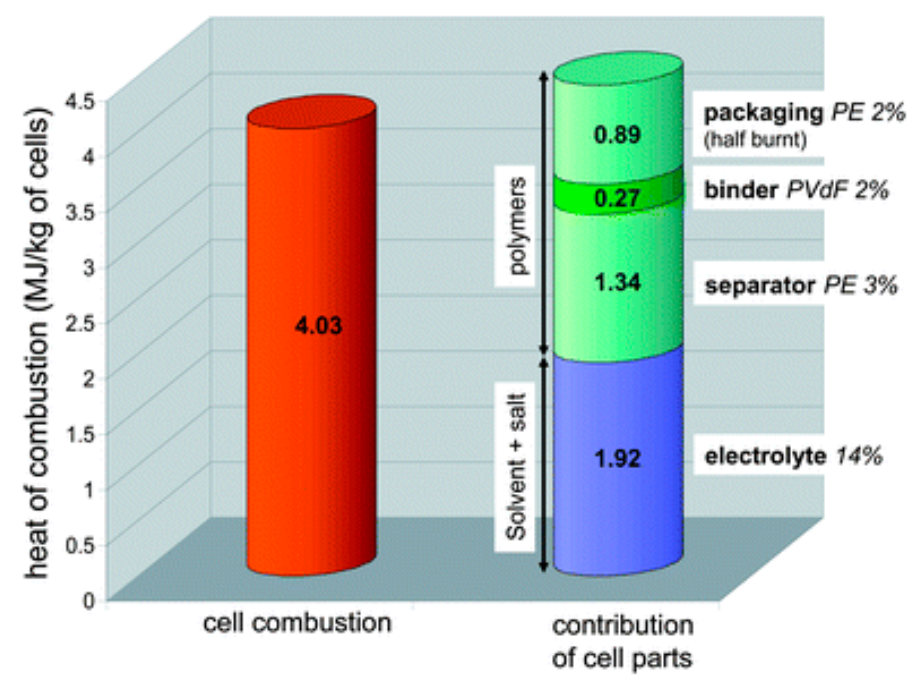

Figure 1. The combustion heat distribution of lithium-ion battery: the overall combustion heat on the left was determined using experimental results, while the combustion heat of battery components on the right was obtained by the thermodynamic calculations. Adopted from Ref. [76].

\subsubsection{Thermal Hazards of a Single Battery}

With the proceeding of chain reactions inside battery during thermal runaway such as the decomposition of SEI layer, the decomposition of electrode and electrolyte, the reactions between electrode and electrolyte, and the combustion of electrolyte [101,102], substantial heat will be generated which leads to the sharp increase of battery temperature. Figure 2 displays the typical curves of battery surface temperature and mass during the thermal runaway process, where the thermal runaway is triggered with a $2.5 \mathrm{~kW}$ electronic heater. As observed, the surface temperature of battery increases stably under the effect of the heater. The SEI layer decomposes at about $69^{\circ} \mathrm{C}$ [90], which enables the reaction between electrolyte and anode to take palace. As the temperature builds up, the intercalated lithium in the anode can also react with electrolyte and release heat [102]. At around $130{ }^{\circ} \mathrm{C}$, the polymer separator will melt [103,104], resulting in the internal short circuit between cathode and anode, therefore a number of reactions take place that contribute to the accumulation of heat and pressure. At approximately $150^{\circ} \mathrm{C}$, the safety vent of battery opens to decrease the pressure, hereafter gases releasing appears. As the continuous rising of battery temperature, the released combustible gases will be ignited, and then thermal runaway occurs. It can be observed that the surface temperature has a sharp increase to the peak value after thermal runaway, which ranges from $400-700{ }^{\circ} \mathrm{C}$ and it is related to battery chemistry, state of charge (SOC) and capacity etc. [105-107].

Once the safety vent cracks, quantities of gases will be ejected, which is accompanied by a clear sound $[108,109]$. The ejected gases are usually high-temperature, toxic and combustible, which will be ignited soon and exhibited as the first combustion. Furthermore, after thermal runaway appears, the second combustion will be generated. It is much more violent than the first one and is usually accompanied with the ejection of flame. The experimental phenomena during thermal runaway can be seen in Figure 3. According to the result of Fu et al., the axial flame temperature could reach as high as $800^{\circ} \mathrm{C}$ [110]. Especially for the condition of overcharge, high-capacity and closed/semi-closed space, tremendous amounts of energy cannot be released effectively which may even result in the explosion of battery. Ouyang et al. researched the thermal runaway behavior of an overcharged 18,650 battery, and they found that the thermal runaway behavior of overcharged battery was much more violent than the normal battery. As depicted in Figure 4, where the safety vent of battery was blown away, the jellyroll was brought out and exposed to air [111]. With the help of an adiabatic calorimeter, vent sizing package 2 (VSP2), Jhu et al. found that the charged battery was prone to experiencing a thermal explosion compared to the uncharged battery, and the heat of reaction was calculated to be $26.2 \mathrm{~kJ}$ [112]. 


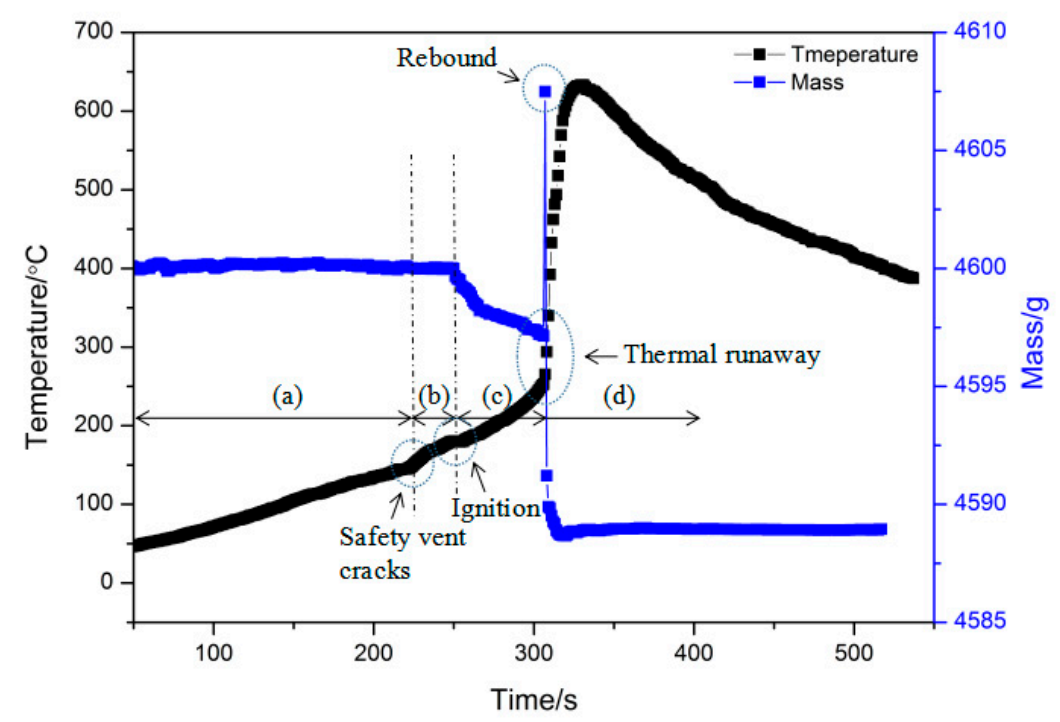

Figure 2. Typical curves of battery surface temperature and mass vs. time.
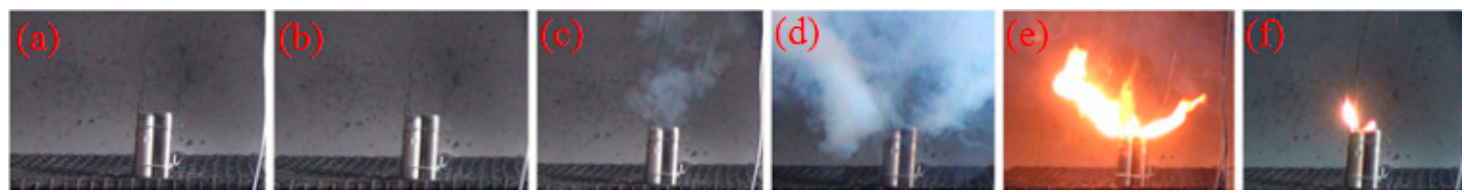

Figure 3. The experimental phenomena during thermal runaway: (a) heating stage; (b) safety vent opening; (c) gases releasing; (d) thermal runaway; (e) ignition and combustion; (f) abatement and extinguishment.
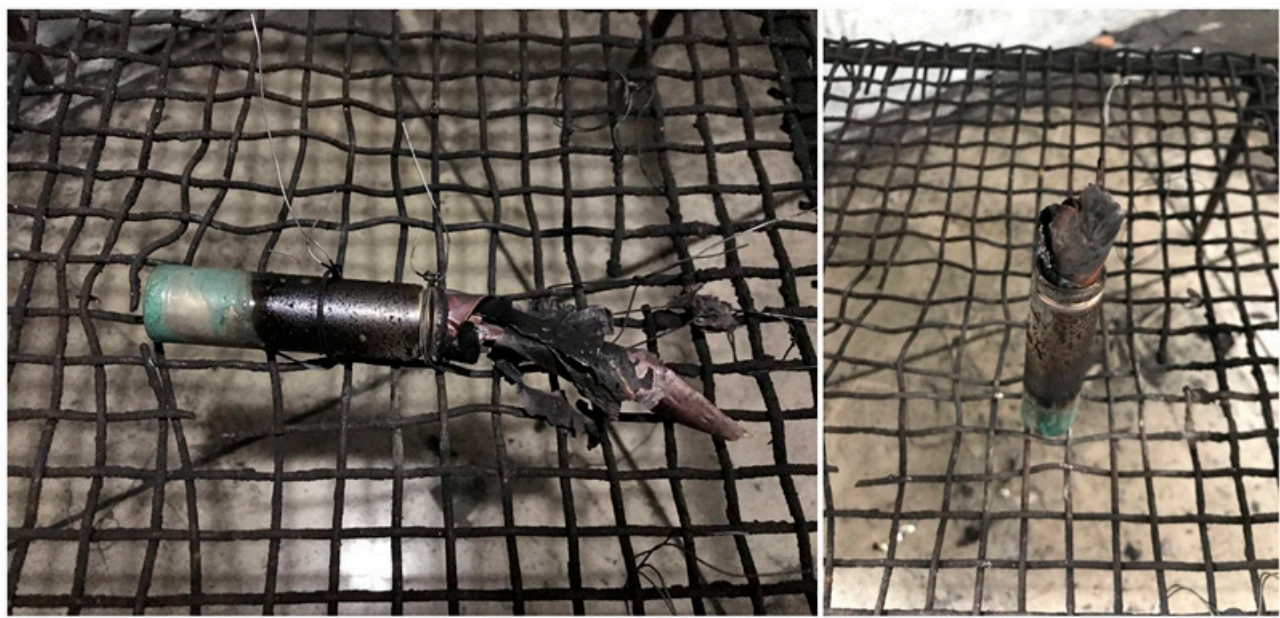

Figure 4. The photographs of the overcharged battery after thermal runaway test.

Commonly, quantities of toxic gases can be generated during the thermal runaway process such as $\mathrm{HF}$, carbon monoxide $(\mathrm{CO})$, nitric oxide $(\mathrm{NO})$, sulfur dioxide $\left(\mathrm{SO}_{2}\right)$, hydrogen chloride $(\mathrm{HCl})$ and hydrogen $\left(\mathrm{H}_{2}\right)[76,113-116]$. Due to the limited thermal stabilization of $\mathrm{LiPF}_{6}$, it may decompose at elevated temperatures and it can be described as $[117,118]$ :

$$
\begin{gathered}
\mathrm{LiPF}_{6} \rightarrow \mathrm{LiF}+\mathrm{PF}_{5} \\
\mathrm{PF}_{5}+\mathrm{H}_{2} \mathrm{O} \rightarrow \mathrm{POF}_{3}+2 \mathrm{HF} \\
\mathrm{LiPF}_{6}+\mathrm{H}_{2} \mathrm{O} \rightarrow \mathrm{LiF}+\mathrm{POF}_{3}+2 \mathrm{HF}
\end{gathered}
$$




$$
\mathrm{POF}_{3}+\mathrm{H}_{2} \mathrm{O} \rightarrow \mathrm{POF}_{2}(\mathrm{OH})+\mathrm{HF}
$$

On the other hand, the reaction between PVDF binder and lithiated graphite will occur in acidic medium and is as follows [119]:

$$
-\mathrm{CH}_{2}-\mathrm{CF}_{2}-\stackrel{\text { acid }}{\rightarrow}-\mathrm{CH}=\mathrm{CF}-+\mathrm{HF}
$$

By means of fire calorimetry, Ribière et al. [76] carried out combustion experiments on pouch batteries and results revealed that an increasing amount of total HF emissions would be generated for the decreasing SOC value of battery. Besides, Ouyang et al. found that the generation of HF increased linearly with the increasing battery quantity and the burning of about 100 batteries $(18,650)$ would release an amount of HF causing the immediate death of humans, $1.5 \mathrm{~g}[120,121]$.

In addition, resulting from the incomplete combustion of battery electrolyte as described in Equation (6), there will be some CO generated during thermal runaway [114]:

$$
\mathrm{O}_{2}+\text { electrolyte } \rightarrow \mathrm{CO}+\mathrm{H}_{2} \mathrm{O}+\text { heat }
$$

It is well-known that $\mathrm{CO}$ can bind with hemoglobin causing oxygen poisoning. By varying battery SOC and ambient pressure, Chen et al. [121] declared that with the increasing battery SOC, the amount of $\mathrm{CO}_{2}$ decreased, while the amount of $\mathrm{CO}$ increased. The decreasing ratio of $\mathrm{CO}_{2} / \mathrm{CO}$ revealed that the combustion efficiency of battery would be lower for the high SOC battery. Besides, a low combustion efficiency could also be obtained under low-pressure conditions, and the battery with higher capacity would generate much more $\mathrm{CO}$ during thermal runaway [114].

Based on the research of Ribière et al. [76], NO may be produced as a reaction product of nitrogen (originating from air or fuel-bound nitrogen) and oxygen from air within the flame (thermal route of $\mathrm{NO}_{\mathrm{x}}$ production), which can be further expressed as:

$$
\begin{aligned}
& \mathrm{O}^{*}+\mathrm{N}_{2} \leftrightarrow \mathrm{NO}+\mathrm{N}^{*} \\
& N^{*}+\mathrm{O}_{2} \leftrightarrow \mathrm{NO}+\mathrm{O}^{*}
\end{aligned}
$$

NO will damage the peogaster of human and destroy the ozonosphere. Furthermore, it can be oxidized as corrosive nitrogen dioxide $\left(\mathrm{NO}_{2}\right)$. With the increase of battery SOC, the amount of NO first ascends and then descends.

Additionally, sulfur-based compounds as additives are known to be used in electrolytes for their property in facilitating SEI formation $[122,123]$. Whereas, they will undergo degradation to form $\mathrm{SO}_{2}$ at high temperatures. Similarly, $\mathrm{SO}_{2}$ is harmful to the peogaster of human and it can also lead to acid rain. Moreover, the amount of $\mathrm{SO}_{2}$ will ascend with the increasing battery SOC.

The generation of $\mathrm{HCl}$ originates from the combustion of polymers inside battery containing a binder, separator and package [124]. It is found that the amount of $\mathrm{HCl}$ is irrelevant to battery SOC.

Finally, one possible source of $\mathrm{H}_{2}$ is the reaction between metal $\mathrm{Li}$ and the separator. Common separator materials are PVDF and carboxymethyl cellulose (CMC). As can be seen from the reaction detailed below, PVDF may react with metal $\mathrm{Li}$ and release $\mathrm{H}_{2}$ under high-temperature conditions [124]:

$$
-\mathrm{CH}_{2}-\mathrm{CF}_{2}+\mathrm{Li} \rightarrow \mathrm{LiF}+-\mathrm{CH}=\mathrm{CF}+0.5 \mathrm{H}_{2}
$$

A similar reaction of $\mathrm{CMC}$ and metal Li may take place to release $\mathrm{H}_{2}$ which is as follows:

$$
\mathrm{CMC}-\mathrm{OH}+\mathrm{Li} \rightarrow \mathrm{CMC}-\mathrm{OLi}+0.5 \mathrm{H}_{2}
$$

$\mathrm{H}_{2}$ is highly reactive, and it may lead to violent combustion or explosion under external high-temperature. 


\subsubsection{Thermal Hazards of a Battery Pack}

Battery packs are generally consisted of single batteries, in which the quantity of batteries depends on the application ranging from several to thousands. For example, one charge-pal usually contains $2-4$ batteries $(18,650)$, while there are more than 7000 batteries for the pack in a Tesla Model S. Consequently, battery pack possesses the thermal hazards of a single battery as described in Section 4.2.1. Whereas, different to a single battery, a battery pack possesses the hazard of thermal failure propagation, that is, the thermal failure of one or several batteries will propagate to the neighboring ones, resulting in catastrophic consequences. The thermal hazard will be heightened during the propagation; hence it is essential to pay attention to the issue of failure propagation within a battery pack [105,125-133].

Ouyang et al. carried out a set of failure propagation experiments in 18,650 packs with a size of $3 \times$ 3 [128]. As depicted in Figure 5, the thermal failure of the battery in the lower right corner of the figure was induced by external heating, and then thermal failure propagated with a domino effect within the pack. Typically, the thermal failure of battery pack could be divided into several phases, i.e., the failure of the batteries in the former phase affected the batteries in the next phase and then caused the hierarchical propagation. Besides, they also researched the influence of several key factors such as the SOC, battery gap, failure location and pack size on the failure propagation. Results showed that higher SOC would worsen the propagation behavior of pack, in which the propagation speed grew linearly with the increasing pack SOC. It can be attributed to the fact that battery SOC affects the internal lithium ions distribution which will further influence the chain-reactions during thermal runaway. By increasing the battery gap, it was found that the risk of failure propagation within pack could be greatly reduced and the propagation speed exhibited a square index decline relationship with the battery gap, which was the result of radiation decay with squared distance. Upon further increasing the battery gap, the propagation behavior would eventually be interrupted. If the battery close to the center of pack underwent thermal failure, the failure propagation was revealed to be aggravated significantly since the failure of the central battery would affect the surrounding batteries with the largest scope and lead to the thermal failure of the whole pack in a relatively short time. Moreover, it was exhibited that with the increase of pack size, it would take more time for the failure propagation to reach the outermost phase, i.e., the thermal failure propagation would be delayed.

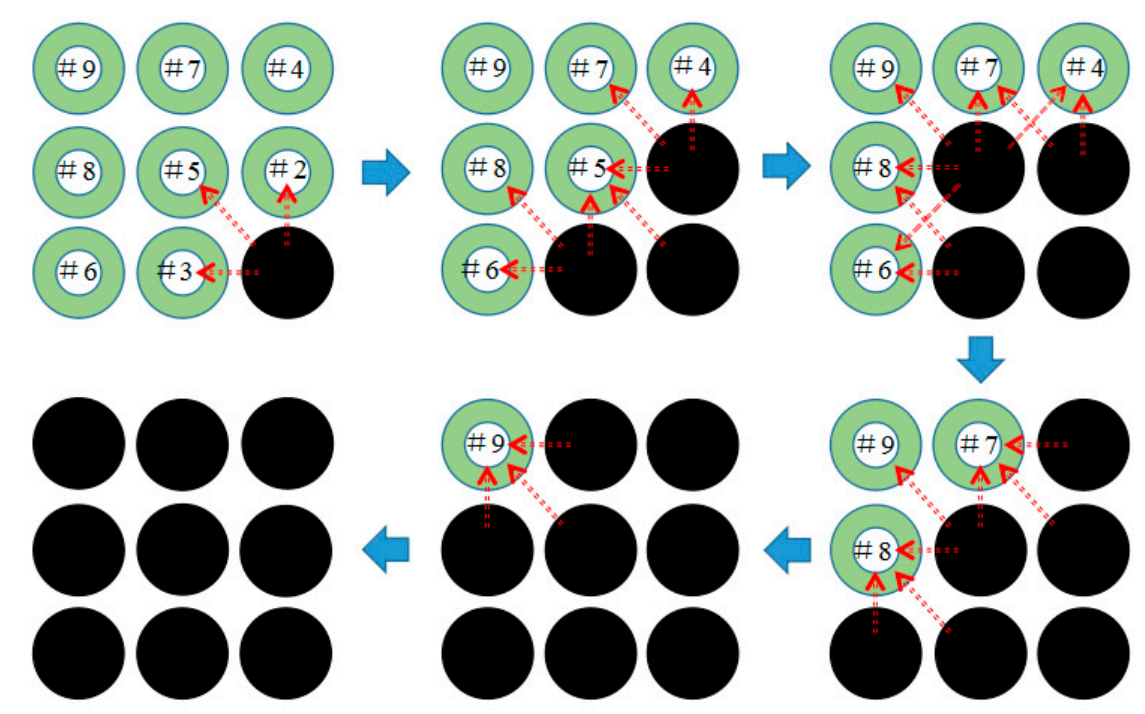

Figure 5. Schematic of thermal failure propagation.

Due to the application scenarios, it is common to see that batteries are generally arranged in various shapes or modes within battery packs. Ouyang et al. [125] compared the thermal failure propagation of battery packs with various shapes, where the triangle pack, rectangle pack, parallelogram pack, line pack, hexagon pack, and square pack were included. The results of failure propagation speed 
are summarized in Figure 6, where the triangular pack and the linear pack are much safer as their propagation speeds are smaller than the others. After combining with the space utilization, it was revealed that the triangular pack might be the best choice of battery module due to its lower propagation hazard and higher space utilization.

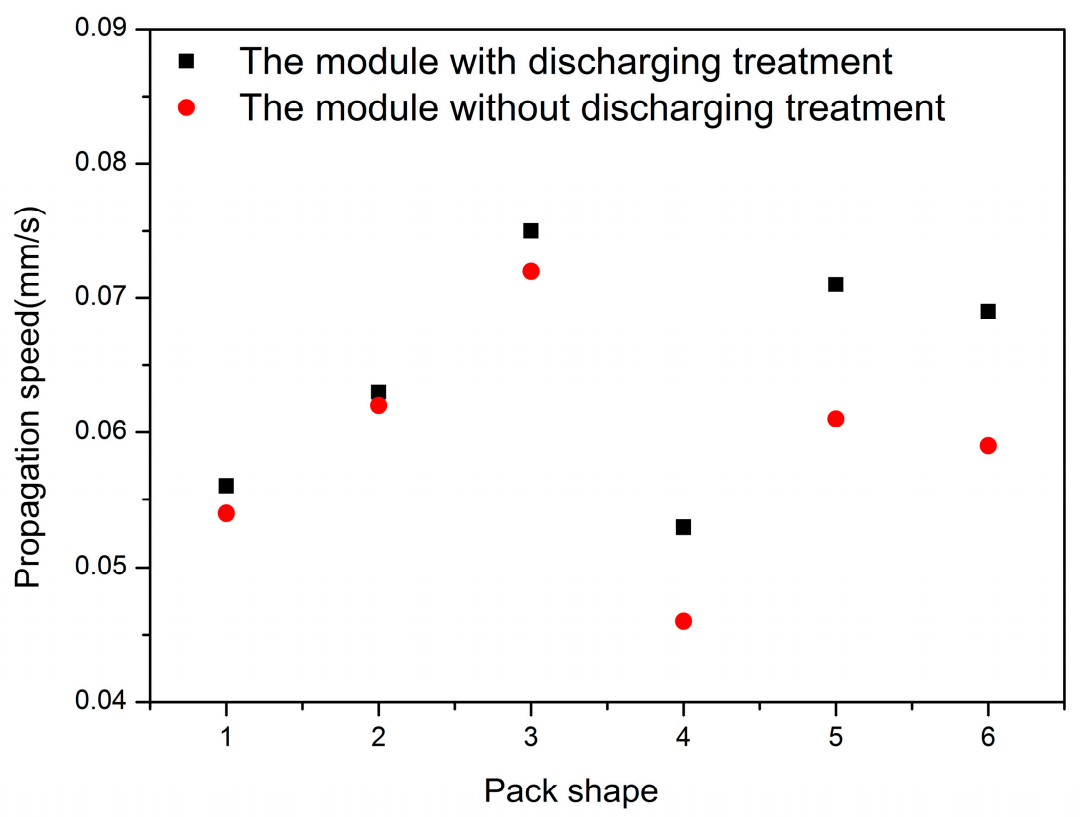

Figure 6. The propagation speeds of packs with various shapes where the numbering 1, 2, 3, 4, 5, and 6 represents the triangle pack, rectangle pack, parallelogram pack, line pack, hexagon pack and square pack respectively.

Additionally, resulting from the disadvantages of traditional PCM such as low conductivity and diffusivity $[134,135]$, it was found that the failure propagation behavior of a pack wrapped with PCM would be severer. The low conductivity and diffusivity of PCM caused a great deal of heat to be accumulated inside pack, and the close stacking of PCM reduced the heat release, therefore the propagation of thermal failure was accelerated. Besides, traditional PCM was flammable and it would be ignited by external heating which further aggravated the thermal failure propagation. In short, it is demanding to avoid the pack wrapped with traditional PCM being exposed to external heating or high temperature, especially for the flammable PCM. On the other hand, more work should be done to improve the thermal conductivity, diffusivity and fire resistance of PCM.

Apart from the factors above, it was determined that tab configuration also had a huge influence on the failure propagation behavior of the pack as a result of the heat transfer from the tab. According to the work of Lopez et al. [126], it was revealed that a branched style of tabbing as shown in Figure 7 improved the voltage retention as well as the safety of the pack over a serpentine style of tabbing as the shorted trigger battery was electrically better isolated from the rest of the pack when the tabs were branched. Lamb et al. [127] examined the failure propagation behavior of packs consisting of cylindrical and pouch batteries respectively, where the thermal failure was induced in a single battery. They observed that cylindrical batteries were less prone to propagation compared to the pouch batteries owing to the limited contact between neighboring batteries.

On the other hand, numerical simulation methods were also applied to investigate the failure propagation behaviors of battery packs [136-144]. Feng et al. [136] established a 3D thermal runaway propagation model for a large format LIB pack based on the energy balance equation. They proposed that the thermal failure propagation could be postponed by increasing the thermal runaway triggering temperature, which was generally reflected as the collapse temperature of battery separator. Furthermore, it was revealed that reducing the total electrical energy released during thermal 
runaway and enhancing the heat dissipation level were beneficial to suppress the thermal failure propagation. Coman et al. $[137,138]$ presented a numerical model to analyze the heat propagation in a custom-made battery pack in which venting of the electrolyte and jellyroll contents were considered. Their results demonstrated that the heat dissipation due to the ejection of electrolyte and jellyroll contents contributed significantly to the failure propagation. In addition, they declared that the combination of small insulating layers wrapped around the batteries and a conductive heat sink were beneficial to the design of a safer battery pack which could mitigate the thermal failure propagation.

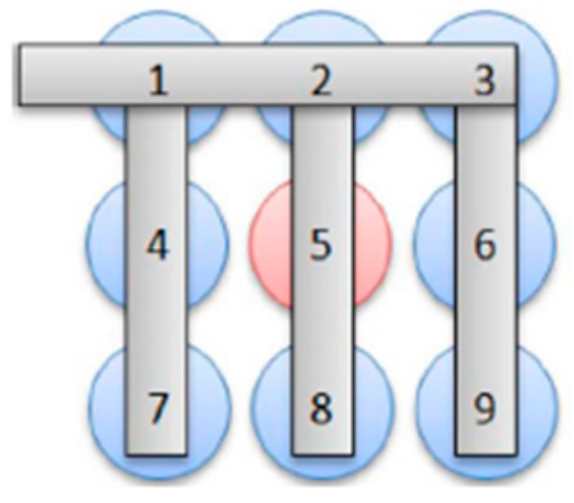

(a)

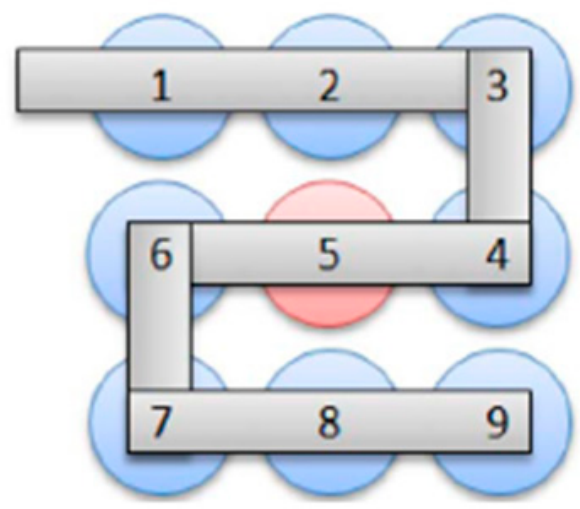

(b)

Figure 7. Two typical tab configurations of packs: (a) branched style of tabbing (M-type); (b) serpentine style of tabbing (S-type). Adopted from Ref. [126].

In short, the thermal failure propagation within a battery pack is severe and the corresponding hazard will be greatly enhanced during the propagation, which may be influenced by several key parameters of the LIB including the SOC, battery gap, package and so on. To decrease the thermal hazard of battery pack, some methods such as improving the separator property, enhancing the heat dissipation, adding an insulation board and decreasing the SOC may be considered.

\subsection{Thermal Hazards of the Lithium-Ion Battery under a Low-Pressure Environment}

In particular, an alarming increase in the number of incidents on airlines caused by malfunctioning LIBs has raised more concerns among safety and aviation experts. The Federal Aviation Administration (FAA) has reported 46 incidents involving LIBs on aircraft in 2017, which is up from 31 in 2016 [145]. It is known that the low-pressure environment not only exists on the plane, but also in some high altitude areas. Moreover, it is important to note that there are many risks associated with both transportation and utilization in low-pressure environments. Fire behaviors under low pressure is different from that under normal conditions. Current research mainly focuses on the influence of low-pressure environment on the combustion characteristics of conventional liquid and solid fuels. Experimental results showed that pressure was the main factor in affecting the ignition [146-148]. More studies concerning the kinetics and mechanisms of fires at low pressures were also conducted to reveal the pressure effects on the burning process [149-162]. However, the research on the combustion characteristics of LIBs under a low-pressure environment is currently insufficient. Chen et al. took the pioneering studies on the fire behaviors of LIBs under low-pressure environment. The experiments were conducted in a sea-level city, Hefei $(100.8 \mathrm{kPa} / 24 \mathrm{~m})$, and a high-altitude city, Lhasa $(64.3 \mathrm{kPa} / 3650$ $\mathrm{m})$ to offer guidance to facilitate the safe handling of battery under normal and high-altitude conditions. The results showed that the ejection behavior of LIBs in Lhasa appeared earlier than that in Hefei as shown in Figure 8, due to the lower pressure required to rupture, meanwhile the mass loss, heat release rate and combustion heat of the fire reduced with decreasing pressure [121]. They also studied the fire behaviors of primary lithium batteries at two different pressures. The mass loss, heat release rate, combustion heat, combustion efficiency and heat flux in Lhasa were smaller than those in 
Hefei which mean that the primary batteries at lower pressure were less dangerous than those at higher pressure [163]. Fu et al. studied the ignition and combustion characteristics of LIBs under low atmospheric pressure using a low-pressure tank from 30 to $101 \mathrm{kPa}$. Results indicated that the low atmospheric pressure could largely extend the ignition and weakened the combustion intensity of LIBs [110]. In summary, the study of the combustion characteristics of LIBs under low-pressure conditions has scarcely been examined, while it is of great importance to the safety management of LIBs in air transport and more work on this issue are necessary to be conducted in the future.

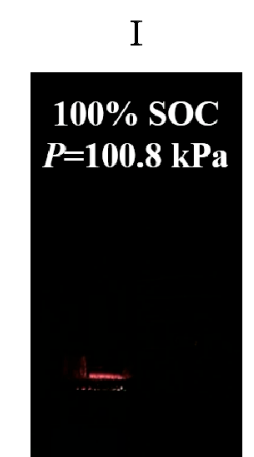

$250 \mathrm{~s}$

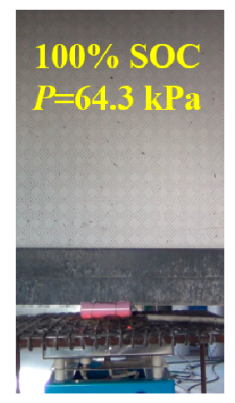

$183 \mathrm{~s}$

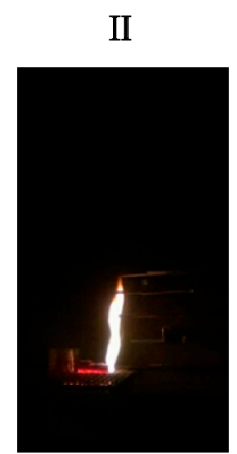

$315 \mathrm{~s}$

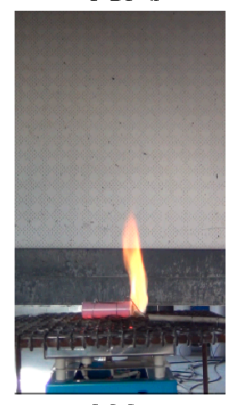

$238 \mathrm{~s}$

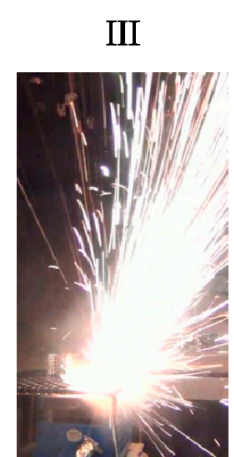

$368 \mathrm{~s}$

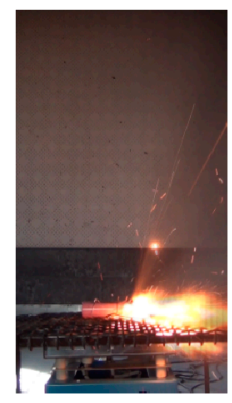

$296 \mathrm{~s}$

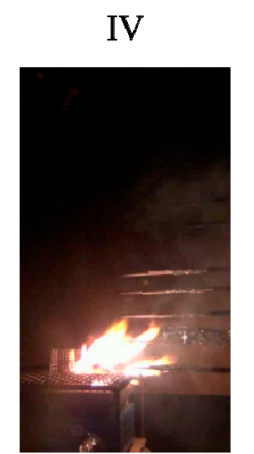

$374 \mathrm{~s}$

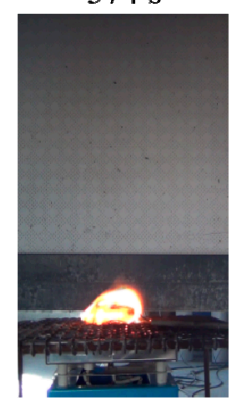

$301 \mathrm{~s}$

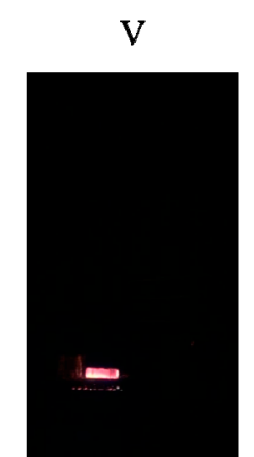

$384 \mathrm{~s}$

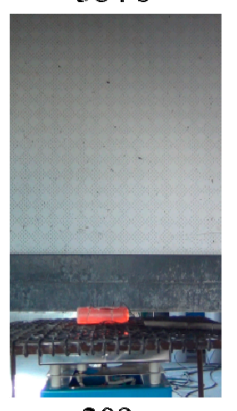

$309 \mathrm{~s}$

Figure 8. The burning process of 100\% SOC (state of charge) 18,650 batteries at two pressures.

\subsection{Thermal Hazards of Typical Commercial Lithium-Ion Batteries}

Lithium cobaltate oxide (LCO) cathode material was first put forward by the team of Prof. Goodenough in 1980, and it was also the first time that Li was introduced into the positive electrode in batteries, which promoted the application and development of a negative electrode without Li and, at the same time, improved the charging voltage of batteries. Most importantly, the lack of Li metal anode greatly improved the safety of batteries [164]. Furthermore, Prof. Goodenough's team proposed the lithium manganate oxide (LMO) cathode material in 1983. Although its theoretical capacity is only about half of that of LCO, its reversible specific capacity is excellent [165]. With the emergence of LCO and LMO, many lamellar and spinel LIB positive electrode materials based on transition metal oxides were developed in the following decade. Subsequently, in 1997, Goodenough's team reported the application of lithium iron phosphate (LFP) positive electrode materials, and, in further research, solved a series of problems of LFP-positive electrode materials by carbon coating modification, so that LFP could be applied commercially on a large scale [166]. Therefore, the commercial cathode material structural system has been built, and the following positive electrode materials are improved on the basis of these three materials, while the NMC and lithium nickel cobalt aluminate oxide (NCA) materials improve the performance of the battery by regulating the content of the three elements in LCO. 


\subsubsection{Lithium cobaltate oxide}

At present, LCO cathode material still occupies a major part in the $3 \mathrm{C}$ field, while the safety is relatively poor, so it is gradually being replaced by other positive electrode materials $[167,168]$. The active surface of the LCO cathode material can catalyze the decomposition of the carbonate electrolyte then release a large amount of heat, thus causing the thermal runaway of battery $[169,170]$. Zhang et al. studied the overcharge capacity degradation mechanism of LCO/graphite battery and found that the dissolution of current collector led to changes in the structure of the SEI layer and electrodes, thereby reducing the battery capacity and increasing the risk of thermal runaway [171]. In view of the safety problem associated with $\mathrm{LCO}$, researchers have proposed a variety of solutions. Ji et al. [172] recommended a phosphazene additive $\mathrm{N}_{3} \mathrm{P}_{3}(\mathrm{OPh}) \mathrm{F}_{5}(\mathrm{PFPN})$, which could be oxidized to form a protective cathode electrolyte interface (CEI) before the electrolyte, greatly improving the safety of battery. Deng et al. [173] coated and doped LCO-positive electrode materials by adding $\mathrm{Al}$ and Ti elements, which greatly improved the thermal stability, increased the thermal runaway critical temperature and reduced the heat release. With the increasing demand for high-voltage LCO batteries, further studies are needed for the modification of LCO cathode materials, safe electrolytes and additives at high voltage.

\subsubsection{Lithium iron phosphate}

LFP is the positive electrode with the best thermal stability among the current commercial LIB cathode materials. Yamada et al. compared the thermal stability of various electrode materials at high temperature, and LFP showed lower oxygen and heat release [174]. Jiang et al. used an ARC to analyze the thermal stability of LCO, NMC and LFP with LiBOB and $\mathrm{LiPF}_{6}$ electrolytes, and the thermal stability of LFP was found to be the best in both systems [175]. The high thermal stability of LFP is rooted in its strong structural stability during charging and discharging [176]. However, due to the poor conductivity of LFP, the migration rate of lithium ions is very low, therefore surface carbon coating, and $\mathrm{Cu}^{2+}$ or $\mathrm{Mg}^{2+}$ plasma doping are required for modification $[177,178]$. Furthermore, the modification of LFP is still a research focus. How to increase the electrochemical performance of LFP while maintaining the high level of safety is a key concern of researchers.

\subsubsection{Lithium nickel manganese cobalt oxide}

NMC ternary material is developed on the basis of LCO positive electrode materials by adjusting the content of Ni, Mn and Co elements. Co element plays an important role in the electronic conductance of battery, while Ni element can improve the capacity. Mn element is responsible for stabilizing the structure of positive electrode material and preventing the capacity decline of battery $[179,180]$. With the rapid development of EVs, ternary materials have attracted extensive attention due to their high capacity, while ternary materials with a high $\mathrm{Ni}$ content have gradually replaced low-Ni materials due to the lower price. However, with the increase of Ni content, the safety of batteries is greatly compromised [181]. The content of Ni in NMC materials increases gradually, from NMC111 to NMC532 and NMC622, but this still cannot meet the current demand for power battery capacity and low cost. Therefore, NMC 811 materials have received extensive attention in recent years, but the extremely high reactivity between positive electrode and electrolyte also brings great safety risks [16]. Ma et al. studied the effect of vinylene carbonate (VC) and fluoroethylene carbonate (FEC) additives on the reactivity of lithium intercalation carbon $\left(\mathrm{Li}_{x} \mathrm{C}\right)$ and electrolyte, and the results showed that the addition of FEC could reduce the self-heating rate between graphite and electrolyte [182]. Three component additives, such as VC211 and PES211, could improve the cycling performance and the chemical stability of electrode/electrolyte, and the effect was much better than that of single or binary additives [183]. According to the latest research results, the thermal runaway of NMC batteries is mainly caused by chemical crosstalk between the electrodes, the oxygen released by cathode diffuses to the anode, at which point, an oxidizing reaction occurs and emits a large amount of heat, causing 
the thermal runaway of the NMC batteries. This is different from the traditional view that the main reason is the breakage of the diaphragm material, which leads to the internal short circuit then causes thermal runaway. Thus, it is possible to fundamentally solve the safety problem of high Ni ternary material [184].

\subsubsection{Lithium nickel cobalt aluminate oxide}

Similar to NMC material, NCA ternary material was also developed on the basis of LCO positive electrode materials by adjusting the content of $\mathrm{Ni}, \mathrm{Co}$ and $\mathrm{Al}$ elements. Within, $\mathrm{Ni}$ and $\mathrm{Co}$ elements are applied to improve the capacity and the electronic conductance, respectively. The main purpose of $\mathrm{Al}$ addition is to stabilize the lattice structure and avoid structural collapse during charging/discharging. So far, NCA materials are generally regarded as one of the most appealing materials due to their comparable operating voltage, energy density and ideal properties for practical applications [185]. Especially for the $\mathrm{LiNi}_{0.80} \mathrm{Co}_{0.15} \mathrm{Al}_{0.05} \mathrm{O}_{2}$ cathode, which has achieved ubiquitous commercial success. The remaining problem for NCA material is the rapid capacity fading during cycling, which is due to the mixing of $\mathrm{Li} / \mathrm{Ni}$ cations [186]. Because the radii of $\mathrm{Ni}^{2+}$ and $\mathrm{Li}^{+}$are similar, it is easy for $\mathrm{Ni}^{2+}$ to enter the lithium layer, therefore results in capacity loss and thermal hazard. At present, several studies have been reported on the strategies to improve the stability of NCA materials [187-189]. These studies are mainly based on various cationic doping in Ni-rich cathode materials to cease the migration of $\mathrm{Ni}^{2+}$ towards the $\mathrm{Li}^{+}$site. Moreover, doping in the $\mathrm{Li}^{+}$intercalation site is also a very important strategy to reduce structural disorientation. Among, magnesium $(\mathrm{Mg})$ and sodium $(\mathrm{Na})$ are the most well-studied dopants that can be embedded into the $\mathrm{Li}^{+}$site.

\section{Management and Countermeasures}

In view of the non-negligible thermal hazards of LIBs involving components, a single battery and a battery pack, management or countermeasures regarding these thermal hazards must be conducted. In the present study, the following is discussed: (1) the use of safety devices within battery; (2) the application of fire retardant (FR) additives; (3) the thermal management of battery; (4) provision of a warning once hazard occurs and (5) the firefighting after thermal hazard forms. The former three countermeasures aim to enhance the inherent safety of LIBs and decrease the possibility of hazard, and the others are applied to constrain the deterioration of thermal hazard, thereby reducing the damage.

\subsection{Safety Devices within Battery}

Due to the inherent hazards accompanied with LIB, manufacturers have developed several safety devices within the battery such as a safety vent, current interrupt device (CID) and positive temperature coefficient (PTC) to prevent the appearance of excessive current, temperature or pressure. Therefore, safety device can be regarded as a protective measure owed by the battery itself.

\subsubsection{Safety Vent}

During the operation of the LIB, especially under abusive conditions, it is common to see that gases will be released inside battery. Thereby, the safety vent was proposed in response to the continuous increase of pressure inside battery, allowing the escape of excessive gases. Generally, a safety vent is composed of a gasket containing a puncture film and a spike. The spike is located at the top of the battery, while the gasket lies below it. Once the pressure inside battery builds up, the gasket squeezes upward and deforms, enabling the puncture film punctured by the spike, therefore the dangerous rupture of battery casing can be terminated [190-193]. Moreover, safety vents can be designed to operate at pre-set internal battery temperatures to meet the requirement of practices. 


\subsubsection{Current Interrupt Device}

Another common safety device is called the CID, and it can be activated by high temperature. Under the conditions such as overheating, overcharging and short-circuiting, an increase of temperature can be seen inside the battery causing an increase in the vapor pressure of the electrolyte solvent; therefore, the solder joints welded to the aluminum sheet and the pressure relief sheet will fall off and the pressure relief sheet will turn over leading to the broken circuit inside battery [193]. Compared to the mechanism of safety vent releasing the internal pressure, the CID is used to interrupt battery current, which subsequently prevents the occurrence of hazard.

\subsubsection{Positive Temperature Coefficient}

Besides, the PTC based on materials are also widely used among LIBs, whose resistance increases dramatically in response to the rapid rise of temperature [194-199]. For example, if a large current flows across the PTC element, its temperature increases abruptly, while the PTC works. A concomitant and abnormally high resistance of the PTC element prevents current flow which limits the further deterioration of heat generation. Once the large current is removed, the battery and PTC element cool and the resistance of the latter drops, allowing the resumption of charge/discharge. Overall, the primary purpose of PTC devices is to protect batteries against abusive electrical conditions such as external short circuit and overcharge etc.

\subsection{Fire Retardant}

As known, the combustibility of conventional battery components, e.g., electrolyte and separator bring an inherent hazard to LIB which may induce the occurrence of fire or combustion. Thereby, an increasing number of researchers endeavor to investigate how to change flammable components into non-flammable ones or how to develop new substance to add into battery to reduce the combustibility. Herein, a summary is detailed on the studies on FR additives of electrolyte and separator in LIB.

\subsubsection{Fire-retardant Electrolyte}

The electrolyte of a commercial LIB is a mixture of organic carbonates such as solvents and lithium salt, in which linear carbonates such as DMC, EMC or diethyl carbonate (DEC) and cyclic carbonates such as EC and propylene carbonate (PC) may be included. These organic carbonates are highly flammable which causes great concerns regarding their safety in LIB [200,201]. To solve this problem, the most straightforward way is to add FR components into solvents or thoroughly replace the flammable solvents [202].

However, some conflicts still exist between the property of FR additive and the electrochemical performance of LIB. In order to ensure the electrochemical performance of battery as much as possible, additives are necessary to meet the following requirements as depicted in Figure 9: (1) good chemical stability, no chemical reaction with battery components; (2) electrochemical inertia, no adverse electrochemical reactions within the normal operating voltage range of LIB; (3) suitable physical properties including conductivity, viscosity, boiling point, density, solubility etc.; (4) low toxicity, good machinability and appropriate cost [202].

Normally, the FR mechanism can be divided into two types: gas physical mechanism and chemical free-radical capture mechanism [203,204]. The former is based on oxygen isolation via the formation of a FR vapor and absorbing heat simultaneously, while the latter one is based on the additives capturing active free radicals and acids produced by combustion reaction to stop combustion development. Based on the elements contained and the working mechanism, currently studied FR additives for electrolytes can be divided into four main categories: phosphorus FR additives, fluoride FR additives, ionic liquid FR additives and composite FR additives, as illustrated in Figure 10. 


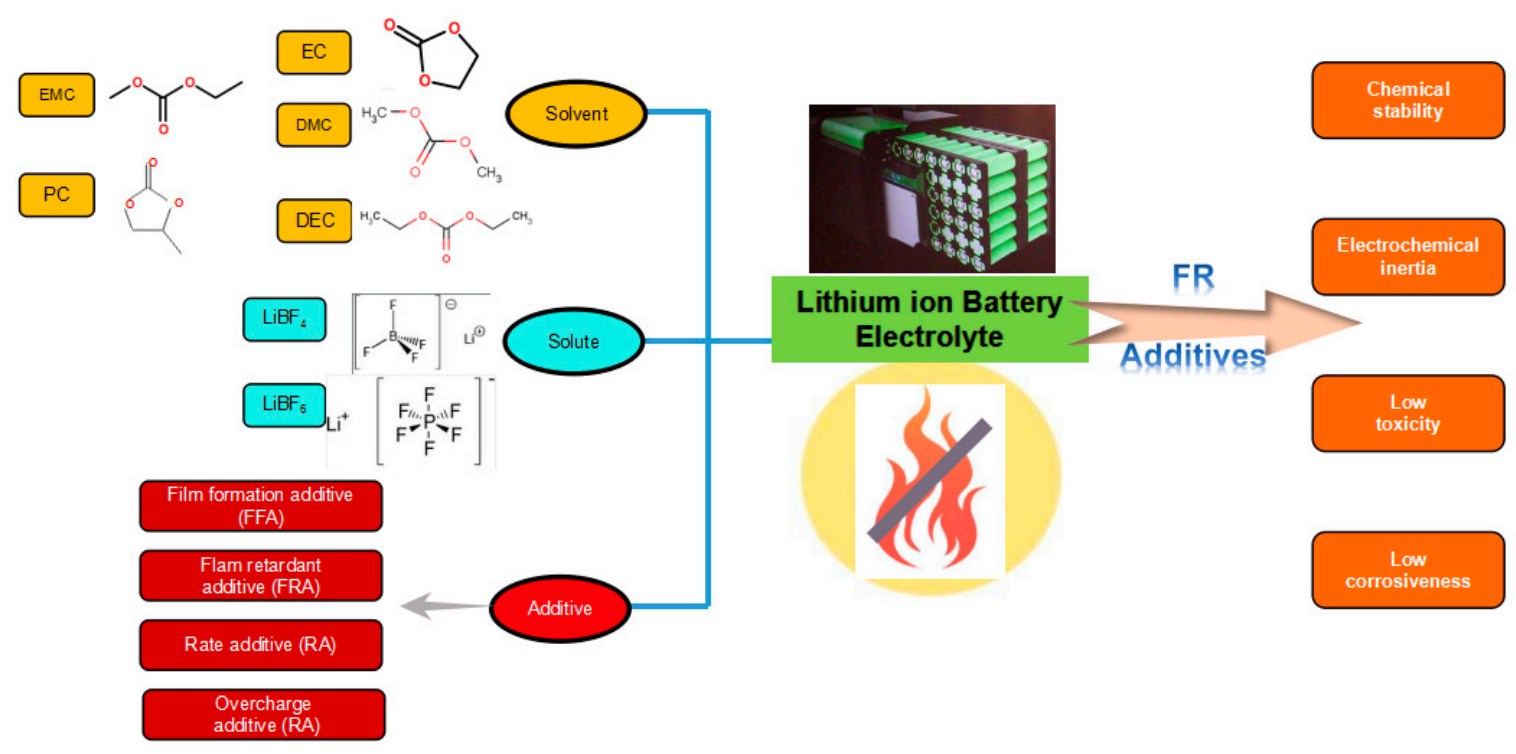

Figure 9. The common constitutes of LIB electrolytes and the requirement of FR additives.

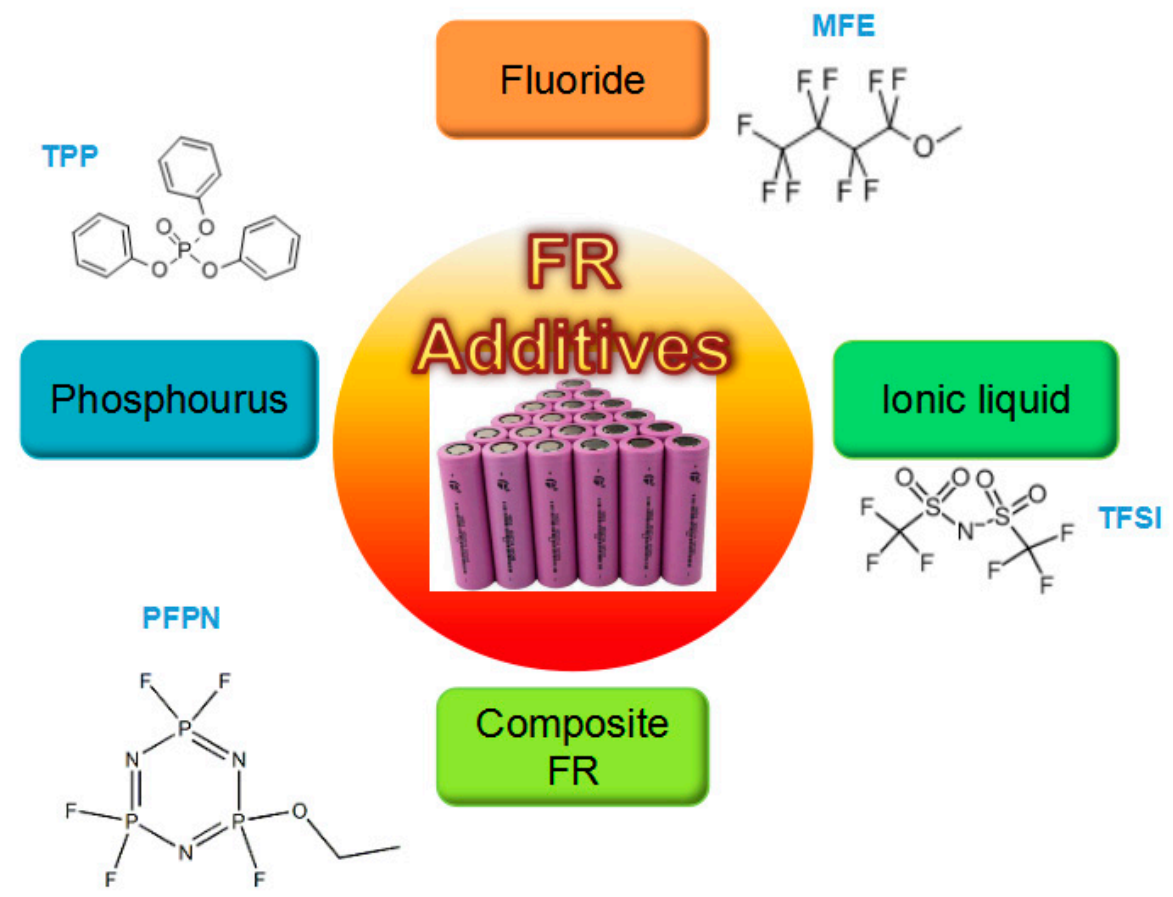

Figure 10. Typical FR additives in LIB electrolytes.

\section{(1) Phosphorus Additives}

Considering their advantages such as environmental persistence, ability to bioaccumulation and low toxicity, organophosphorus compounds are one of the most popular candidates for FR additives in LIBs [205]. They will decompose at high temperature to produce hydrogen phosphate $\left(\mathrm{H}_{3} \mathrm{PO}_{4}\right)$, which will continue to transform into meta phosphorous acid $\left(\mathrm{HPO}_{2}\right), \mathrm{PO}$ and $\mathrm{PO}_{2} \cdot \mathrm{HPO}_{2}$ will promote the carbonation reaction of carbonate, $\mathrm{PO} \cdot$ and $\mathrm{PO}_{2} \cdot$ will capture $\mathrm{H} \cdot$ and $\mathrm{O} \cdot$ and; therefore suppress the combustion of electrolytes. Until now, Xiang et al. [206] investigated the electrolyte with three kinds of dimethyl methylphosphonate (DMMP) additives respectively which could significantly suppress the flammability while only causing a small decrease in the electrochemical performance of battery, see Figure 11a. Hu et al. [207] synthesized a new phisohinamidate bis(N,N-diethyl) (2-methoxyethoxy) 
methylphosphonamidate (DEMEMPA) as the N-P collaborative FR additive in electrolyte and found that $10 \mathrm{vol} \%$ of DEMEMPA to $0.9 \mathrm{M} \mathrm{LiPF}_{6} / \mathrm{EC} / \mathrm{DMC}$ could significantly inhibit the burning of electrolytes and provide a wide electrochemical window, see Figure 11b. Besides, Murmann et al. [203] performed studies on several phosphates with different fluorination concentrations to determine the influence of fluorination degree within organophosphate on the flammability and electrochemical performance. Their results depicted that the partially fluorinated phosphate offered the best cycling and FR results.<smiles>[R]O[R]([R])([R])[O-]</smiles>

Scheme 1<smiles>[R]OP([R])(=O)O[R]</smiles>

Scheme 2<smiles>[R]OP([R])[R]</smiles>

Scheme 3

(a)

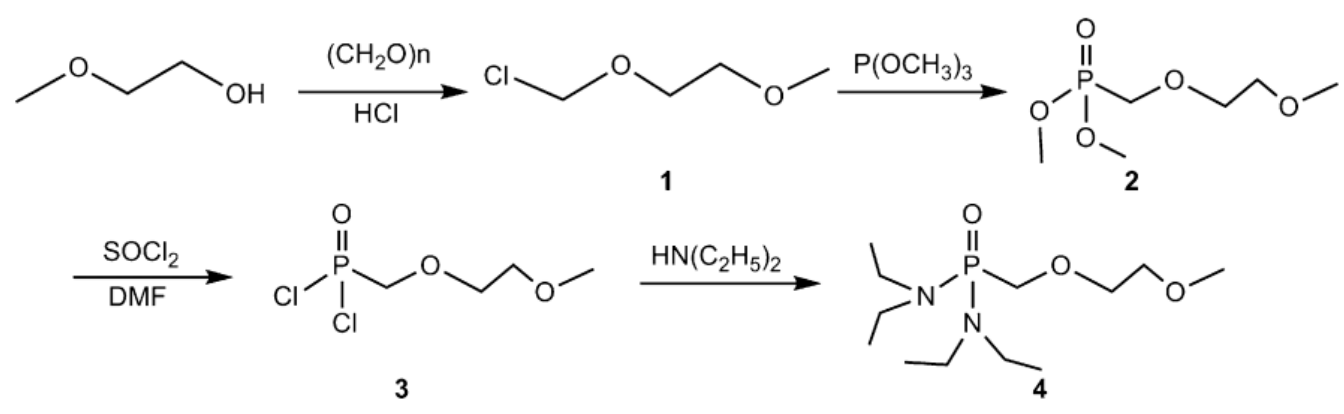

(b)

Figure 11. (a) Schemes for the three kinds of phosphorus. Adopted from Ref. [206]; (b) The synthetic route of DEMEMPA. Adopted from Ref. [207].

(2) Fluoride Additives

Flurorinated substituents in organic molecules are known to suppress the flammability of molecules and reduce the boiling temperature and viscosity. By replacing hydrogen atoms with fluorine atoms, $\mathrm{H}$. radicals can be reduced or eliminated to yield a non-flammable electrolyte. Ding et al. [208] introduced tris(2,2,2-trifluoroethyl) phosphate (TFP) as the FR additive into a $\mathrm{LiPF}_{6}$-based electrolytes containing $\mathrm{EC} / \mathrm{PC} / \mathrm{EMC}$, and their results showed that the addition of TFP caused a continuous decrease in the dielectric constant, and a continuous increase in the glass transition and boiling temperatures. Therefore, the flammability of electrolytes was substantially reduced. Zeng et al. [209] synthesized a novel fluorinated alkyl phosphonate bis(2, 2, 2-trifluoroethyl) methylphosphonate (TFMP) as the FR additive to reduce the flammability of electrolyte, see Figure 12. Their experiments demonstrated that the addition of 20 vol.\% TFMP could yield an electrolyte that was hardly flammable while having the least impact on the electrochemical performance.

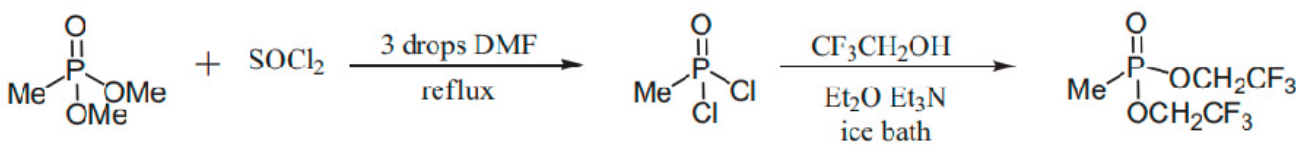

Figure 12. The synthetic route of bis(2, 2, 2-trifluoroethyl) methylphosphonate (TFMP). Adopted from Ref. [209].

(3) Ionic Liquid 
An ionic liquid usually refers to a liquid salt at room temperature solely composed of anions and cations. It possesses certain characteristics such as it is non-volatile, nonflammable, pollution free and has a wide electrochemical window. Hence, the electrolyte with ionic liquid added is hoped to replace the traditional organic electrolyte to improve the safety of LIBs [210-214]. Rectenwald et al. [215] reported the successful design of a new class of lithium salts, phosphoryl-rich FR ions (FRIONs) for safer LIB, see Figure 13. The thermogravimetric analysis of these lithium salts showed that they were thermally stable up to around $200{ }^{\circ} \mathrm{C}$. Moreover, the pyrolysis combustion flow calorimetry revealed that these salts would produce high char yields upon combustion which indicated the excellent FR property. Besides, the promising ionic liquid pentafluorocyclotriphosphazene (FPPN) is known to exhibit both an excellent FR performance and electrochemical properties. Dagger et al. [216] investigated a standard electrolyte mixed with $5 \mathrm{wt}$.\% FPPN towards abuse tolerance in a 5 Ah battery and their results showed that FPPN significantly reduced the self-heating rate of the battery in the temperature range from 80 to $110^{\circ} \mathrm{C}$. Further, they conducted nail penetration and external short circuit experiments but found no significant difference between standard and FPPN-containing batteries.

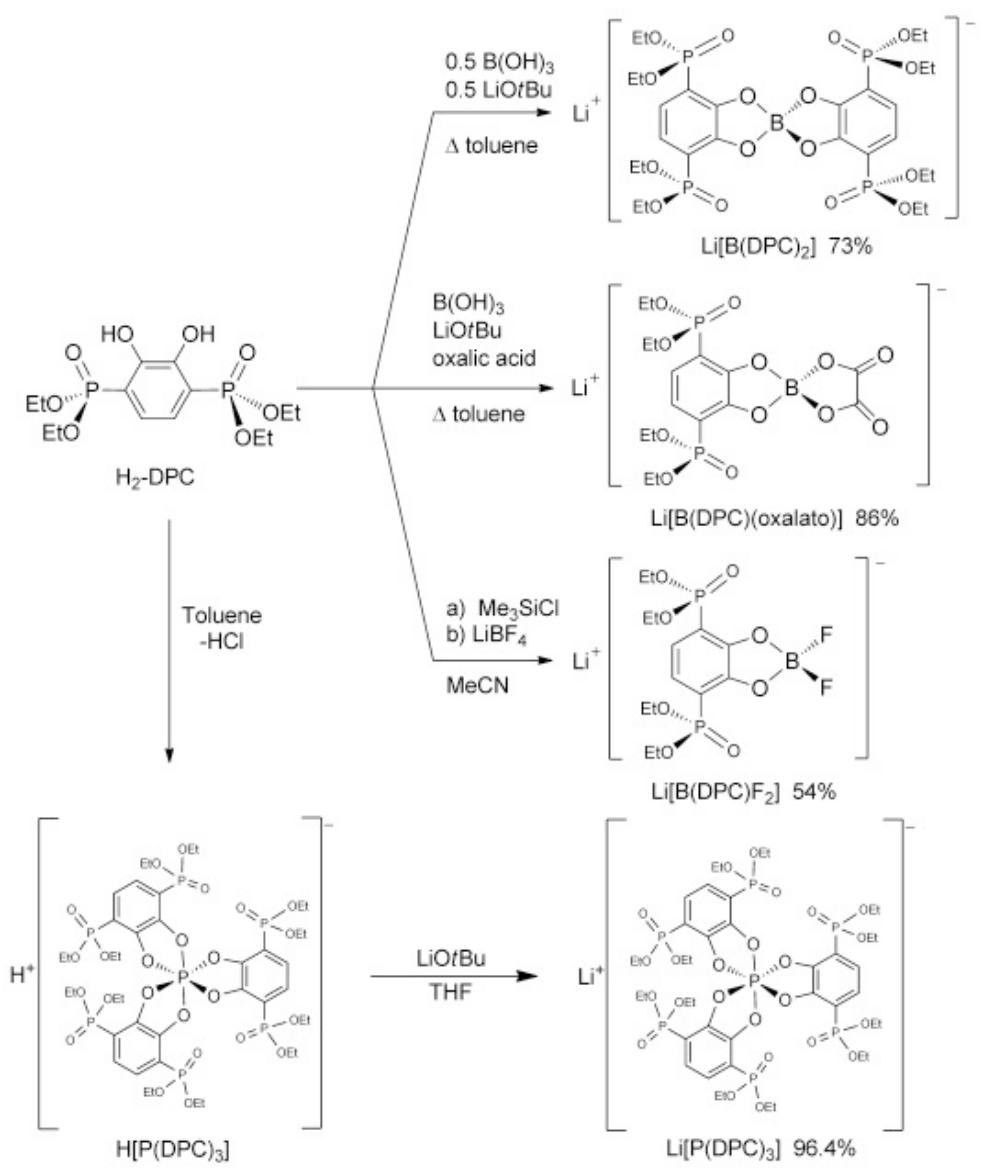

Figure 13. Conversion of 1,2-diphosphinatocatechol into phosphoryl-rich FR ions (FRIONs). Adopted from Ref. [215].

\section{(4) Composite Additives}

Use of a single flame retardant generally requires adding a large amount. In addition, the solubility of the additive and the electrolyte compatibility are also relatively limited. Thus, it is necessary to use a composite approach by comparing the advantages and disadvantages of various types of retardants to configure more suitable additives for LIB. Wu et al. [217] synthesized a phosphazene compound triethoxyphosphazen-N-phosphoryldiethylester (PNP) by a facile method and characterized it as a FR electrolyte additive for LIB, see Figure 14. They found that the self-extinguishing time (SET) value 
of $10 \%$ PNP in the electrolyte was decreased by $40 \%$ compared to the base electrolyte, implying a strong inhabitation to the flammability. Additionally, Li et al. [218] synthesized a multi-functional FR electrolyte additive pentafluoro cyclotriphosphazene (PFPN). The electrolyte with 5 vol.\% of PFPN was found to be a non-flammable electrolyte, moreover it could reduce the charge transfer resistance of battery resulting in a decreased electrode polarization and enhanced electrochemical performance at low temperature. Finally, several representatives belonging to the four kinds of additives above are listed in Figure 15.<smiles>CCOP(=O)(OCC)OCCNN</smiles><smiles>CCOP(=O)(N=[PH](=O)(OCC)OCC)OCC</smiles>

Figure 14. The synthetic route of triethoxyphosphazen-N-phosphoryldiethylester (PNP). Adopted from Ref. [217].

a

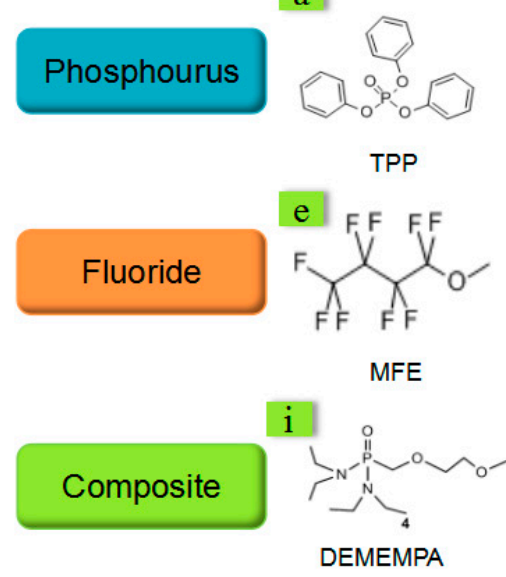

$\mathrm{m}$

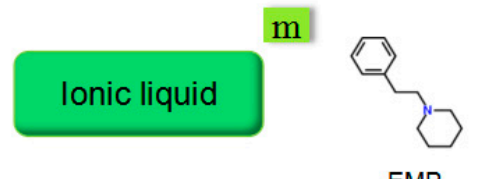

$\mathrm{b}$

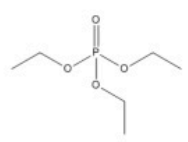

TEP

f

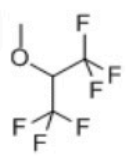

HFPN

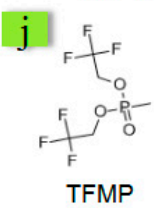

$\mathrm{n}$

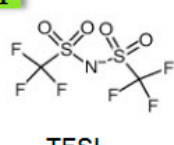

c

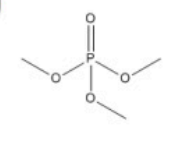

TMP

g

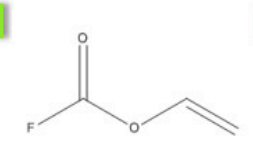

FEC

$\mathrm{k}$
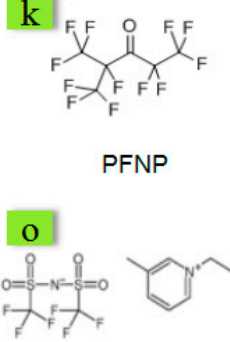

EMP-TFSI d

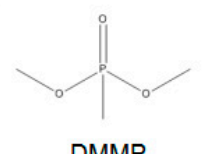

$\mathrm{h}$

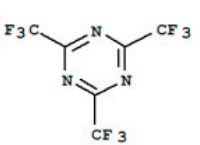

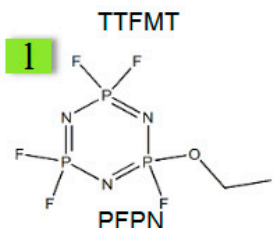

$\mathrm{p}$

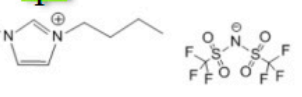

[BMIm][NTf $f_{2}$

Figure 15. The chemical structures of several typical retardant electrolyte additives.

Commonly, the choice of FR electrolyte additive requires a comprehensive consideration including conductivity, solubility, retardant efficiency and cost etc. Table 2 summarizes the advantages/disadvantages of the typical FR additives stated above. It can be observed that the key challenges of these four kinds of FR additives which remain to be solved are: (1) the phosphorus FR needs to prevent reductive decomposition and cointercalation; (2) a better retardant efficiency and a lower cost are necessary for fluoride FR; (3) the ionic liquid FR shall be enhanced by reducing its cost while enhancing the electrochemical compatibility; (4) the composite FR must simplify their synthesis process and thus they can be obtained at a lower cost and in a shorter time. In brief, the development of FR additive aims to achieve a balance between the electrochemical performance and the retardant effect. Going forward, we will obtain knowledge of a more advanced substance and then make good use of synergistic effect to get a win-win situation. 
Table 2. The comparison of several typical fire-retardant electrolyte additives.

\begin{tabular}{|c|c|c|}
\hline Type & Advantages & Disadvantages \\
\hline Phosphorus & Low cost; Simple synthesis process & $\begin{array}{l}\text { Poor electrochemical compatibility; } \\
\text { Low retardant efficiency }\end{array}$ \\
\hline Fluoride & $\begin{array}{l}\text { Good electrochemical compatibility; Simple } \\
\text { synthesis process }\end{array}$ & Low retardant efficiency; High cost \\
\hline Ionic liquid & $\begin{array}{l}\text { Appropriate to low-temperature } \\
\text { environment }\end{array}$ & $\begin{array}{c}\text { Complicated synthesis process; } \\
\text { Low thermal stability; Low } \\
\text { retardant efficiency }\end{array}$ \\
\hline Composite & $\begin{array}{l}\text { High retardant efficiency; Good } \\
\text { electrochemical compatibility }\end{array}$ & $\begin{array}{c}\text { Complicated synthesis process; } \\
\text { High cost }\end{array}$ \\
\hline
\end{tabular}

\subsubsection{FR Separator}

Within LIB, a separator is considered to be a critical component in securing battery safety [219-222]. It acts as the separation between the cathode and the anode while providing a pathway for lithium ion migration. Once the separator fails, an internal short circuit between electrodes may occur and lead to the thermal failure of LIBs [223-225]. As shown in Figure 16, a safe separator has strict demands on the following six factors: (1) chemical/mechanical stability; (2) thickness; (3) thermal stability; (4) wettability; (5) barrier property and (6) porous property.

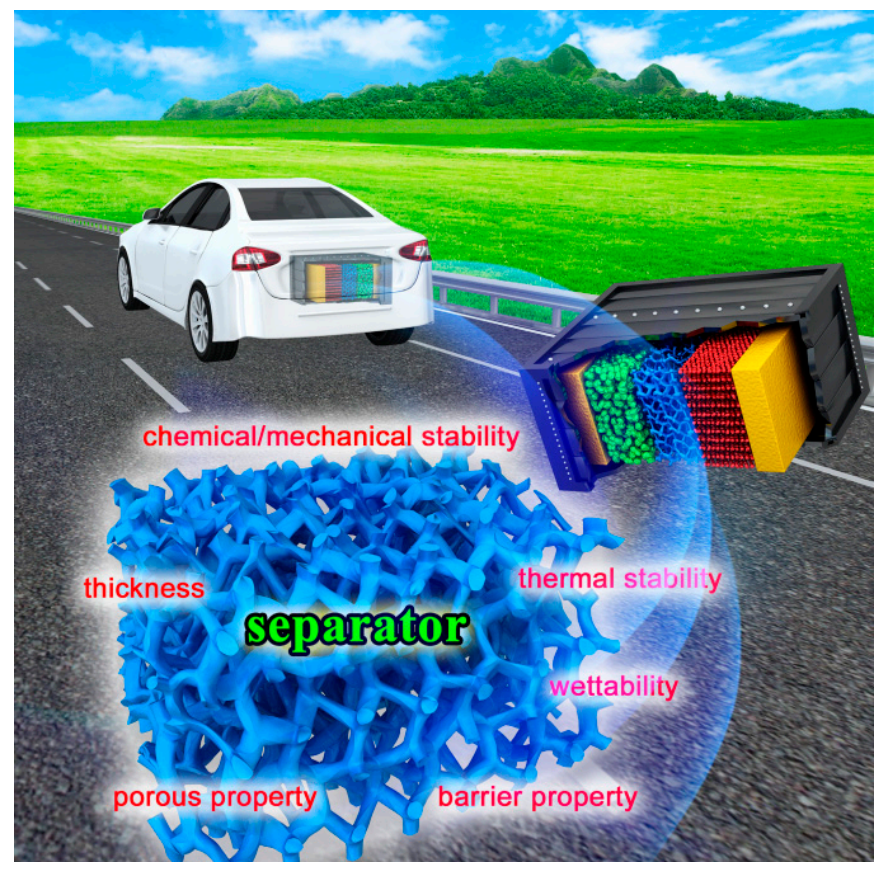

Figure 16. The schematic diagram of separator and the requirement for safety.

As stated before, a commercialized separator typically consists of PE or PP, and has persistent drawbacks of a low melting temperature and poor wettability for liquid electrolytes which make it difficult to widely adopt in large-scale LIB. To overcome these obstacles and enhance its thermal safety, a composite separator may be a feasible solution. Yeon et al. [226] synthesized several FR composites $\left(\mathrm{Al}_{2} \mathrm{O}_{3}\right.$-sputtered $\mathrm{PE}$ separator, $\mathrm{Al}(\mathrm{OH})_{2}$-composite, $\mathrm{Mg}(\mathrm{OH})_{3}$-composite) and verified in their experiments that these composites exhibited superior FR properties compared to traditional separator as they could release water at high temperatures. Meanwhile, bromine is another choice as a composite FR separator. Lee et al. [227,228] developed and investigated a brominated poly(2,6-dimethyl-1,4-phenylene oxide) (BPPO) coated separator to improve the FR ability and thermal 
ability. Besides, Zhang et al. [229] developed a sustainable, heat-resistant and cellulose-based composite FR separator for high-performance LIB, namely FCCN, i.e., flame-retardant and thermal resistant cellulose-based composite nonwoven separator which showed superior heat tolerance and good mechanical strength.

\subsection{Battery Management System}

In practical applications, LIBs are required to operate at different conditions where a complicated temperature environment such as high temperature, low temperature and a largely varying temperature etc. may be involved. As stated by many scholars, temperature greatly affects battery from both safety and performance points of view [230-234]. Hence, it is of great importance to configure an efficient battery management system (BMS) that allows for control of battery temperature and prevents the occurrence of thermal hazard.

BMS applied in EV is usually comprised of sensors, actuators and controllers, and it is used to achieve three main aims: (1) to protect battery from being damaged; (2) to make battery operate within the proper voltage and temperature interval; (3) to maintain the performance of battery to meet the requirement of vehicles [235]. Traditionally, BMS can be briefly divided into two categories: internal thermal management (ITM) and external thermal management (ETM), which is further displayed in Figure 17.

Battery Management System (BMS)

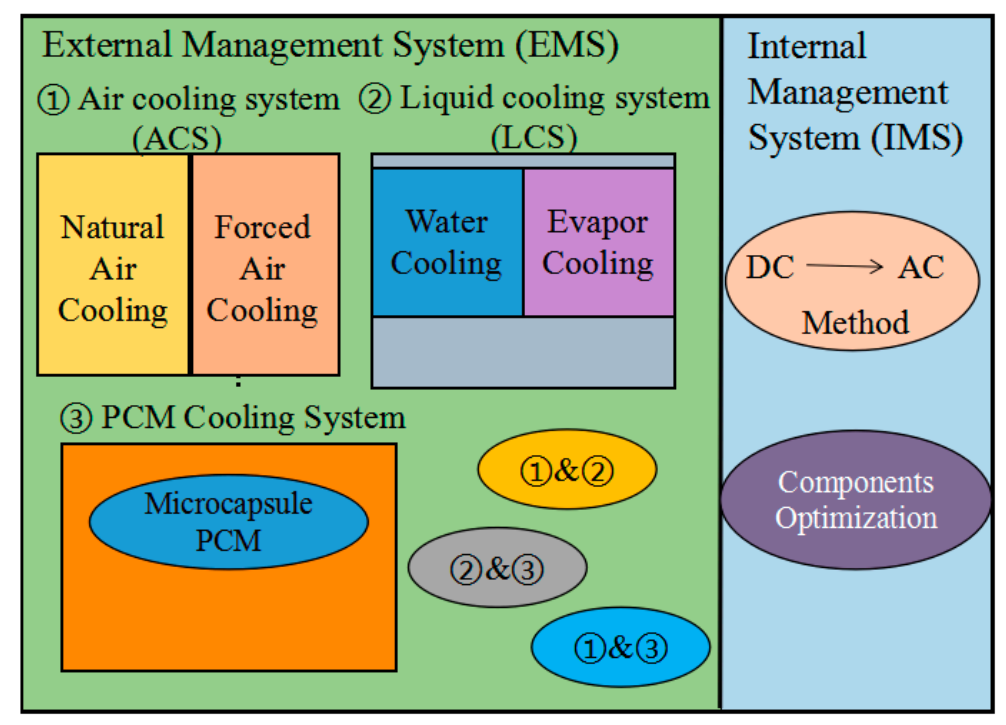

Figure 17. Summary of battery thermal management systems including the external management system (air cooling system, liquid cooling system, PCM cooling system) and the internal management system (alternating current, component optimization).

ITM, also known as intrinsic safety management, refers to those thermal management methods applied at the battery level in which the thermal management strategies exist in the core region of the battery monomer. One common approach is via optimizing battery components to be safer so that less heat is generated and better uniformly can be achieved. Choi et al. [236] proposed a cooling method to remove the heat generated within the lead-acid battery by means of controlling electrolyte circulation rate. Their results showed that such an approach could provide a uniform temperature field and the temperature could be controlled to a desirable level. As shown in Figure 18a, Mohammadian et al. [237] introduced a particular type of internal cooling method, where liquid electrolyte served as a coolant and flowed through the micro-channels dispersed in electrodes. Besides, Bandhauer et al. [238] developed a novel system that utilized an internal evaporator with micro-channels incorporated in a thick current collector and then applied to side cooling, see Figure $18 \mathrm{~b}$. 


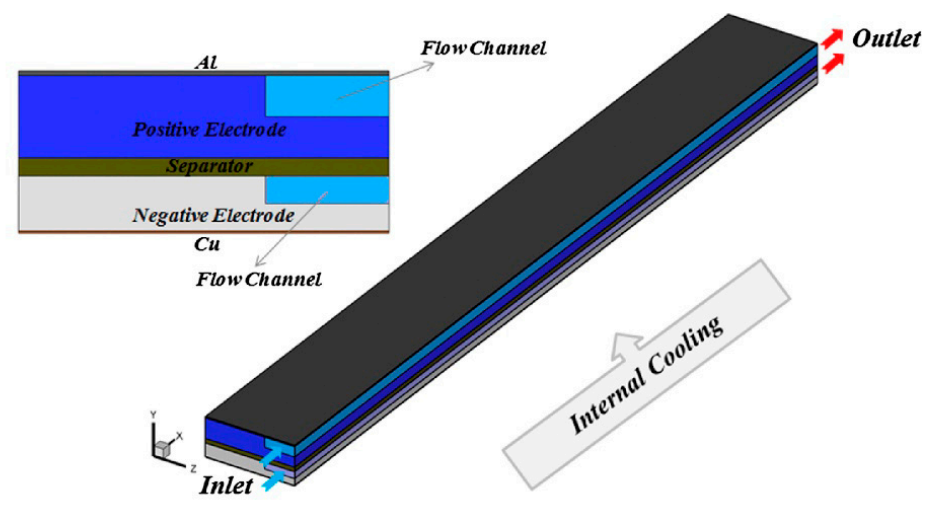

(a)

Original Battery Unit Cell

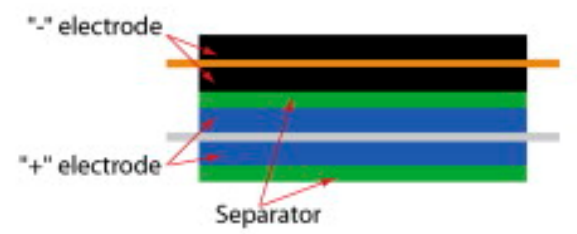

Internal Cooling Concept 1
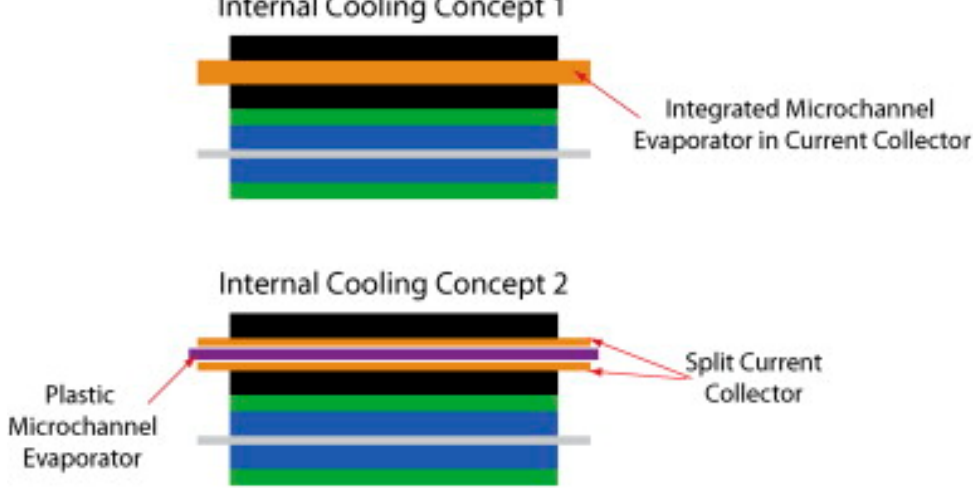

(b)

Figure 18. Internal thermal management: (a) internal cooling by micro-channel in electrode, adopted from Ref. [237]; (b) internal cooling by micro-channel evaporator in current collector, adopted from Ref. [238].

Another way to achieve ITM is via the application of alternating current (AC) that can efficiently heat battery without a substantial change of SOC. Stuart et al. [239] first proposed using AC to warm battery up rather than using an external heater. For this method, the heating rate increased with the increasing signal amplitude, however the effect of signal frequency on the heating performance was not taken into account. To address this problem, Ruan et al. [240] proposed an effective strategy to analyze the optimal frequency. Their results demonstrated that constant frequency was more promising than variable one for engineering realization and the optimal frequency could be evaluated according to the intermediate temperature.

Nevertheless, in practical applications, the ITM method is difficult to operate and some disadvantages such as low cooling efficiency and temperature gradient etc. also limit its usage [240]. Comparatively, another BMS, i.e., ETM has received a more universal application.

Corresponding to the ITM, ETM refers to the thermal management methods that improve heat dissipation from external environment. In order to promote heat dissipation, it is important to choose 
a suitable medium. On the basis of the medium, ETM can be further divided into three kinds: air cooling system (ACS), liquid cooling system (LCS) and PCM cooling system (PCM-CS).

There are two types of air flow patterns in ACS: natural convection (NC) and forced convection (FC). For the ACS, air flow rate is an important factor in the promotion of the heat transfer coefficient, thus improving the efficiency of heat dissipation. Additionally, certain factors such as battery arrangement, flow path number and width also influence the performance. Wang et al. [241] investigated the thermal behaviors of an air-cooled LIB. Their results showed that temperature non-uniformity caused by heat accumulation and concentration was mitigated by reciprocating air-flow with optimized reversing strategy and forward air-flow. Liu et al. [242] conducted a set of optimization methods in reciprocating air flow of LIB thermal management. They found that the reciprocating flow could achieve good dissipation, reduce the temperature difference, improve the temperature uniformity and effectively reduce the maximum temperature of battery. As displayed in Figure 19, Zhang et al. [243] proposed a novel battery pack with a wedge-shaped runner, optimizing the position of inlet/outlet, the width of the wedge-shaped flow path, the inclination angle of the battery and the clearance among batteries. Their results showed that the temperature distribution was exacerbated with the increase of the inlet temperature and improved with the increasing inlet velocity. However, despite the fact that researchers have never stopped optimizing the structure of ACS, it is still hard for ACS to meet the demands of EV at present. Nelson et al. [244] argued that using an air-based system it was difficult to cool the battery to less than $52{ }^{\circ} \mathrm{C}$ when the battery temperature was above $66^{\circ} \mathrm{C}$.

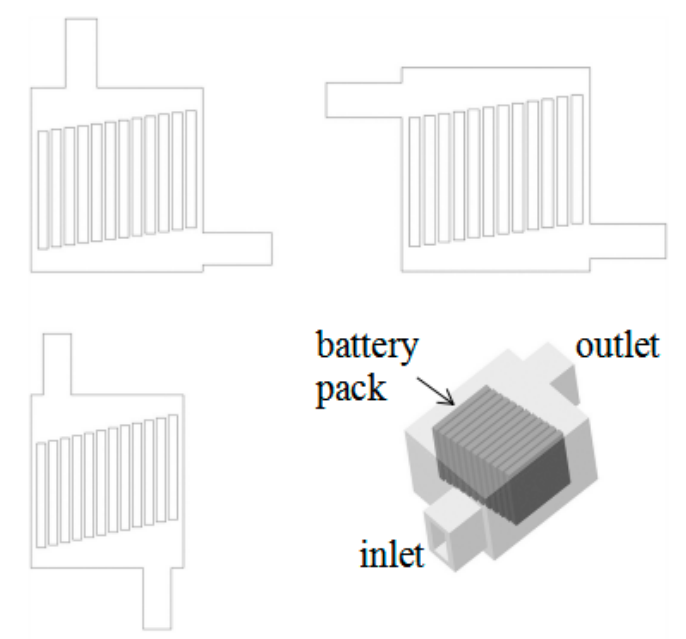

Figure 19. A representative air-cooling system. Adopted from Ref. [243].

Compared to the ACS, a liquid-based cooling system possesses better performance due to its higher heat transfer coefficient. Normally, the LCS can be divided into two kinds according to whether a phase change occurs during the process, namely whether water changes into vapor which usually takes place in the heat pipe. Apparently, the phase change may be a driving force in heat absorption. Shang et al. [245] designed a LCS for LIB by varying the contact surface, and the results showed that increasing inlet mass flow could effectively limit the maximum temperature, however, it could not significantly improve the temperature uniformity. As shown in Figure 20, Zhao et al. [246] developed two cooling approaches via channeled liquid flow to minimize the thermal non-uniformity in a battery pack and found that the two LCSs could reduce the non-uniformity of battery under 5C discharging operation to values lower than 2.2 and $0.7^{\circ} \mathrm{C}$, respectively. In addition, Wang et al. [247] developed a new LCS based on thermal silica plates, which could greatly improve the cooling capacity and therefore decrease the maximum temperature difference within a battery.

Nevertheless, the fluidity of liquid is a huge barrier for electronic system which requires advanced and complicated design before application, therefore resulting in a high cost. Recently, Ren et al. [248] presented a novel method of employing water evaporation, as displayed in Figure 21. The thin sodium 
film (SA-1 film) with a water content of $99 \mathrm{wt} . \%$ was prepared and their results revealed that under the condition of a cycle rate larger than $1 \mathrm{C}$, the temperature rise rate of battery could be reduced by half. Meanwhile, the liquid barrier was successfully solved by the proposed SA-1 film such that there was not a large effect on the electronic system.

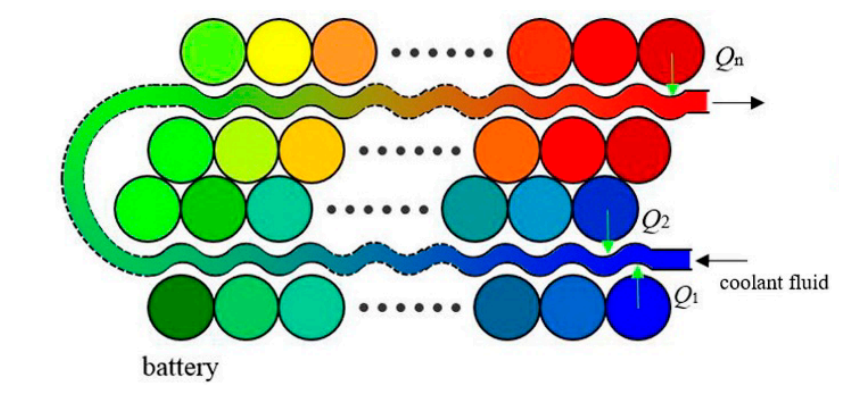

temperature:

low

high

Figure 20. The procedure of a representative liquid cooling method. Adopted from Ref. [246].

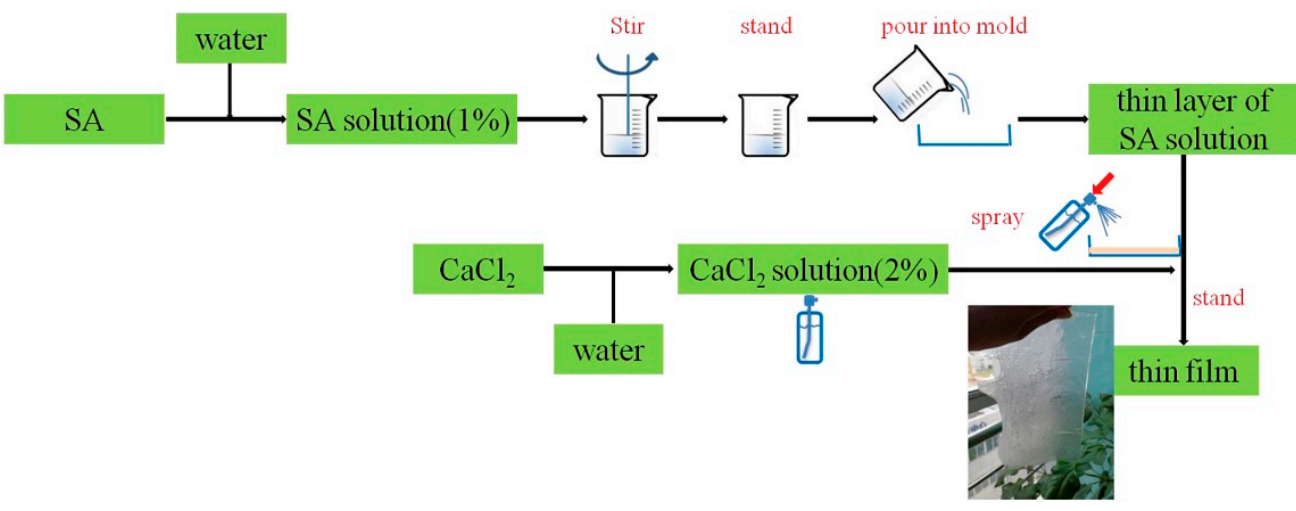

(a)

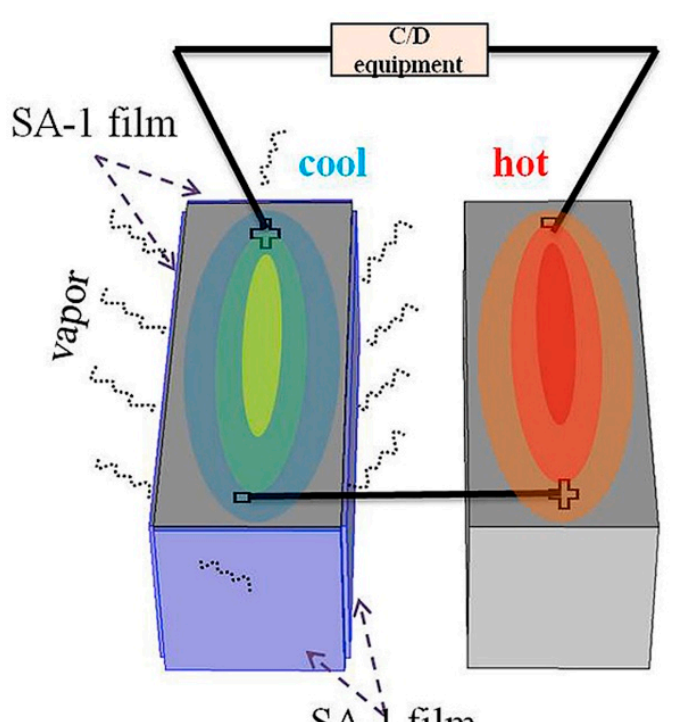

SA-1 film

(b)

Figure 21. (a) The preparation process of thin sodium film (SA-1 film); (b) The application of SA-1 film in the system. Adopted from Ref. [248]. 
PCM is a type of material that is able to absorb thermal energy and then release it by a reverse process; hence, it is considered as a novel medium in BMS [249]. Commonly, it consists of three categories: the organic, the inorganic and the eutectic. The organic PCM contains carbon element, in which paraffin is the most common compound. For organic PCM, it possesses the advantage of no needing a container as their volume variation is relatively low, besides the chemical stability and non-corrosiveness [250]. The inorganic PCMs usually contain one or more metallic atoms. They have a good thermal conductivity and latent heat. Additionally, they are nonflammable and nontoxic. Nevertheless, some of them are corrosive and the reversibility of phase change is difficult to maintain in the long term. Moreover, the metals contained in inorganic PCM result in a high density which greatly limits its practical application. The eutectic PCM is a specific mixture of the previous PCMs, which permits the obtainment of a PCM with properties different to pure materials.

For most PCMs, their latent heat is large, while their thermal conductivity is relatively poor. Hence, considerable studies have been carried out to enhance the thermal conductivity of existing PCMs as displayed in Table 3, and some other materials with high thermal conductivity such as expanded graphite (EG), foamed metal and nanomaterials are also introduced to synthesize composite phase change material (CPCM). Wang et al. [251] developed an improved BMS based on the CPCM with aluminum boxes. Their results showed that the CPCM could significantly reduce the average temperature and improve temperature uniformity of a battery pack. Huang et al. [252] investigated the cooling effectiveness of CPCM on the thermal response of a battery under overcharge condition and found that the battery cooled down remarkably as compared to the natural convection condition when CPCM was attached to the pouch battery. Ling et al. [253] compared two CPCMs, a highly thermal conductive $60 \mathrm{wt} . \%$ RT44HC/EG composite and a $60 \mathrm{wt} . \%$ RT44HC/fumed silica composite with a lower thermal conductivity. Their results indicated that the low thermal conductivity of the CPCM would induce an even higher temperature difference over the battery pack in the absence of PCM.

Table 3. Research cases to enhance the thermal conductivity of phase change material.

\begin{tabular}{|c|c|c|c|c|}
\hline Authors/Reference & СРCM/Proportions & $\begin{array}{c}\text { Melting } \\
\text { Temperature }\left({ }^{\circ} \mathrm{C}\right)\end{array}$ & $\begin{array}{l}\text { Latent Heat } \\
(\mathrm{kJ} / \mathrm{kg})\end{array}$ & $\begin{array}{c}\text { Thermal Conductivity } \\
(\mathrm{W} / \mathrm{m} \cdot \mathrm{K})\end{array}$ \\
\hline Zhang et al. [254] & Alum/EG & 87.9 & 214.9 & $0.95-5.88$ \\
\hline Wang et al. [255] & $\begin{array}{l}\text { Polyethylene glycol } \\
\text { (PEG)/EG }\end{array}$ & 61.5 & 161.2 & $0.30-1.32$ \\
\hline Javieradrain et al. [256] & Alum foam/EG/parraffin & 60.1 & 190.0 & $0.20-1.20$ \\
\hline Kim et al. [257] & $\begin{array}{l}\text { Octadecane }(\mathrm{OD}) / \text { Expanded } \\
\text { graphite (WEPG) }\end{array}$ & 30.1 & 198.8 & l \\
\hline Sheng et al. [258] & Alum/Erythritol & 118.0 & / & $4.00-30.00$ \\
\hline $\begin{array}{l}\text { Zhang et al. [259] } \\
\text { (Figure 22a) }\end{array}$ & $\begin{array}{l}\text { Diamond foam } \\
\text { (DF)/parraffin }\end{array}$ & 90.0 & 124.7 & $0.25-6.70$ \\
\hline Darkwa et al. [260] & Alum/Hexadecane & 24.9 & 167.0 & $0.15-1.25$ \\
\hline Hasse et al. [261] & Parraffin & 27.9 & 170.1 & 0.19 \\
\hline $\begin{array}{l}\text { Yang et al. [262] } \\
\text { (Figure 22b) }\end{array}$ & PEG/EG & 25.9 & 98.6 & / \\
\hline
\end{tabular}

In summary, each type of BMS has its own merits and drawbacks, herein a comparison is conducted among these different types of BMS, shown in Table 4. Most scholars agree on the fact that air cooling is easy to operate but is not enough to cope with the temperature elevation of battery. Liquid cooling is performant but complex and presents the shortest lifespan. As for PCM, the leakage danger is a problem in application, thus a container is necessary.

Nowadays, many researchers have focused on developing a combined battery management system (CBMS), in which more than one of the above thermal management methods are applied. In this way, different methods can complement mutual strengths and weaknesses to present excellent performance. Ling et al. [263] developed a hybrid thermal management system for LIB-integrated PCM with forced-air cooling, as depicted in Figure 23. This CBMS successfully prevented heat accumulation and maintained the maximum temperature under $50{ }^{\circ} \mathrm{C}$, in which the PCM dictated the maximum temperature rise and temperature uniformity within the battery pack while forced air convection 
succeeded in recovering the thermal energy storage capacity of PCM. Fathabadi et al. [264] proposed a novel battery pack design including a hybrid active-passive thermal management system. Their developed CBMS could be divided into two parts: the active part applied distributed thin ducts, air flow and natural convection as cooling media while the passive part utilized PCM/EG as the cooling component to optimize the thermal performance of the proposed battery pack. Xie et al. [265] developed a CPCM-based thermal management system coupled with air cooling and their results showed that the cooling effect of the integrated system was evidently better than that of the air cooling system. Furthermore, it was more energy-efficient due to the relatively lower air flow rate.

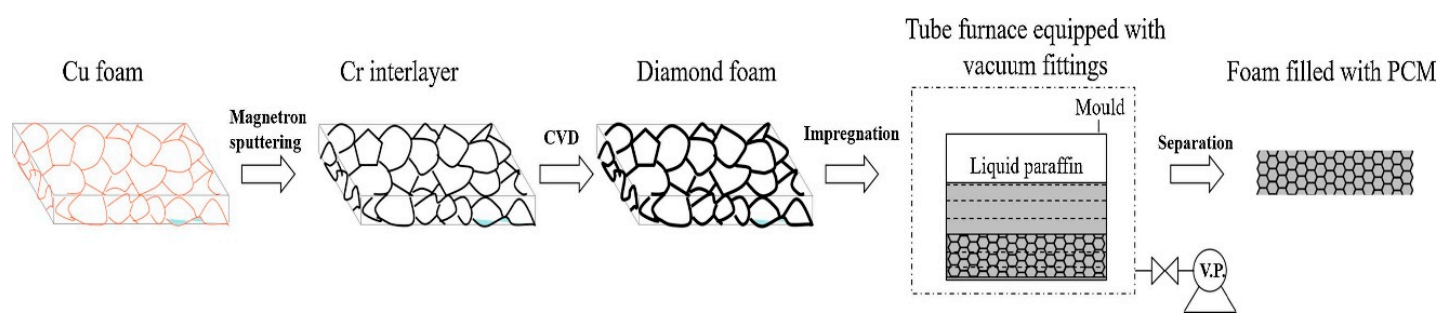

(a)

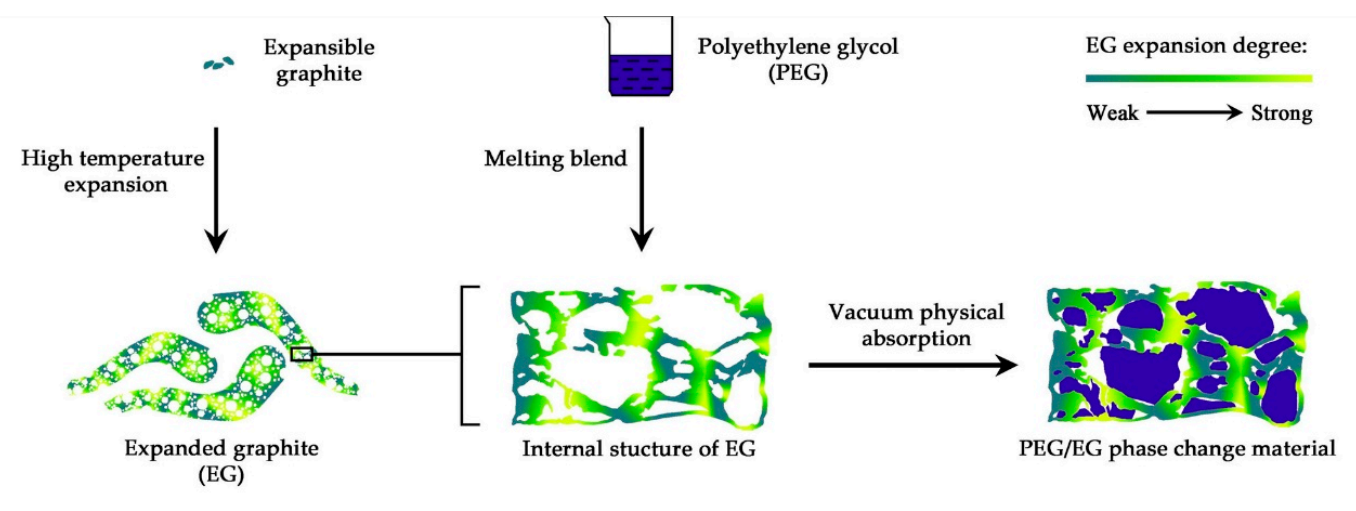

(b)

Figure 22. (a) The fabrication procedure of diamond foam and the generated composite phase change material (CPCM), adopted from Ref. [259]; (b) The synthetic route of polyethylene glycol/expanded graphite (PEG/EG), adopted from Ref. [262].

Table 4. Comparison among different kinds of battery management system.

\begin{tabular}{ccll}
\hline \multicolumn{2}{c}{ BMS } & \multicolumn{1}{c}{ Advantages } & \multicolumn{1}{c}{ Disadvantages } \\
\hline ACS & NC & $\begin{array}{l}\text { Low cost; Simple structure; Easy to } \\
\text { integrate; Little electricity } \\
\text { consumption }\end{array}$ & $\begin{array}{l}\text { Low heat transfer coefficient; } \\
\text { Dependent on ambient temperature; } \\
\text { Uneven temperature distribution } \\
\text { Low efficiency; Dependent on } \\
\text { ambient environment; Insufficient } \\
\text { for extreme condition }\end{array}$ \\
\hline \multirow{2}{*}{ LCS } & Liquid cooling & $\begin{array}{l}\text { Low cost; Easy to maintain } \\
\text { Higher efficiency; Low operate cost; } \\
\text { Better uniformity }\end{array}$ & $\begin{array}{l}\text { Risk of leakage } \\
\text { Higher cost for structure design; } \\
\text { High cost for circulation }\end{array}$ \\
\hline \multirow{2}{*}{ PCM-CS } & Vapor cooling & $\begin{array}{l}\text { Risk of leakage; Volume difference } \\
\text { with phase change; Risk of } \\
\text { supercooling }\end{array}$ \\
\hline
\end{tabular}

As shown in Figure 24, Song et al. [266] investigated a CBMS that integrated liquid cooling and PCM together. Their results demonstrated that both the battery temperature ramp-up rate and the battery steady-state temperature were significantly reduced by the conjugated cooling, in comparison 
with single PCM or liquid cooling condition. Ling et al. [267] investigated an optimization method, the response surface methodology (RSM) with PCM and liquid cooling integrated for LIB, which helped retain the PCM mass by up to $94.1 \%$ and the volume by up to $55.6 \%$. Compared with the conventional LCS, the hybrid system is not only highly efficient but lightweight and flexible for the batteries with arbitrary shapes. Zheng et al. [268] proposed a BMS combining liquid cooling and PCM for a fast-charging LIB pack and their results depicted that the improved system controlled the temperature well in an 8C-rate charging battery pack.

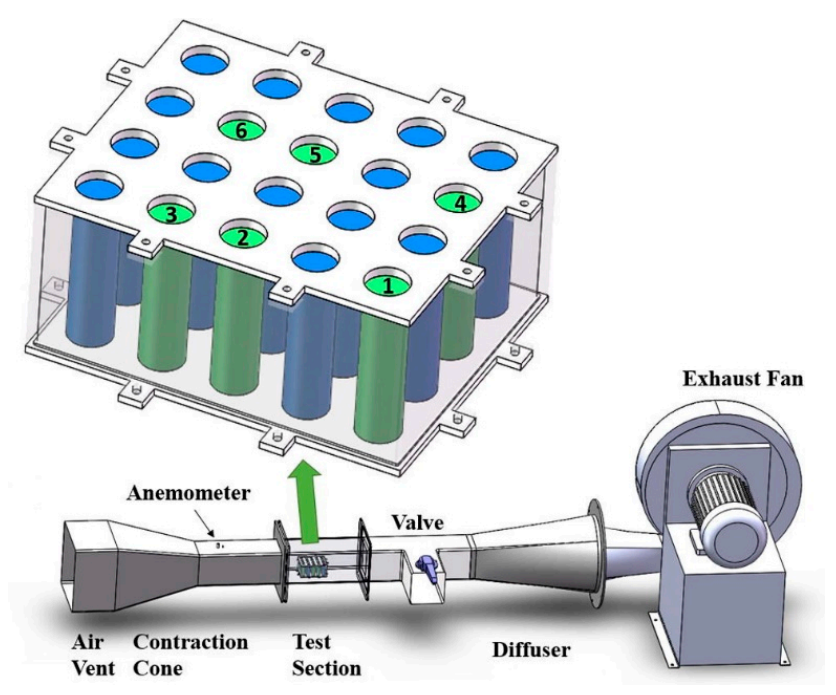

Figure 23. Schematic of a combined battery management system (CBMS) integrated phase change material (PCM) with forced-air cooling. Adopted from Ref. [263].
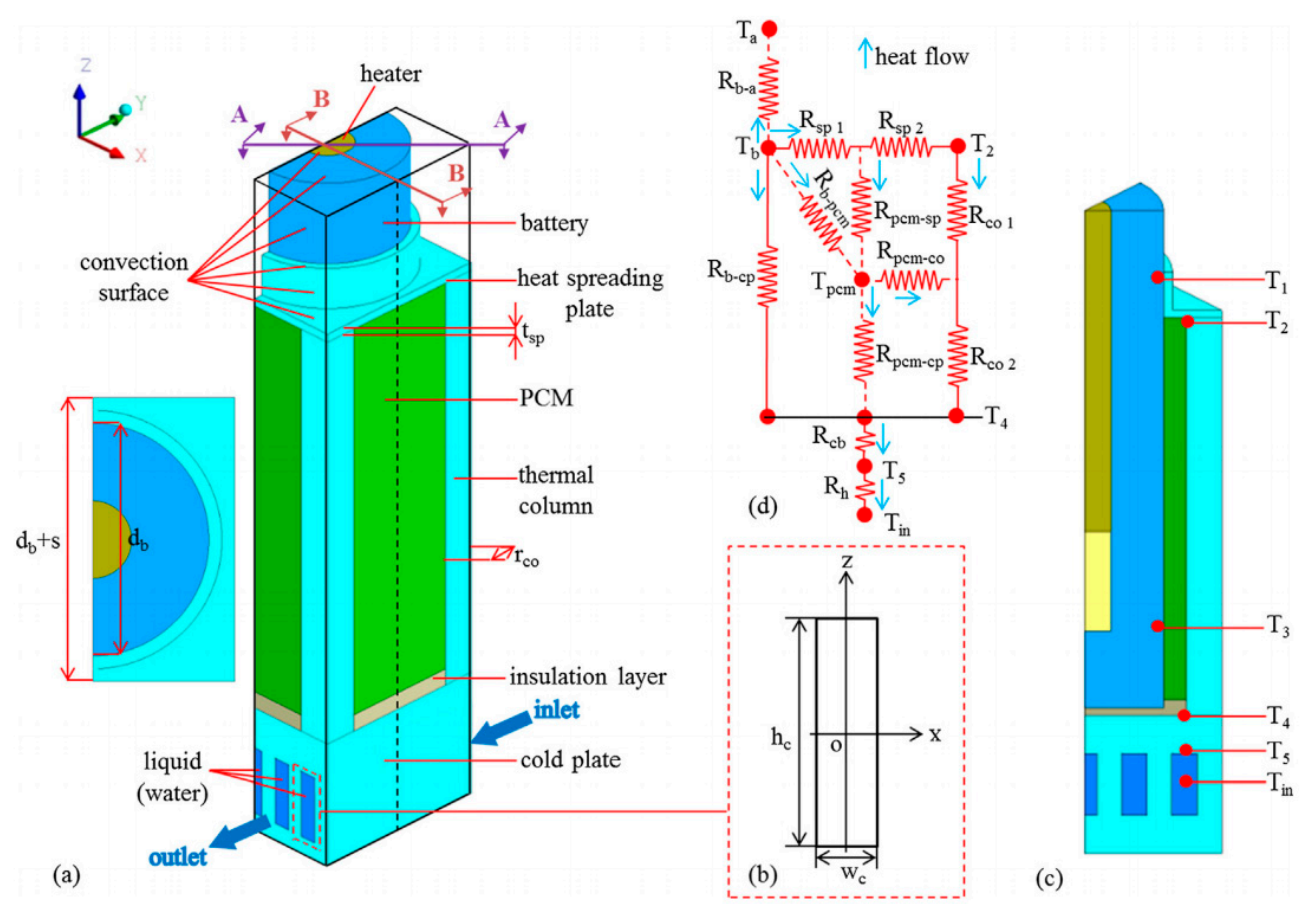

(c)

Figure 24. Schematic of a CBMS combining PCM and liquid cooling techniques. Adopted from Ref. [266]: (a) the numerical model of single battery; (b) cross section of the flow channel; (c) temperature monitoring points in A-A cross-section; (d) the simplified thermal resistance network at steady state, with dotted thermal path absent for the liquid cooling condition. 
To conclude, it is worth noting that both the application of FR additives and the thermal management on battery are compliant before the appearance of battery hazard, that is, the normal operation process. Even the safety device acts as a protective method for battery thermal hazard. Whereas, once thermal hazard occurs, it is essential to take certain countermeasures such as the warning of hazard and subsequent firefighting methods to reduce the damage inflicted by the hazard and suppress further deterioration.

\subsection{Warning}

There are two aspects from the perspective of early warning in order to solve the safety problem associated with LIB. The first is for a single battery; real-time monitoring of voltage, current, resistance and other data should take place prior to the occurrence of thermal hazard, allowing for an alarm to be raised when an abnormality appears. The second is to carry out management monitoring for a battery pack, that is, to analyze and alarm the abnormalities occurring during the operation of the entire battery pack. The early warning includes monitoring the changes in voltage, current, resistance and other electrical performance parameters, the temperature change and the escaping gases. An early warning and monitoring system is disclosed by Xie et al. [269] for battery packs. During normal cycling of a battery, surface temperature, voltage, current and impedance may be monitored to determine if abnormalities exist in the battery. Hermann invented a method for detecting LIB failure within a battery pack based on variations in the measured electrical isolation resistance of the battery pack [270]. Besides, escaping gas from LIB is becoming a growing concern since the volatile organics emitted are flammable and their unpredictable release represents a safety risk. Davion et al. [271] illustrated the results that the sensor could detect escaping gas prior to thermal events. With enough prior warning from the sensor, there is a desire to determine whether it provides suitable control at the fringes of battery performance. Somov et al. [272] applied an autonomous wireless sensor system for early fire and gas leak detection of LIBs. The system consisted of two modules: a gas sensor module and a power management module. At the same time, there have been more studies on the thermal runaway and fire releasing gases of LIBs; therefore, the number of gas detection methods that can be used for thermal runaway and fire warning has also increased [273-275]. The problem of thermal runaway and fire in LIBs is now more serious, therefore some advanced means are needed to predict the occurrence of disasters. Accurate warning of thermal runaway and fire shall be achieved through more quantitative data analysis.

\subsection{Firefighting}

As displayed in Table 5, fires are generally classified into five different kinds (classes A, B, C, D and K) [276]. Nevertheless, due to the complexity of battery components and the diversity of usage conditions, the classification of LIB fire is controversial and it may vary among classes A, B, and C. In view of the uncertainty, there are currently no unified and specific requirements for the suppression of LIB fires, and effective fighting technology for LIB fire is still a challenge. Suppressing LIB fire involves extinguishing the open flame and decreasing the battery temperature. If the battery temperature is sufficiently high after the open flame is extinguished, there is still a possibility that the battery will reignite.

To investigate how LIB fire can be suppressed effectively, researchers and institutions have conducted extensive studies to date. The National Technical Information Service (NTIS) assessed the fire hazards of LIBs and tested the extinguishing effect of different Halon products on battery fire $[277,278]$. Their results showed that the Halon extinguishing agents could suppress the open fire, while the battery temperature would still increase after the flame was extinguished. Later, Egelhaaf et al. studied the fighting effect of water combined with a surfactant and a gelling agent on battery fire [279]. They measured the battery temperature and the water consumption and found that water was capable of extinguishing the battery fire and additives helped to apparently reduce the amount of water required to fight the fire. Additionally, the Fire Protection Research Foundation (FPRF) performed a 
full-scale suppression test for the fire involving EV battery [280]. They proposed that although the water jet could quickly extinguish the battery fire, the toxic or flammable smoke and gas would still release after suppression. The FAA conducted experiments to screen the effective fire extinguishing agent for battery fire [281]. Experimental results indicated that water-based extinguishing agents (water, AF-31, AF-21, A-B-D, and Novec $\left.1230\left(\mathrm{C}_{6} \mathrm{~F}_{12} \mathrm{O}\right)\right)$ were the most effective, especially the evident cooling effect, while nonaqueous extinguishing agents (gas, dry powder, etc.) were the least effective. The Det Norske Veritas and Germanischer Lloyd (DNVGL) carried out a series experiments to evaluate the extinguishing effect of the F500, Fireice, PyroCool, aerosol and water on battery fire respectively [282]. Their results showed that all extinguishers used in this work could put down battery fire if they were sprayed immediately upon the detection of a thermal spike. Among, water exhibited the best cooling effect for a battery with thermal runaway. Hui et al. selected carbon dioxide, superfine powder and heptafluoropropane to conduct the battery fire suppression test series [283] in which heptafluoropropane was verified to be the most effective in controlling battery fires and suppressing the thermal runaway reactions. Further, Wang et al. investigated the efficiency of heptafluoropropane fire extinguishing agent (HFC-227ea), and they found that heptafluoropropane could suppress individual battery and even small-format battery pack fire [284]. However, the battery might be reignited due to the fiercely exothermic reactions inside battery after the fire was extinguished. Liu et al. investigated the suppression efficiency of dodecafluoro-2-methylpentan-3-one $\left(\mathrm{C}_{6} \mathrm{~F}_{12} \mathrm{O}\right)$ in large-capacity battery fires [39]. They proposed that $\mathrm{C}_{6} \mathrm{~F}_{12} \mathrm{O}$ first showed a negative inhibitory effect, which was then transformed into an inhibitory effect as the dose increased, and they also calculated the proper dose of $\mathrm{C}_{6} \mathrm{~F}_{12} \mathrm{O}$ under their conditions. Besides, Luo et al. studied the fire extinguishing effect of a water mist containing additives system on a power battery [285]. Their results indicated that $5 \%$ F-500 solution and 5\% self-made solution yielded a more significant extinguishing effect than pure water on battery fire.

Table 5. Classification of fires.

\begin{tabular}{cl}
\hline Class & \multicolumn{1}{c}{ Description } \\
\hline A & Fires in ordinary combustible materials such as wood, cloth, paper, rubber and many plastics. \\
\hline B & $\begin{array}{l}\text { Fires in flammable liquids, combustible liquids, petroleum greases, tars, oils, oil-based paints, } \\
\text { solvents, lacquers, alcohols and flammable gases. }\end{array}$ \\
\hline C & Fires that involve energized electrical equipment. \\
\hline D & $\begin{array}{l}\text { Fires in combustible metals such as magnesium, titanium, zirconium, sodium, lithium and } \\
\text { potassium. }\end{array}$ \\
\hline K & Fires in cooking appliances that involve combustible cooking media. \\
\hline
\end{tabular}

In summary, the previous studies mainly focused on the comparison of fire extinguishing effects among different extinguishing agents, such as Halon, water, carbon dioxide, foam, dry powders and so on. However, some deficiencies still exist and challenging questions are being proposed regarding fighting battery fire. For example, the spray time of the agent, dose of agent, damage degree of the battery, cost and scenario, etc. shall be quantitatively or qualitatively estimated. Furthermore, standard specifications and guidelines for the firefighting of battery fire shall be formulated and promulgated as soon as possible to meet the requirements of the market.

\section{Summary and Outlook}

With the global energy policy transitioning from fossil energy to renewable energy, LIBs, as a type of energy storage method, show great advantages over other kinds of batteries. Therefore, they have attracted considerable attention. However, the safety concerns regarding LIB are still a main obstacle that hinder large-scale applications of LIBs in many fields. Benefiting from the fast spread of information today, incidents of fire or explosions induced by LIBs are often reported ranging from 
mobile telephones and EVs to airplanes. These incidents greatly threaten consumers' lives and property, while damage human's confidence on LIBs, thereby restricting the progression of their use. Therefore, paying more attention to the thermal hazards of LIBs and the corresponding countermeasures is of great importance.

Generally, the thermal hazards of LIBs can be caused by several abusive factors, e.g., physical, electrical and thermal factors, manufacturing defect and battery aging. The physical factor can trigger electrical abuse, and the electrical abuse releases heat which will further induce thermal abuse; namely, thermal hazard and even thermal runaway. During the process of battery thermal hazard, a series of destructive reactions among battery components such as the decomposition of electrodes/electrolytes, the reaction between electrodes, the reaction between electrode and electrolyte, etc. are induced, substantial heat is released and quantities of combustible gases are generated. Besides battery components, the thermal hazards of a single battery and a battery pack are also reviewed. For the former, the thermal hazards that are generally exhibited are high-temperature, ejection, combustion, explosion and toxic gases during thermal runaway. While for a battery pack, thermal failure propagation provides a thermal hazard in addition to thermal runaway. Thermal failure propagation will aggravate the thermal hazard further, resulting in a serious incident. In addition, the influence of low-pressure environment and cathode chemistry on the thermal hazard of LIBs is discussed here. However, it still lacks sufficient examinations on the thermal behavior of LIBs under low pressure, the hazard difference between normal condition and low-pressure condition is worth noting in future research.

In an aim to decrease the thermal hazards of LIBs as much as possible, certain management or countermeasures must be implemented. In current work, the measures discussed were (1) the usage of safety devices inside battery; (2) the application of FR additives; (3) the thermal management of battery; (4) the warning of thermal hazard and (5) firefighting upon the occurrence of a hazard. However, challenges still remain. Effective FR additives and thermal management systems still need to be developed to meet the requirement of practices including performance, cost and so on. The current warning method is not sufficiently sensitive to give the humans the time necessary to escape danger or take the appropriate measurements. Moreover, standard guidelines for the fighting of battery fire remain to be formulated and promulgated. In short, to decrease the challenges of battery thermal hazards and create LIBs that better benefit humankind, there is still a lot of work to do.

Author Contributions: D.O., M.C., Q.H., J.W., Z.W. and J.W. wrote this paper together.

Funding: This work was supported by the National Key R\&D Program of China (No. 2018YFC0808600) and the Open Project Program of the State Key Laboratory of Fire Science (No. HZ2019-KF10).

Conflicts of Interest: The authors declare no conflict of interest.

\section{References}

1. Kannan, N.; Vakeesan, D. Solar energy for future world: A review. Renew. Sustain. Energy Rev. 2016, 62, 1092-10111. [CrossRef]

2. Lewis, N.S. Research opportunities to advance solar energy utilization. Science 2016, 351, aad1920. [CrossRef] [PubMed]

3. Pérez-Collazo, C.; Greaves, D.; Iglesias, G. A review of combined wave and offshore wind energy. Renew. Sustain. Energy Rev. 2015, 42, 141-153. [CrossRef]

4. Lewis, M.; Neill, S.P.; Robins, P.E.; Hashemi, M.R. Resource assessment for future generations of tidal-stream energy arrays. Energy 2015, 83, 403-415. [CrossRef]

5. Dyer, C.K. Fuel cells for portable applications. J. Power Sources 2002, 106, 31-34. [CrossRef]

6. Saevarsdottir, G.; Tao, P.; Stefansson, H.; Harvey, W. Potential use of geothermal energy sources for the production of lithium-ion batteries. Renew. Energy 2014, 61, 17-22. [CrossRef]

7. Richter, F.; Vie, P.J.S.; Kjelstrup, S.; Burheim, O.S. Measurements of ageing and thermal conductivity in a secondary NMC-hard carbon Li-ion battery and the impact on internal temperature profiles. Electrochim. Acta 2017, 250, 228-237. [CrossRef] 
8. Maleki, H.; Howard, J.N. Effects of overdischarge on performance and thermal stability of a Li-ion cell. J. Power Sources 2006, 160, 1395-1402. [CrossRef]

9. Doughty, D.H.; Roth, E.P. A general discussion of Li ion battery safety. Electrochem. Soc. Interface 2012, 21, 37-44. [CrossRef]

10. Belov, D.; Yang, M.H. Failure mechanism of Li-ion battery at overcharge conditions. J. Solid State Electrochem. 2008, 12, 885-894. [CrossRef]

11. Kim, T.H.; Park, J.S.; Chang, S.K.; Choi, S.; Ryu, J.H.; Song, H.K. The current move of lithium ion batteries towards the next phase. Adv. Energy Mater. 2012, 2, 860-872. [CrossRef]

12. Lisbona, D.; Snee, T. A review of hazards associated with primary lithium and lithium-ion batteries. Process Saf. Environ. Prot. 2011, 89, 434-442. [CrossRef]

13. Feng, X.; Ouyang, M.; Liu, X.; Lu, L.; Xia, W.; He, X. Thermal runaway mechanism of lithium ion battery for electric vehicles: A review. Energy Storage Mater. 2018, 10, 246-267. [CrossRef]

14. Wang, Q.; Ping, P.; Zhao, X.; Chu, G.; Sun, J.; Chen, C. Thermal runaway caused fire and explosion of lithium ion battery. J. Power Sources 2012, 208, 210-224. [CrossRef]

15. Huang, Q.; Ma, L.; Liu, A.; Ma, X.W.; Li, J.; Wang, J.; Dahn, J.R. The reactivity of charged positive $\mathrm{Li}_{1-\mathrm{n}}\left[\mathrm{Ni}_{\mathrm{x}} \mathrm{Mn}_{\mathrm{y}} \mathrm{Co}_{\mathrm{z}}\right] \mathrm{O}_{2}$ electrodes with electrolyte at elevated temperatures using accelerating rate calorimetry. J. Power Sources 2018, 390, 78-86. [CrossRef]

16. Ma, L.; Nie, M.; Xia, J.; Dahn, J.R. A systematic study on the reactivity of different grades of charged Li $\left[\mathrm{Ni}_{\mathrm{x}} \mathrm{Mn}_{\mathrm{y}} \mathrm{Co}_{\mathrm{z}}\right] \mathrm{O}_{2}$ with electrolyte at elevated temperatures using accelerating rate calorimetry. J. Power Sources 2016, 327, 145-150. [CrossRef]

17. Xia, L.; Li, S.L.; Ai, X.P.; Yang, H.X.; Cao, Y.L. Temperature-sensitive cathode materials for safer lithium-ion batteries. Energy Environ. Sci. 2011, 4, 2845-2848. [CrossRef]

18. Zhong, H.; Kong, C.; Zhan, H.; Zhan, C.; Zhou, Y. Safe positive temperature coefficient composite cathode for lithium ion battery. J. Power Sources 2012, 216, 273-280. [CrossRef]

19. Kovalenko, I.; Zdyrko, B.; Magasinski, A.; Benjamin, H. A major constituent of brown algae for use in high-capacity Li-ion batteries. Science 2011, 334, 75-79. [CrossRef]

20. Ryou, M.H.; Kim, J.; Lee, I.; Kim, S.J. Mussel-inspired adhesive binders for high-performance silicon nanoparticle anodes in lithium-ion batteries. Adv. Mater. 2013, 25, 1571-1576. [CrossRef]

21. Wu, H.; Chan, G.; Choi, J.W.; Ryu, I. Stable cycling of double-walled silicon nanotube battery anodes through solid-electrolyte interphase control. Nat. Nanotechnol. 2012, 7, 310-315. [CrossRef] [PubMed]

22. Kim, Y.S.; Kim, T.H.; Lee, H.; Song, H.K. Electronegativity-induced enhancement of thermal stability by succinonitrile as an additive for Li ion batteries. Energy Environ. Sci. 2011, 4, 4038-4045. [CrossRef]

23. Kim, G.Y.; Dahn, J.R. The effect of some nitriles as electrolyte additives in Li-ion batteries. J. Electrochem. Soc. 2015, 162, A437-A447. [CrossRef]

24. Chen, R.; Liu, F.; Chen, Y.; Ye, Y.; Huang, Y. An investigation of functionalized electrolyte using succinonitrile additive for high voltage lithium-ion batteries. J. Power Sources 2016, 306, 70-77. [CrossRef]

25. Zhu, Y.; Wang, F.; Liu, L.; Xiao, S. Composite of a nonwoven fabric with poly (vinylidene fluoride) as a gel membrane of high safety for lithium ion battery. Energy Environ. Sci. 2013, 6, 618-624. [CrossRef]

26. Zhang, J.; Liu, Z.; Kong, Q. Renewable and superior thermal-resistant cellulose-based composite nonwoven as lithium-ion battery separator. ACS Appl. Mater. Interfaces 2012, 5, 128-134. [CrossRef] [PubMed]

27. Kang, S.M.; Ryou, M.H.; Choi, J.W. Mussel-and diatom-inspired silica coating on separators yields improved power and safety in Li-ion batteries. Chem. Mater. 2012, 24, 3481-3485. [CrossRef]

28. Saw, L.H.; Ye, Y.; Tay, A.A.O. Computational fluid dynamic and thermal analysis of Lithium-ion battery pack with air cooling. Appl. Energy 2016, 177, 783-792. [CrossRef]

29. Huo, Y.; Rao, Z.; Liu, X. Investigation of power battery thermal management by using mini-channel cold plate. Energy Convers. Manag. 2015, 89, 387-395. [CrossRef]

30. Li, K.; Yan, J.; Chen, H. Water cooling based strategy for lithium ion battery pack dynamic cycling for thermal management system. Appl. Thermal Eng. 2018, 132, 575-585. [CrossRef]

31. Zhao, J.; Rao, Z.; Huo, Y. Thermal management of cylindrical power battery module for extending the life of new energy electric vehicles. Appl. Thermal Eng. 2015, 85, 33-43. [CrossRef]

32. Wang, Z.; Li, X.; Zhang, G. Experimental study of a passive thermal management system for three types of battery using copper foam saturated with phase change materials. RSC Adv. 2017, 7, 27441-27448. [CrossRef] 
33. Al-Zareer, M.; Dincer, I.; Rosen, M.A. Novel thermal management system using boiling cooling for high-powered lithium-ion battery packs for hybrid electric vehicles. J. Power Sources 2017, 363, $291-303$. [CrossRef]

34. Lee, C.Y.; Lee, S.J.; Tang, M.S. In situ monitoring of temperature inside lithium-ion batteries by flexible micro temperature sensors. Sensors 2011, 11, 9942-9950. [CrossRef] [PubMed]

35. Wu, C.; Yin, P.; Zhu, X. Synthesis of hematite $\left(\alpha-\mathrm{Fe}_{2} \mathrm{O}_{3}\right)$ nanorods: Diameter-size and shape effects on their applications in magnetism, lithium ion battery, and gas sensors. J. Phys. Chem. B 2006, 110, 17806-17812. [CrossRef] [PubMed]

36. Mutyala, M.S.K.; Zhao, J.; Li, J.; Pan, H.; Yuan, C.; Li, X. In-situ temperature measurement in lithium ion battery by transferable flexible thin film thermocouples. J. Power Sources 2014, 260, 43-49. [CrossRef]

37. Chen, J.; Xu, L.; Li, W.; Gou, X. $\alpha-\mathrm{Fe}_{2} \mathrm{O}_{3}$ nanotubes in gas sensor and lithium-ion battery applications. Adv. Mater. 2005, 17, 582-586. [CrossRef]

38. Reif, R.H.; Liffers, M.; Forrester, N.; Peal, K. Lithium Battery Safety: A look at Woods Hole Oceanographic Institution's Program. Prof. Saf. 2010, 55, 32-37.

39. Liu, Y.; Duan, Q.; Xu, J. Experimental study on the efficiency of dodecafluoro-2-methylpentan-3-one on suppressing lithium-ion battery fires. RSC Adv. 2018, 8, 42223-42232. [CrossRef]

40. Williard, N.; He, W.; Hendricks, C.; Pecht, M. Lessons learned from the 787 dreamliner issue on lithium-ion battery reliability. Energies 2013, 6, 4682-4695. [CrossRef]

41. Kolly, J.M.; Panagiotou, J.; Czech, B.A. The Investigation of a Lithium-Ion Battery Fire Onboard a Boeing 787 by the US National Transportation Safety Board; Safety Research Corporation of America: Dothan, AL, USA, 2013; pp. 1-18.

42. Goto, N. Aircraft Serious Incident Investigation Report: All Nippon Airways Co. Ltd. JA804A; Report No. AI2014-4; Japan Transport Safety Board: Tokyo, Japan, 25 September 2014.

43. Aircraft Incident Report: Auxiliary Power Unit Battery Fire, Japan Airlines Boeing 787, JA 829 J, Boston, Massachusetts, January 7, 2013; Report No. PB2014-108867; National Transportation Safety Board: Washington, DC, USA, 21 November 2014.

44. Abraham, D.P.; Roth, E.P.; Kostecki, R. Diagnostic examination of thermally abused high-power lithium-ion cells. J. Power Sources 2006, 161, 648-657. [CrossRef]

45. Karter, M.J. Fire Loss in the United States During 2013; National Fire Protection Association: Quincy, MA, USA, 2014.

46. The Samsung Note7 Exploded. Available online: http://www.sohu.com/a/125020048_467791/ (accessed on 23 January 2017).

47. Is the Heart of the Distortion or Moral Bankruptcy? Available online: https://www.caishimv.com/party/ 1476152753.html/ (accessed on 11 October 2016).

48. Huawei P9 Plus Exploded and the Attitude Was Worse than Samsung Note7. Available online: http: //www.sohu.com/a/116273061_162764/ (accessed on 16 October 2016).

49. An iPhone 7 Took Fire and Burned a Car in Australia. Available online: http://news.mydrivers.com/1/504/ 504106.htm/ (accessed on 21 October 2016).

50. Too Scary! Suddenly, the iPhone Battery Exploded and Seven People Were Hospitalized. Available online: https://baijiahao.baidu.com/s?id=1589274155032747498\&wfr=spider\&for=pc/ (accessed on 11 January 2018).

51. An iPhone XS Max Caught Fire for the First Time and the Users Said They Might Sue Apple. Available online: http://www.sohu.com/a/285734633_499322/(accessed on 30 December 2018).

52. A Summary Analysis on the 35 Fire Accidents of New Energy Vehicles in 2016. Available online: http: //www.sohu.com/a/123335110_526255/ (accessed on 4 January 2017).

53. Electric Vehicle Fire Accident Inventory in the First Half of 2017. Available online: https://www.sohu.com/a/ 155869592_118021/ (accessed on 10 July 2017).

54. Electric Vehicle Fire Accident Inventory in the First Half of 2018. Available online: http://www.evpartner. com/news/8/detail-36915.html/ (accessed on 8 June 2018).

55. Flight UPS6 Crashed in Dubai on 3 September 2010. Available online: http://m.yzwb.net/a/180910225943473. $\mathrm{html} /$ (accessed on 10 September 2018).

56. The Boeing 787's Lithium Battery Troubles. Available online: http://www.360doc.com/content/13/0522/10/ 7536781_287205631.shtml/ (accessed on 22 May 2013). 
57. Why Lithium Batteries Are 'Frowned Upon' by Aircraft? Available online: http://www.fx361.com/page/2017/ 0731/2112773.shtml/ (accessed on 31 July 2017).

58. Wen, J.; Yu, Y.; Chen, C. A Review on Lithium-Ion Batteries Safety Issues: Existing Problems and Possible Solutions. Mater. Express 2012, 2, 197-212. [CrossRef]

59. Lyon, R.E.; Walters, R.N. Energetics of lithium ion battery failure. J. Hazard. Mater. 2016, 318, $164-172$. [CrossRef] [PubMed]

60. Liu, X.; Stoliarov, S.I.; Denlinger, M.; Masias, A.; Snyder, K. Comprehensive calorimetry of the thermally-induced failure of a lithium ion battery. J. Power Sources 2015, 280, 516-525. [CrossRef]

61. Ouyang, D.; He, Y.; Chen, M.; Liu, J.; Wang, J. Experimental study on the thermal behaviors of lithium-ion batteries under discharge and overcharge conditions. J. Thermal Anal. Calorim. 2018, 132, 65-75. [CrossRef]

62. Wang, Z.; Ouyang, D.; Chen, M.; Wang, X.; Zhang, Z.; Wang, J. Fire behavior of lithium-ion battery with different states of charge induced by high incident heat fluxes. J. Thermal Anal. Calorim. 2019, 136, 2239-2247. [CrossRef]

63. Zhang, J.; Lu, B.; Song, Y.; Ji, X. Diffusion induced stress in layered Li-ion battery electrode plates. J. Power Sources 2012, 209, 220-227. [CrossRef]

64. Riley, L.A.; Cavanagh, A.S.; George, S.M.; Jung, Y.S.; Yan, Y.; Lee, S.H.; Dillon, A.C. Conformal Surface Coatings to Enable High Volume Expansion Li-Ion Anode Materials. ChemPhysChem 2010, 11, 2124-2130. [CrossRef] [PubMed]

65. Basu, S.; Suresh, S.; Ghatak, K.; Bartolucci, S.; Gupta, T.; Hundekar, P.; Kumar, R.; Lu, T.; Datta, D.; Shi, Y. Utilizing van der Waals slippery interfaces to enhance the electrochemical stability of Silicon film anodes in lithium-ion batteries. ACS Appl. Mater. Interfaces 2018, 10, 13442-13451. [CrossRef]

66. Wu, Y.; Saxena, S.; Xing, Y.; Wang, Y.; Li, C.; Yung, W.; Pecht, M. Analysis of manufacturing-induced defects and structural deformations in Lithium-ion batteries using computed tomography. Energies 2018, 11, 925. [CrossRef]

67. Samsung Expands Recall to All Galaxy Note7 Devices. Available online: http://www.samsung.com/us/ note7recall/ (accessed on 20 August 2017).

68. Mohanty, D.; Hockaday, E.; Li, J.; Hensley, D.K.; Daniel, C.; Wood, D.L., III. Effect of electrode manufacturing defects on electrochemical performance of lithium-ion batteries: Cognizance of the battery failure sources. J. Power Sources 2016, 312, 70-79. [CrossRef]

69. Cannarella, J.; Arnold, C.B. The effects of defects on localized plating in lithium-ion batteries. J. Electrochem. Soc. 2015, 162, A1365-A1373. [CrossRef]

70. Kong, D.; Wen, R.; Ping, P.; Peng, R.; Zhang, J.; Chen, G. Study on degradation behavior of commercial 18650 LiAlNiCoO 2 cells in over-charge conditions. Int. J. Energy Res. 2019, 43, 552-567. [CrossRef]

71. Wu, W.; Wu, W.; Qiu, X.; Wang, S. Low-temperature reversible capacity loss and aging mechanism in lithium-ion batteries for different discharge profiles. Int. J. Energy Res. 2019, 43, 243-253. [CrossRef]

72. Kawamura, T.; Kimura, A.; Egashira, M.; Okada, S.; Yamaki, J.I. Thermal stability of alkyl carbonate mixed-solvent electrolytes for lithium ion cells. J. Power Sources 2002, 104, 260-264. [CrossRef]

73. Sloop, S.E.; Kerr, J.B.; Kinoshita, K. The role of Li-ion battery electrolyte reactivity in performance decline and self-discharge. J. Power Sources 2003, 119, 330-337. [CrossRef]

74. Nagasubramanian, G. Comparison of the thermal and electrochemical properties of $\mathrm{LiPF}_{6}$ and $\mathrm{LiN}\left(\mathrm{SO}_{2} \mathrm{C}_{2} \mathrm{~F}_{5}\right)_{2}$ salts in organic electrolytes. J. Power Sources 2003, 119, 811-814. [CrossRef]

75. Wang, Q.; Sun, J.; Yao, X.; Chen, C. C80 Calorimeter Studies of the Thermal Behavior of LiPF 6 Solutions. J. Solut. Chem. 2006, 35, 179-189. [CrossRef]

76. Ribière, P.; Grugeon, S.; Morcrette, M.; Boyanov, S.; Laruelle, S.; Marlair, G. Investigation on the fire-induced hazards of Li-ion battery cells by fire calorimetry. Energy Environ. Sci. 2012, 5, 5271-5280. [CrossRef]

77. Takata, K.; Morita, M.; Matsuda, Y.; Matsui, K. Cycling characteristics of secondary Li electrode in LiBF4/mixed ether electrolytes. J. Electrochem. Soc. 1985, 132, 126-128. [CrossRef]

78. Zhang, S.S.; Xu, K.; Jow, T.R. A new approach toward improved low temperature performance of Li-ion battery. Electrochem. Commun. 2002, 4, 928-932. [CrossRef]

79. Xu, K.; Zhang, S.S.; Lee, U.; Allen, J.L.; Jow, T.R. LiBOB: Is it an alternative salt for lithium ion chemistry? J. Power Sources 2005, 146, 79-85. [CrossRef]

80. $\mathrm{Xu}, \mathrm{W}$;; Angell, C.A. LiBOB and Its Derivatives: Weakly Coordinating Anions, and the Exceptional Conductivity of Their Nonaqueous Solutions. Electrochem. Solid State Lett. 2001, 4, E1-E4. [CrossRef] 
81. Li, Y.; Wang, Z.; Li, C.; Cao, Y.; Guo, X. Densification and ionic-conduction improvement of lithium garnet solid electrolytes by flowing oxygen sintering. J. Power Sources 2014, 248, 642-646. [CrossRef]

82. Zhang, Y.; Chen, F.; Tu, R.; Shen, Q.; Zhang, L. Field assisted sintering of dense Al-substituted cubic phase $\mathrm{Li}_{7} \mathrm{La}_{3} \mathrm{Zr}_{2} \mathrm{O}_{12}$ solid electrolytes. J. Power Sources 2014, 268, 960-964. [CrossRef]

83. Kobayashi, Y.; Miyashiro, H.; Takeuchi, T.; Shigemura, H.; Balakrishnan, N.; Tabuchi, M.; Kageyama, H.; Iwahori, T. All-solid-state lithium secondary battery with ceramic/polymer composite electrolyte. Solid State Ion. 2002, s152-s153, 137-142. [CrossRef]

84. Mei, A.; Wang, X.L.; Lan, J.L.; Feng, Y.C.; Geng, H.X.; Lin, Y.H.; Nan, C.W. Role of amorphous boundary layer in enhancing ionic conductivity of lithium-lanthanum-titanate electrolyte. Electrochim. Acta 2010, 55, 2958-2963. [CrossRef]

85. Nelson, K.J.; d’Eon, G.L.; Wright, A.T.B.; Ma, L.; Xia, J.; Dahn, J.R. Studies of the effect of high voltage on the impedance and cycling performance of $\mathrm{Li}\left[\mathrm{Ni}_{0.4} \mathrm{Mn}_{0.4} \mathrm{Co}_{0.2}\right] \mathrm{O}_{2} /$ graphite lithium-ion pouch cells. J. Electrochem. Soc. 2015, 162, A1046-A1054. [CrossRef]

86. Kim, H.; Oh, S.-M.; Scrosati, B.; Sun, Y.-K. High-performance electrode materials for lithium-ion batteries for electric vehicles. Adv. Battery Technol. Electr. Veh. 2015, 191-241. [CrossRef]

87. Li, J.; Cameron, A.R.; Li, H.; Glazier, S.; Xiong, D.; Chatzidakis, M.; Allen, J.; Botton, G.A.; Dahn, J.R. Comparison of Single Crystal and Polycrystalline $\mathrm{LiNi}_{0.5} \mathrm{Mn}_{0.3} \mathrm{Co}_{0.2} \mathrm{O}_{2}$ Positive Electrode Materials for High Voltage Li-Ion Cells. J. Electrochem. Soc. 2017, 164, A1534-A1544. [CrossRef]

88. Zhang, Z.; Fouchard, D.; Rea, J.R. Differential scanning calorimetry material studies: Implications for the safety of lithium-ion cells. J. Power Sources 1998, 70, 16-20. [CrossRef]

89. Wang, Q.; Sun, J.; Chen, X.; Chu, G.; Chen, C. Effects of solvents and salt on the thermal stability of charged $\mathrm{LiCoO}_{2}$. Mater. Res. Bull. 2009, 44, 543-548. [CrossRef]

90. Wang, Q.; Sun, J.; Yao, X.; Chen, C. Thermal Behavior of Lithiated Graphite with Electrolyte in Lithium-Ion Batteries. J. Electrochem. Soc. 2006, 153, A329-A333. [CrossRef]

91. Yamaki, J.I.; Takatsuji, H.; Kawamura, T.; Egashira, M. Thermal stability of graphite anode with electrolyte in lithium-ion cells. Solid State Ion. 2002, 148, 241-245. [CrossRef]

92. Zinigrad, E.; Larush-Asraf, L.; Gnanaraj, J.S.; Gottlieb, H.E.; Sprecher, M.; Aurbach, D. Calorimetric studies of the thermal stability of electrolyte solutions based on alkyl carbonates and the effect of the contact with lithium. J. Power Sources 2005, 146, 176-179. [CrossRef]

93. Bowden, P.B.; Young, R.J. Deformation mechanisms in crystalline polymers. J. Mater. Sci. 1974, 9, $2034-2051$. [CrossRef]

94. Liu, N.; Wu, H.; Mcdowell, M.T.; Yao, Y.; Wang, C.; Cui, Y. A yolk-shell design for stabilized and scalable Li-ion battery alloy anodes. Nano Lett. 2012, 12, 3315-3321. [CrossRef]

95. Wagemaker, M.; Mulder, F.M. Properties and promises of nanosized insertion materials for Li-ion batteries. Acc. Chem. Res. 2012, 46, 1206-1215. [CrossRef]

96. Zhong, Y.J.; Li, J.T.; Wu, Z.G.; Guo, X.D.; Zhong, B.H.; Sun, S.G. $\mathrm{LiMn}_{0.5} \mathrm{Fe}_{0.5} \mathrm{PO}_{4}$ solid solution materials synthesized by rheological phase reaction and their excellent electrochemical performances as cathode of lithium ion battery. J. Power Sources 2013, 234, 217-222. [CrossRef]

97. Lu, C.; Qi, W.; Li, L.; Xu, J.; Chen, P.; Xu, R.; Han, L.; Yu, Q. Electrochemical performance and thermal property of electrospun PPESK/PVDF/PPESK composite separator for lithium-ion battery. J. Appl. Electrochem. 2013, 43, 711-720. [CrossRef]

98. Gong, W.; Wei, S.; Ruan, S.; Shen, C. Electrospun coaxial PPESK/PVDF fibrous membranes with thermal shutdown property used for lithium-ion batteries. Mater. Lett. 2019, 244, 126-129. [CrossRef]

99. Zhang, S.; Liu, P.; Chen, Y.; Jin, J.; Hu, L.; Jian, X. Preparation of thermally stable composite forward osmosis hollow fiber membranes based on copoly (phthalazinone biphenyl ether sulfone) substrates. Chem. Eng. Sci. 2017, 166, 91-100. [CrossRef]

100. Wang, G.; Zhang, H.; Qian, B.; Wang, J.; Jian, X.; Qiu, J. Preparation and characterization of electrospun poly (phthalazinone ether nitrile ketone) membrane with novel thermally stable properties. Appl. Surf. Sci. 2015, 351, 169-174. [CrossRef]

101. Kim, G.H.; Pesaran, A.; Spotnitz, R. A three-dimensional thermal abuse model for lithium-ion cells. J. Power Sources 2007, 170, 476-489. [CrossRef]

102. Spotnitz, R.; Franklin, J. Abuse behavior of high-power, lithium-ion cells. J. Power Sources 2003, 113, 81-100. [CrossRef] 
103. Venugopal, G. Characterization of thermal cut-off mechanisms in prismatic lithium-ion batteries. J. Power Sources 2001, 101, 231-237. [CrossRef]

104. Wang, Q.; Sun, J. Enhancing the safety of lithium ion batteries by 4-isopropyl phenyl diphenyl phosphate. Mater. Lett. 2007, 61, 3338-3340. [CrossRef]

105. Ouyang, D.; Liu, J.; Chen, M.; Weng, J.; Wang, J. An experimental study on the thermal failure propagation in lithium-ion battery pack. J. Electrochem. Soc. 2018, 165, A2184-A2193. [CrossRef]

106. Huang, P.; Wang, Q.; Li, K.; Ping, P.; Sun, J. The combustion behavior of large scale lithium titanate battery. Sci. Rep. 2015, 5, 7788. [CrossRef]

107. Ouyang, D.; Liu, J.; Chen, M.; Wang, J. Investigation into the Fire Hazards of Lithium-Ion Batteries under Overcharging. Appl. Sci. 2017, 7, 1314. [CrossRef]

108. Ping, P.; Wang, Q.S.; Huang, P.F.; Li, K.; Sun, J.H.; Kong, D.P.; Chen, C.H. Study of the fire behavior of high-energy lithium-ion batteries with full-scale burning test. J. Power Sources 2015, 285, 80-89. [CrossRef]

109. Chen, M.; Zhou, D.; Chen, X.; Zhang, W.; Liu, J.; Yuen, R.; Wang, J. Investigation on the thermal hazards of 18650 lithium ion batteries by fire calorimeter. J. Therm. Anal. Calorim. 2015, 122, 755-763. [CrossRef]

110. Fu, Y.; Lu, S.; Shi, L.; Cheng, X.; Zhang, H. Ignition and combustion characteristics of lithium ion batteries under low atmospheric pressure. Energy 2018, 161, 38-45. [CrossRef]

111. Ouyang, D.; Chen, M.; Liu, J.; Wei, R.; Weng, J.; Wang, J. Investigation of a commercial lithium-ion battery under overcharge/over-discharge failure conditions. RSC Adv. 2018, 8, 33414-33424. [CrossRef]

112. Jhu, C.Y.; Wang, Y.W.; Shu, C.M.; Chang, J.C.; Wu, H.C. Thermal explosion hazards on 18650 lithium ion batteries with a VSP2 adiabatic calorimeter. J. Hazard. Mater. 2011, 192, 99-107.87. [CrossRef]

113. Larsson, F.; Andersson, P.; Blomqvist, P.; Lorén, A.; Mellander, B.E. Characteristics of lithium-ion batteries during fire tests. J. Power Sources 2014, 271, 414-420. [CrossRef]

114. Golubkov, A.W.; Fuchs, D.; Wagner, J.; Wiltsche, H.; Stangl, C.; Fauler, G.; Voitic, G.; Thaler, A.; Hacher, V. Thermal-runaway experiments on consumer Li-ion batteries with metal-oxide and olivin-type cathodes. RSC Adv. 2014, 4, 3633-3642. [CrossRef]

115. Sun, J.; Li, J.; Zhou, T.; Yang, K.; Wei, S.; Tang, N.; Dang, N.; Li, H.; Qiu, X.; Chen, L. Toxicity, a serious concern of thermal runaway from commercial Li-ion battery. Nano Energy 2016, 27, 313-319. [CrossRef]

116. Yang, H.; Zhuang, G.V.; Ross, P.N. Thermal stability of $\mathrm{LiPF}_{6}$ salt and Li-ion battery electrolytes containing $\mathrm{LiPF}_{6}$. J. Power Sources 2006, 161, 573-579. [CrossRef]

117. Maleki, H.; Deng, G.; Anani, A. Thermal Stability Studies of Li-Ion Cells and Components. J. Electrochem. Soc. 1999, 146, 3224-3229. [CrossRef]

118. Gray, F.M. Solid Polymer Electrolytes; VCH: New York, NY, USA, 1991.

119. Braun, J.; Stöss, H.; Zober, A. Intoxication following the inhalation of hydrogen fluoride. Arch. Toxicol. 1984, 56, 50-54. [CrossRef] [PubMed]

120. Ouyang, D.; Chen, M.; Wei, R.; Wang, Z.; Wang, J. A study on the fire behaviors of 18650 battery and batteries pack under discharge. J. Therm. Anal. Calorim. 2019, 136, 1915-1926. [CrossRef]

121. Chen, M.; Liu, J.; He, Y.; Yuen, R.; Wang, J. Study of the fire hazards of lithium-ion batteries at different pressures. Appl. Therm. Eng. 2017, 125, 1061-1074. [CrossRef]

122. Wagner, M.W.; Liebenow, C.; Besenhard, J.O. Effect of polysulfide-containing electrolyte on the film formation of the negative electrode. J. Power Sources 1997, 68, 328-332. [CrossRef]

123. Wrodnigg, G.H.; Besenhard, J.O.; Winter, M. Cyclic and acyclic sulfites: New solvents and electrolyte additives for lithium ion batteries with graphitic anodes? J. Power Sources 2001, 97, 592-594. [CrossRef]

124. Lee, J.H.; Paik, U.; Hackley, V.A.; Choi, Y.M. Effect of carboxymethyl cellulose on aqueous processing of natural graphite negative electrodes and their electrochemical performance for lithium batteries. J. Electrochem. Soc. 2005, 152, A1763-A1769. [CrossRef]

125. Ouyang, D.; Liu, J.; Chen, M.; Weng, J.; Wang, J. Thermal Failure Propagation in Lithium-Ion Battery Modules with Various Shapes. Appl. Sci. 2018, 8, 1263. [CrossRef]

126. Lopez, C.F.; Jeevarajan, J.A.; Mukherjee, P.P. Experimental analysis of thermal runaway and propagation in lithium-ion battery modules. J. Electrochem. Soc. 2015, 162, A1905-A1915. [CrossRef]

127. Lamb, J.; Orendorff, C.J.; Steele, L.A.M.; Spangler, S.W. Failure propagation in multi-cell lithium ion batteries. J. Power Sources 2015, 283, 517-523. [CrossRef] 
128. Larsson, F.; Anderson, J.; Andersson, P.; Mellander, B.E. Thermal modelling of cell-to-cell fire propagation and cascading thermal runaway failure effects for lithium-ion battery cells and modules using fire walls. $J$. Electrochem. Soc. 2016, 163, A2854-A2865. [CrossRef]

129. Feng, X.; He, X.; Ouyang, M.; Lu, L.; Wu, P.; Kulp, C.; Prasser, S. Thermal runaway propagation model for designing a safer battery pack with $25 \mathrm{Ah} \mathrm{LiNi}_{\mathrm{x}} \mathrm{Co}_{\mathrm{y}} \mathrm{Mn}_{\mathrm{z}} \mathrm{O}_{2}$ large format lithium ion battery. Appl. Energy 2015, 154, 74-91. [CrossRef]

130. Wilke, S.; Schweitzer, B.; Khateeb, S.; Al-Hallaj, S. Preventing thermal runaway propagation in lithium ion battery packs using a phase change composite material: An experimental study. J. Power Sources 2017, 340, 51-59. [CrossRef]

131. Spinner, N.S.; Field, C.R.; Hammond, M.H.; Williams, B.A.; Myers, K.M.; Lubrano, A.L.; Rose- Pehrsson, S.L.; Tuttle, S.G. Physical and chemical analysis of lithium-ion battery cell-to-cell failure events inside custom fire chamber. J. Power Sources 2015, 279, 713-721. [CrossRef]

132. Gao, S.; Feng, X.; Lu, L. Thermal Runaway Propagation Assessment of Different Battery Pack Designs Using the TF5 Draft as Framework. J. Electrochem. Soc. 2019, 166, A1653-A1659. [CrossRef]

133. Feng, X.; Sun, J.; Ouyang, M.; Wang, F.; He, X.; Lu, L.; Peng, H. Characterization of penetration induced thermal runaway propagation process within a large format lithium ion battery module. J. Power Sources 2015, 275, 261-273. [CrossRef]

134. Alshaer, W.G.; Nada, S.A.; Rady, M.A.; Le Bot, C.; Del Barrio, E.P. Numerical investigations of using carbon foam/PCM/Nano carbon tubes composites in thermal management of electronic equipment. Energy Convers. Manag. 2015, 89, 873-884. [CrossRef]

135. Şahan, N.; Fois, M.; Paksoy, H. Improving thermal conductivity phase change materials-A study of paraffin nanomagnetite composites. Sol. Energy Mater. Sol. Cells 2015, 137, 61-67. [CrossRef]

136. Feng, X.; Lu, L.; Ouyang, M.; Li, J.; He, X. A 3D thermal runaway propagation model for a large format lithium ion battery module. Energy 2016, 115, 194-208. [CrossRef]

137. Coman, P.T.; Darcy, E.C.; Veje, C.T.; White, R.E. Numerical analysis of heat propagation in a battery pack using a novel technology for triggering thermal runaway. Appl. Energy 2017, 203, 189-200. [CrossRef]

138. Coman, P.T.; Rayman, S.; White, R.E. A lumped model of venting during thermal runaway in a cylindrical Lithium Cobalt Oxide lithium-ion cell. J. Power Sources 2016, 307, 56-62. [CrossRef]

139. Richard, M.N.; Dahn, J.R. Accelerating rate calorimetry study on the thermal stability of lithium intercalated graphite in electrolyte. I. Experimental. J. Electrochem. Soc. 1999, 146, 2068-2077. [CrossRef]

140. Richard, M.N.; Dahn, J.R. Accelerating rate calorimetry study on the thermal stability of lithium intercalated graphite in electrolyte. II. Modeling the results and predicting differential scanning calorimeter curves. J. Electrochem. Soc. 1999, 146, 2078-2084. [CrossRef]

141. Guo, G.; Long, B.; Cheng, B. Three-dimensional thermal finite element modeling of lithium-ion battery in thermal abuse application. J. Power Sources 2010, 195, 2393-2398. [CrossRef]

142. Hatchard, T.D.; MacNeil, D.D.; Basu, A.; Dahn, J.R. Thermal model of cylindrical and prismatic lithium-ion cells. J. Electrochem. Soc. 2001, 148, A755-A761. [CrossRef]

143. Yeow, K.F.; Teng, H. Characterizing thermal runaway of lithium-ion cells in a battery system using finite element analysis approach. Sae Int. J. Altern. Powertrains 2013, 2, 179-186. [CrossRef]

144. Spotnitz, R.M.; Weaver, J.; Yeduvaka, G.; Doughty, D.H.; Roth, E.P. Simulation of abuse tolerance of lithium-ion battery packs. J. Power Sources 2007, 163, 1080-1086. [CrossRef]

145. Kieler, A. At Least 17 Lithium-Ion Batteries Have Exploded on Planes This Year. Available online: https:// consumerist.com/2017/06/09/at-least-17-lithium-ion-batteries-have-exploded-on-planes-this-year/ (accessed on 6 September 2017).

146. Yafei, W.; Lizhong, Y.; Xiaodong, Z.; Jiakun, D.; Yupeng, Z.; Zhihua, D. Experiment study of the altitude effects on spontaneous ignition characteristics of wood. Fuel 2010, 89, 1029-1034. [CrossRef]

147. Niu, Y.; He, Y.; Hu, X.; Zhou, D.; Lin, C.; Yin, J.; Yao, W. Experimental study of burning rates of cardboard box fires near sea level and at high altitude. Proc. Combust. Inst. 2013, 34, 2565-2573. [CrossRef]

148. Yao, W.; Hu, X.; Rong, J.; Wang, J.; Zhang, H. Experimental study of large-scale fire behavior under low pressure at high altitude. J. Fire Sci. 2013, 31, 481-494. [CrossRef]

149. Li, Z.; He, Y.; Zhang, H.; Wang, J. Combustion characteristics of n-heptane and wood crib fires at different altitudes. Proc. Combust. Inst. 2009, 32, 2481-2488. [CrossRef] 
150. McAllister, S.; Fernandez-Pello, C.; Urban, D.; Ruff, G. The combined effect of pressure and oxygen concentration on piloted ignition of a solid combustible. Combust. Flame 2010, 157, 1753-1759. [CrossRef]

151. Zarzecki, M.; Quintiere, J.G.; Lyon, R.E.; Rossmann, T.; Diez, F.J. The effect of pressure and oxygen concentration on the combustion of PMMA. Combust. Flame 2013, 160, 1519-1530. [CrossRef]

152. Weng, W.G.; Hasemi, Y.; Fan, W.C. Predicting the pyrolysis of wood considering char oxidation under different ambient oxygen concentrations. Combust. Flame 2006, 145, 723-729. [CrossRef]

153. Liu, J.; He, Y.; Zhou, Z.; Yao, W.; Yuen, R.; Wang, J. The burning behaviors of pool fire flames under low pressure. Fire Mater. 2016, 40, 318-334. [CrossRef]

154. Hu, X.; He, Y.; Li, Z.; Wang, J. Combustion characteristics of $\mathrm{n}$-heptane at high altitudes. Proc. Combust. Inst. 2011, 33, 2607-2615. [CrossRef]

155. Tu, R.; Fang, J.; Zhang, Y.M.; Zhang, J.; Zeng, Y. Effects of low air pressure on radiation-controlled rectangular ethanol and n-heptane pool fires. Proc. Combust. Inst. 2013, 34, 2591-2598. [CrossRef]

156. Tao, C.; He, Y.; Li, Y.; Wang, X. Effects of oblique air flow on burning rates of square ethanol pool fires. J. Hazard. Mater. 2013, 260, 552-562. [CrossRef] [PubMed]

157. Yin, J.; Yao, W.; Liu, Q.; Zhou, Z.; Wu, N.; Zhang, H.; Lin, C.H.; Wu, T.; Meier, O.C. Experimental study of n-Heptane pool fire behavior in an altitude chamber. Int. J. Heat Mass Transf. 2013, 62, 543-552. [CrossRef]

158. Jiusheng, Y.; Wei, Y.; Quanyi, L.; Wu, N.; Zhou, Z.; Wu, Y.; Zhang, H. Experimental study of n-heptane pool fire behaviors under dynamic pressures in an altitude chamber. Procedia Eng. 2013, 52, 548-556. [CrossRef]

159. Yao, J.; Liu, J.; Chen, X.; Li, H.; Niu, Y.; Zhou, Z.; Wang, J. Experimental study of small scale n-heptane pool fire with water bath in an altitude chamber. Int. J. Heat Mass Transf. 2015, 90, 1153-1159. [CrossRef]

160. Fang, J.; Tu, R.; Guan, J.; Wang, J.; Zhang, Y. Influence of low air pressure on combustion characteristics and flame pulsation frequency of pool fires. Fuel 2011, 90, 2760-2766. [CrossRef]

161. Liu, J.; He, Y.; Zhou, Z.; Yuen, R.; Wang, J. Investigation of enclosure effect of pressure chamber on the burning behavior of a hydrocarbon fuel. Appl. Therm. Eng. 2016, 101, 202-216. [CrossRef]

162. Zeng, Y.; Fang, J.; Tu, R.; Wang, J.; Zhang, Y. Study on burning characteristics of small-scale ethanol pool fire in closed and open space under low air pressure. In ASME 2011 International Mechanical Engineering Congress and Exposition; American Society of Mechanical Engineers: New York, NY, USA, 2011; pp. 1423-1430.

163. Chen, M.; Liu, J.; Lin, X.; Huang, Q.; Yuen, R.; Wang, J. Combustion characteristics of primary lithium battery at two altitudes. J. Therm. Anal. Calorim. 2016, 124, 865-870. [CrossRef]

164. Mizushima, K.; Jones, P.; Wiseman, P.; Goodenough, J.B. $\mathrm{LixCoO}_{2}(0<\mathrm{x}<-1)$ : A new cathode material for batteries of high energy density. Mater. Res. Bull. 1980, 15, 783-789.

165. Thackeray, M.; David, W.; Bruce, P.; Goodenough, J.B. Lithium insertion into manganese spinels. Mater. Res. Bull. 1983, 18, 461-472. [CrossRef]

166. Padhi, A.K.; Nanjundaswamy, K.S.; Goodenough, J.B. Phospho-olivines as positive-electrode materials for rechargeable lithium batteries. J. Electrochem. Soc. 1997, 144, 1188-1194. [CrossRef]

167. Kraytsberg, A.; Ein-Eli, Y. Higher, Stronger, Better ... A Review of 5 Volt Cathode Materials for Advanced Lithium-Ion Batteries. Adv. Energy Mater. 2012, 2, 922-939. [CrossRef]

168. Takahashi, Y.; Tode, S.; Kinoshita, A.; Fujimoto, H.; Nakane, I.; Fujitani, S. Development of Lithium-Ion Batteries with a $\mathrm{LiCoO}_{2}$ Cathode Toward High Capacity by Elevating Charging Potential. J. Electrochem. Soc. 2008, 155, A537-A541. [CrossRef]

169. Yin, R.-Z.; Kim, Y.-S.; Shin, S.-J.; Jung, I.; Kim, J.S.; Jeong, S.K. In situ XRD investigation and thermal properties of $\mathrm{Mg}$ doped $\mathrm{LiCoO}_{2}$ for lithium ion batteries. J. Electrochem. Soc. 2012, 159, A253-A258. [CrossRef]

170. Ahn, S.; Kim, H.-S.; Yang, S.; Do, J.Y.; Kim, B.H.; Kim, K. Thermal stability and performance studies of $\mathrm{LiCo}_{1 / 3} \mathrm{Ni}_{1 / 3} \mathrm{Mn}_{1 / 3} \mathrm{O}_{2}$ with phosphazene additives for Li-ion batteries. J. Electroceram. 2009, 23, 289-294. [CrossRef]

171. Zhang, L.; Ma, Y.; Cheng, X.; Du, C.; Guan, T.; Cui, Y.; Sun, S.; Zuo, P.; Gao, Y.; Yin, G. Capacity fading mechanism during long-term cycling of over-discharged $\mathrm{LiCoO}_{2} /$ mesocarbon microbeads battery. J. Power Sources 2015, 293, 1006-1015. [CrossRef]

172. Ji, Y.; Zhang, P.; Lin, M.; Zhao, W.; Zhang, Z.; Zhao, Y.; Yang, Y. Toward a stable electrochemical interphase with enhanced safety on high-voltage $\mathrm{LiCoO}_{2}$ cathode: A case of phosphazene additives. J. Power Sources 2017, 359, 391-399. [CrossRef] 
173. Deng, Y.; Kang, T.; Ma, Z.; Tan, X.; Song, X.; Wang, Z.; Pang, P.; Shu, D.; Zuo, X.; Nan, J. Safety influences of the $\mathrm{Al}$ and Ti elements modified $\mathrm{LiCoO}_{2}$ materials on $\mathrm{LiCoO}_{2} /$ graphite batteries under the abusive conditions. Electrochim. Acta 2019, 295, 703-709. [CrossRef]

174. Yamada, A.; Chung, S.-C.; Hinokuma, K. Optimized $\mathrm{LiFePO}_{4}$ for lithium battery cathodes. J. Electrochem. Soc. 2001, 148, A224-A229. [CrossRef]

175. Jiang, J.; Dahn, J. ARC studies of the thermal stability of three different cathode materials: $\mathrm{LiCoO}_{2}$; $\mathrm{Li}\left[\mathrm{Ni}_{0.1} \mathrm{Co}_{0.8} \mathrm{Mn}_{0.1}\right] \mathrm{O}_{2}$; and $\mathrm{LiFePO}_{4}$, in $\mathrm{LiPF}_{6}$ and LiBoB EC/DEC electrolytes. Electrochem. Commun. 2004, 6, 39-43. [CrossRef]

176. Bazzi, K.; Nazri, M.; Naik, V.; Garg, V.K.; Oliveira, A.C.; Nazri, G.A.; Naik, R. Enhancement of electrochemical behavior of nanostructured $\mathrm{LiFePO}_{4} /$ Carbon cathode material with excess Li. J. Power Sources 2016, 306, 17-23. [CrossRef]

177. Johnson, I.D.; Lübke, M.; Wu, O.Y.; Makwana, N.M.; Smales, G.J.; Islam, H.U.; Dedigama, R.Y.; Gruar, R.I.; Tighe, C.J.; Scanlon, D.O.; et al. Pilot-scale continuous synthesis of a vanadium-doped $\mathrm{LiFePO}_{4} / \mathrm{C}$ nanocomposite high-rate cathodes for lithium-ion batteries. J. Power Sources 2016, 302, 410-418. [CrossRef]

178. Huang, Y.; Liu, H.; Gong, L.; Hou, Y.; Li, Q. A simple route to improve rate performance of $\mathrm{LiFePO}_{4} /$ reduced graphene oxide composite cathode by adding $\mathrm{Mg}^{2+}$ via mechanical mixing. J. Power Sources 2017, 347, 29-36. [CrossRef]

179. Ohzuku, T.; Makimura, Y. Layered lithium insertion material of $\mathrm{LiCo}_{1 / 3} \mathrm{Ni}_{1 / 3} \mathrm{Mn}_{1 / 3} \mathrm{O}_{2}$ for lithium-ion batteries. Chem. Lett. 2001, 30, 642-643. [CrossRef]

180. Liu, Z.; Yu, A.; Lee, J.Y. Synthesis and characterization of $\mathrm{LiNi}_{1-x-y} \mathrm{Co}_{x} \mathrm{Mn}_{y} \mathrm{O}_{2}$ as the cathode materials of secondary lithium batteries. J. Power Sources 1999, 81, 416-419. [CrossRef]

181. Myung, S.-T.; Maglia, F.; Park, K.-J.; Yoon, C.S.; Lamp, P.; Kim, S.J.; Sun, Y.K. Nickel-rich layered cathode materials for automotive lithium-ion batteries: Achievements and perspectives. ACS Energy Lett. 2016, 2, 196-223. [CrossRef]

182. Ma, L.; Xia, J.; Xia, X.; Dahn, J.R. The impact of vinylene carbonate, fluoroethylene carbonate and vinyl ethylene carbonate electrolyte additives on electrode/electrolyte reactivity studied using accelerating rate calorimetry. J. Electrochem. Soc. 2014, 161, A1495-A1498. [CrossRef]

183. Ma, L.; Xia, J.; Dahn, J. Ternary electrolyte additive mixtures for Li-ion cells that promote long lifetime and less reactivity with charged electrodes at elevated temperatures. J. Electrochem. Soc. 2015, 162, A1170-A1174. [CrossRef]

184. Liu, X.; Ren, D.; Hsu, H.; Feng, X.; Xu, G.L.; Zhuang, M.; Gao, H.; Lu, L.; Han, X.; Chu, Z.; et al. Thermal runaway of lithium-ion batteries without internal short circuit. Joule 2018, 2, 2047-2064. [CrossRef]

185. Hwang, S.; Chang, W.; Kim, S.M.; Su, D.; Kim, D.H.; Lee, J.Y.; Chung, K.Y.; Stach, E.A. Investigation of changes in the surface structure of $\mathrm{Li}_{\mathrm{x}} \mathrm{Ni}_{0.8} \mathrm{Co}_{0.15} \mathrm{Al}_{0.05} \mathrm{O}_{2}$ cathode materials induced by the initial charge. Chem. Mater. 2014, 26, 1084-1092. [CrossRef]

186. Cai, L.; Liu, Z.; An, K.; Liang, C. Probing Li-Ni Cation Disorder in $\mathrm{Li}_{1-x} \mathrm{Ni}_{1+x-y} \mathrm{Al}_{\mathrm{y}} \mathrm{O}_{2}$ Cathode Materials by Neutron Diffraction. J. Electrochem. Soc. 2012, 159, A924-A928. [CrossRef]

187. Lee, M.J.; Noh, M.; Park, M.H.; Jo, M.; Kim, H.; Nam, H.; Cho, J. The role of nanoscale-range vanadium treatment in $\mathrm{LiNi}_{0.8} \mathrm{Co}_{0.15} \mathrm{Al}_{0.05} \mathrm{O}_{2}$ cathode materials for Li-ion batteries at elevated temperatures. J. Mater. Chem. A 2015, 3, 13453-13460. [CrossRef]

188. Muto, S.; Tatsumi, K.; Kojima, Y.; Oka, H.; Kondo, H.; Horibuchi, K.; Ukyo, Y. Effect of Mg-doping on the degradation of $\mathrm{LiNiO}_{2}$-based cathode materials by combined spectroscopic methods. J. Power Sources 2012, 205, 449-455. [CrossRef]

189. Huang, B.; Li, X.; Wang, Z.; Guo, H.; Xiong, X. Synthesis of Mg-doped $\mathrm{LiNi}_{0.8} \mathrm{Co}_{0.15} \mathrm{Al}_{0.05} \mathrm{O}_{2}$ oxide and its electrochemical behavior in high-voltage lithium-ion batteries. Ceram. Int. 2014, 40, 13223-13230. [CrossRef]

190. Wang, Q.; Mao, B.; Stoliarov, S.I. A review of lithium ion battery failure mechanisms and fire prevention strategies. Prog. Energy Combust. Sci. 2019, 73, 95-131. [CrossRef]

191. Kong, L.; Li, C.; Jiang, J.; Pecht, M.G. Li-ion battery fire hazards and safety strategies. Energies 2018, $11,2191$. [CrossRef]

192. Mier, F.A.; Hargather, M.J.; Ferreira, S.R. Experimental Quantification of Vent Mechanism Flow Parameters in 18650 Format Lithium Ion Batteries; Sandia National Lab.(SNL-NM): Albuquerque, NM, USA, 2019.

193. Balakrishnan, P.G.; Ramesh, R.; Kumar, T.P. Safety mechanisms in lithium-ion batteries. J. Power Sources 2006, 155, 401-414. [CrossRef] 
194. Meyer, J. Glass transition temperature as a guide to selection of polymers suitable for PTC materials. Polym. Eng. Sci. 1973, 13, 462-468. [CrossRef]

195. Johnson, B.A.; White, R.E. Characterization of commercially available lithium-ion batteries. J. Power Sources 1998, 70, 48-54. [CrossRef]

196. Huo, W.; Qu, Y. Effects of $\mathrm{Bi}_{1 / 2} \mathrm{Na}_{1 / 2} \mathrm{TiO}_{3}$ on the Curie temperature and the PTC effects of $\mathrm{BaTiO}_{3}$-based positive temperature coefficient ceramics. Sens. Actuators A Phys. 2006, 128, 265-269. [CrossRef]

197. Ding, S.W.; Jia, G.; Wang, J.; He, Z.Y. Electrical properties of Y-and Mn-doped $\mathrm{BaTiO}_{3}$-based PTC ceramics. Ceram. Int. 2008, 34, 2007-2010. [CrossRef]

198. Zhao, S.; Li, G.; Liu, H.; Dai, K.; Zheng, G.; Yan, X.; Liu, C.; Chen, J.; Shen, C.; Guo, Z. Positive Temperature Coefficient (PTC) Evolution of Segregated Structural Conductive Polypropylene Nanocomposites with Visually Traceable Carbon Black Conductive Network. Adv. Mater. Interfaces 2017, 4, 1700265. [CrossRef]

199. Zhao, S.; Lou, D.; Zhan, P.; Li, G.; Dai, K.; Guo, J.; Zheng, G.; Liu, C.; Shen, C.; Guo, Z. Heating-induced negative temperature coefficient effect in conductive graphene/polymer ternary nanocomposites with a segregated and double-percolated structure. J. Mater. Chem. C 2017, 5, 8233-8242. [CrossRef]

200. Dunn, B.; Kamath, H.; Tarascon, J.M. Electrical energy storage for the grid: A battery of choices. Science 2011, 334, 928-935. [CrossRef]

201. Mönnighoff, X.; Murmann, P.; Weber, W.; Winter, M.; Nowak, S. Post-mortem investigations of fluorinated flame retardants for lithium ion battery electrolytes by gas chromatography with chemical ionization. Electrochim. Acta 2017, 246, 1042-1051. [CrossRef]

202. Wang, Q.; Jiang, L.; Yu, Y.; Sun, J. Progress of enhancing the safety of lithium ion battery from the electrolyte aspect. Nano Energy 2019, 55, 93-114. [CrossRef]

203. Murmann, P.; Mönnighoff, X.; von Aspern, N.; Janssen, P.; Kalinovich, N.; Shevchuk, M.; Kazakova, O.; RöschenthaleR, G.V.; Cekic-Laskovic, I.; Winter, M. Influence of the fluorination degree of organophosphates on flammability and electrochemical performance in lithium ion batteries: Studies on fluorinated compounds deriving from triethyl phosphate. J. Electrochem. Soc. 2016, 163, A751-A757. [CrossRef]

204. Xu, K.; Ding, M.S.; Zhang, S.; Allen, J.L.; Jow, T.R. An attempt to formulate nonflammable lithium ion electrolytes with alkyl phosphates and phosphazenes. J. Electrochem. Soc. 2002, 149, A622-A626. [CrossRef]

205. Laoutid, F.; Bonnaud, L.; Alexandre, M.; Lopez-Cuesta, J.M.; Dubois, P. New prospects in flame retardant polymer materials: From fundamentals to nanocomposites. Mater. Sci. Eng. R Rep. 2009, 63, 100-125. [CrossRef]

206. Xiang, H.F.; Xu, H.Y.; Wang, Z.Z.; Chen, C. Dimethyl methylphosphonate (DMMP) as an efficient flame retardant additive for the lithium-ion battery electrolytes. J. Power Sources 2007, 173, 562-564. [CrossRef]

207. Hu, J.; Jin, Z.; Zhong, H.; Zhan, H.; Zhou, Y.; Li, Z. A new phosphonamidate as flame retardant additive in electrolytes for lithium ion batteries. J. Power Sources 2012, 197, 297-300. [CrossRef]

208. Ding, M.S.; Xu, K.; Jow, T.R. Effects of tris (2, 2, 2-trifluoroethyl) phosphate as a flame-retarding cosolvent on physicochemical properties of electrolytes of LiPF6 in EC-PC-EMC of 3, 3, 4 weight ratios. J. Electrochem. Soc. 2002, 149, A1489-A1498. [CrossRef]

209. Zeng, Z.; Jiang, X.; Wu, B.; Xiao, L.; Ai, X.; Yang, H.; Cao, Y. Bis (2, 2, 2-trifluoroethyl) methylphosphonate: An novel flame-retardant additive for safe lithium-ion battery. Electrochim. Acta 2014, 129, 300-304. [CrossRef]

210. Moreno, M.; Simonetti, E.; Appetecchi, G.B.; Carewska, M.; Montaninoc, M.; Kim, G.T.; Loeffler, N.; Passerini, S. Ionic Liquid Electrolytes for Safer Lithium Batteries I. Investigation around Optimal Formulation. J. Electrochem. Soc. 2017, 164, A6026-A6031. [CrossRef]

211. Chawla, N.; Bharti, N.; Singh, S. Recent advances in non-flammable electrolytes for safer lithium-ion batteries. Batteries 2019, 5, 19. [CrossRef]

212. Shi, P.; Zheng, H.; Liang, X.; Sun, Y.; Cheng, S.; Chen, C.; Xiang, H. A highly concentrated phosphate-based electrolyte for high-safety rechargeable lithium batteries. Chem. Commun. 2018, 54, 4453-4456. [CrossRef] [PubMed]

213. Safa, M.; Chamaani, A.; Chawla, N.; El-Zahab, B. Polymeric ionic liquid gel electrolyte for room temperature lithium battery applications. Electrochim. Acta 2016, 213, 587-593. [CrossRef]

214. Guo, Q.; Han, Y.; Wang, H.; Xiong, S.; Sun, W.; Zheng, C.; Xie, K. Flame Retardant and Stable $\mathrm{Li}_{1.5} \mathrm{~A}_{10.5} \mathrm{Ge}_{1.5}\left(\mathrm{PO}_{4}\right)_{3}$-Supported Ionic Liquid Gel Polymer Electrolytes for High Safety Rechargeable Solid-State Lithium Metal Batteries. J. Phys. Chem. C 2018, 122, 10334-10342. [CrossRef] 
215. Rectenwald, M.F.; Gaffen, J.R.; Rheingold, A.L.; Morgan, A.B.; Protasiewicz, J.D. Phosphoryl-Rich Flame-Retardant Ions (FRIONs): Towards Safer Lithium-Ion Batteries. Angew. Chem. 2014, 126, 4257-4260. [CrossRef]

216. Dagger, T.; Meier, V.; Hildebrand, S.; Brüggemann, D.; Winter, M.; Schappacher, F.M. Safety Performance of 5 Ah Lithium Ion Battery Cells Containing the Flame Retardant Electrolyte Additive (Phenoxy) Pentafluorocyclotriphosphazene. Energy Technol. 2018, 6, 2001-2010. [CrossRef]

217. Wu, B.; Pei, F.; Wu, Y.; Mao, R.; Ai, X.; Yang, H.; Cao, Y. An electrochemically compatible and flame-retardant electrolyte additive for safe lithium ion batteries. J. Power Sources 2013, 227, 106-110. [CrossRef]

218. Li, X.; Li, W.; Chen, L.; Lu, Y.; Su, Y.; Bao, L.; Wang, J.; Chen, R.; Chen, S.; Wu, F. Ethoxy (pentafluoro) cyclotriphosphazene (PFPN) as a multi-functional flame retardant electrolyte additive for lithium-ion batteries. J. Power Sources 2018, 378, 707-716. [CrossRef]

219. Wu, H.; Zhuo, D.; Kong, D. Improving battery safety by early detection of internal shorting with a bifunctional separator. Nat. Commun. 2014, 5, 5193. [CrossRef]

220. Ryou, M.H.; Lee, D.J.; Lee, J.N.; Lee, J.K.; Park, J.K.; Choi, J.W. Excellent cycle life of lithium-metal anodes in lithium-ion batteries with mussel-inspired polydopamine-coated separators. Adv. Energy Mater. 2012, 2, 645-650. [CrossRef]

221. Kim, J.H.; Kim, J.H.; Choi, K.H.; Yu, H.K.; Kim, J.H.; Lee, J.S.; Lee, S.Y. Inverse opal-inspired, nanoscaffold battery separators: A new membrane opportunity for high-performance energy storage systems. Nano Lett. 2014, 14, 4438-4448. [CrossRef]

222. Orendorff, C.J. The role of separators in lithium-ion cell safety. Electrochem. Soc. Interface 2012, 21, 61-65. [CrossRef]

223. Xiang, Y.; Li, J.; Lei, J.; Liu, D.; Xie, Z.; Qu, D.; Li, K.; Deng, T.; Tang, H. Advanced separators for lithium-ion and lithium-sulfur batteries: A review of recent progress. ChemSusChem 2016, 9, 3023-3039. [CrossRef] [PubMed]

224. Arora, P.; Zhang, Z. Battery separators. Chem. Rev. 2004, 104, 4419-4462. [CrossRef] [PubMed]

225. Ryou, M.H.; Lee, J.N.; Lee, D.J.; Kim, W.K.; Jeong, Y.K.; Choi, J.W.; Park, J.K.; Lee, Y.M. Effects of lithium salts on thermal stabilities of lithium alkyl carbonates in SEI layer. Electrochim. Acta 2012, 83, 259-263. [CrossRef]

226. Yeon, D.; Lee, Y.; Ryou, M.H.; Lee, Y.M. New flame-retardant composite separators based on metal hydroxides for lithium-ion batteries. Electrochim. Acta 2015, 157, 282-289. [CrossRef]

227. Lee, T.; Kim, W.K.; Lee, Y.; Ryou, M.H.; Lee, Y.M. Effect of $\mathrm{Al}_{2} \mathrm{O}_{3}$ coatings prepared by RF sputtering on polyethylene separators for high-power lithium ion batteries. Macromol. Res. 2014, 22, 1190-1195. [CrossRef]

228. Lee, J.Y.; Shin, S.H.; Moon, S.H. Flame retardant coated polyolefin separators for the safety of lithium ion batteries. Korean J. Chem. Eng. 2016, 33, 285-289. [CrossRef]

229. Zhang, J.; Yue, L.; Kong, Q.; Liu, Z.; Zhou, X.; Zhang, C.; Xu, Q.; Zhang, B.; Ding, G.; Qin, B.; et al. Sustainable, heat-resistant and flame-retardant cellulose-based composite separator for high-performance lithium ion battery. Sci. Rep. 2014, 4, 3935. [CrossRef]

230. Wu, W.; Wang, S.; Wu, W.; Chen, K.; Hong, S.; Lai, Y. A critical review of battery thermal performance and liquid based battery thermal management. Energy Convers. Manag. 2019, 182, 262-281. [CrossRef]

231. Ramadass, P.; Haran, B.; White, R.; Popov, B. Capacity fade of Sony 18650 cells cycled at elevated temperatures: Part II. Capacity fade analysis. J. Power Sources 2002, 112, 614-620. [CrossRef]

232. Smart, M.C.; Ratnakumar, B.V.; Whitcanack, L.D.; Chin, K.B.; Surampudi, S.; Croft, H.; Tice, D.; Staniewicz, R. Improved low-temperature performance of lithium-ion cells with quaternary carbonate-based electrolytes. $J$. Power Sources 2003, 119, 349-358. [CrossRef]

233. Ouyang, M.; Chu, Z.; Lu, L.; Li, J.; Han, X.; Feng, X.; Liu, G. Low temperature aging mechanism identification and lithium deposition in a large format lithium iron phosphate battery for different charge profiles. J. Power Sources 2015, 286, 309-320. [CrossRef]

234. Feng, X.; Xu, C.; He, X.; Wang, L.; Zhang, G.; Ouyang, M. Mechanisms for the evolution of cell variations within a LiNixCoyMnzO $\mathrm{O}_{2}$ /graphite lithium-ion battery pack caused by temperature non-uniformity. J. Clean. Prod. 2018, 205, 447-462. [CrossRef]

235. Lu, L.; Han, X.; Li, J.; Hua, J.; Ouyang, M. A review on the key issues for lithium-ion battery management in electric vehicles. J. Power Sources 2013, 226, 272-288. [CrossRef]

236. Choi, K.W.; Yao, N.P. Heat Transfer in Lead-Acid Batteries Designed for Electric-Vehicle Propulsion Application. J. Electrochem. Soc. 1979, 126, 1321-1328. [CrossRef] 
237. Mohammadian, S.K.; He, Y.L.; Zhang, Y. Internal cooling of a lithium-ion battery using electrolyte as coolant through microchannels embedded inside the electrodes. J. Power Sources 2015, 293, 458-466. [CrossRef]

238. Bandhauer, T.M.; Garimella, S. Passive, internal thermal management system for batteries using microscale liquid-vapor phase change. Appl. Therm. Eng. 2013, 61, 756-769. [CrossRef]

239. Stuart, T.A.; Hande, A. HEV battery heating using AC currents. J. Power Sources 2004, 129, 368-378. [CrossRef]

240. Ruan, H.; Jiang, J.; Sun, B.; Zhang, W.; Gao, W.; Wang, L.; Ma, Z. A rapid low-temperature internal heating strategy with optimal frequency based on constant polarization voltage for lithium-ion batteries. Appl. Energy 2016, 177, 771-782. [CrossRef]

241. Wang, S.; Li, K.; Tian, Y.; Wang, J.; Wu, Y.; Ji, S. Improved thermal performance of a large laminated lithium-ion power battery by reciprocating air flow. Appl. Therm. Eng. 2019, 152, 445-454. [CrossRef]

242. Liu, Y.; Ouyang, C.; Jiang, Q.; Liang, B. Design and parametric optimization of thermal management of lithium-ion battery module with reciprocating air-flow. J. Cent. South Univ. 2015, 22, 3970-3976. [CrossRef]

243. Zhang, J.; Kang, H.; Wu, K.; Li, J.; Wang, Y. The impact of enclosure and boundary conditions with a wedge-shaped path and air cooling for battery thermal management in electric vehicles. Int. J. Energy Res. 2018, 42, 4054-4069. [CrossRef]

244. Nelson, P.; Dees, D.; Amine, K.; Henriksen, G. Modeling thermal management of lithium-ion PNGV batteries. J. Power Sources 2002, 110, 349-356. [CrossRef]

245. Shang, Z.; Qi, H.; Liu, X.; Ouyang, C.; Wang, Y. Structural optimization of lithium-ion battery for improving thermal performance based on a liquid cooling system. Int. J. Heat Mass Transf. 2019, 130, 33-41. [CrossRef]

246. Zhao, C.; Sousa, A.C.M.; Jiang, F. Minimization of thermal non-uniformity in lithium-ion battery pack cooled by channeled liquid flow. Int. J. Heat Mass Transf. 2019, 129, 660-670. [CrossRef]

247. Wang, C.; Zhang, G.; Li, X.; Huang, J.; Wang, Z.; Lv, Y.; Meng, L.; Situ, W.; Rao, M. Experimental examination of large capacity liFePO 4 battery pack at high temperature and rapid discharge using novel liquid cooling strategy. Int. J. Energy Res. 2018, 42, 1172-1182. [CrossRef]

248. Ren, Y.; Yu, Z.; Song, G. Thermal management of a Li-ion battery pack employing water evaporation. J. Power Sources 2017, 360, 166-171. [CrossRef]

249. Ianniciello, L.; Biwolé, P.H.; Achard, P. Electric vehicles batteries thermal management systems employing phase change materials. J. Power Sources 2018, 378, 383-403. [CrossRef]

250. Fan, Y.F.; Zhang, X.X.; Wang, X.C.; Li, J.; Zhu, Q.B. Super-cooling prevention of microencapsulated phase change material. Thermochim. Acta 2004, 413,1-6. [CrossRef]

251. Wang, W.; Zhang, X.; Xin, C.; Rao, Z. An experimental study on thermal management of lithium ion battery packs using an improved passive method. Appl. Therm. Eng. 2018, 134, 163-170. [CrossRef]

252. Huang, P.; Verma, A.; Robles, D.J.; Wang, Q.; Mukherjee, P.; Sun, J. Probing the cooling effectiveness of phase change materials on lithium-ion battery thermal response under overcharge condition. Appl. Therm. Eng. 2018, 132, 521-530. [CrossRef]

253. Ling, Z.; Wen, X.; Zhang, Z.; Fang, X.; Gao, X. Thermal management performance of phase change materials with different thermal conductivities for Li-ion battery packs operated at low temperatures. Energy 2018, 144, 977-983. [CrossRef]

254. Zhang, S.; Wu, W.; Wang, S. Experimental investigations of Alum/expanded graphite composite phase change material for thermal energy storage and its compatibility with metals. Energy 2018, 161, 508-516. [CrossRef]

255. Wang, W.; Yang, X.; Fang, Y.; Ding, J.; Yan, J. Preparation and thermal properties of polyethylene glycol/expanded graphite blends for energy storage. Appl. Energy 2009, 86, 1479-1483. [CrossRef]

256. Ruiz, J.; Ganatra, Y.; Bruce, A.; Howarter, J.; Marconnet, A.M. Investigation of aluminum foams and graphite fillers for improving the thermal conductivity of paraffin wax-based phase change materials. In Proceedings of the 2017 16th IEEE Intersociety Conference on Thermal and Thermomechanical Phenomena in Electronic Systems (ITherm), Orlando, FL, USA, 30 May-2 June 2017; pp. 384-389.

257. Kim, D.; Jung, J.; Kim, Y.; Lee, M.; Seo, J.; Khan, S.B. Structure and thermal properties of octadecane/expanded graphite composites as shape-stabilized phase change materials. Int. J. Heat Mass Transf. 2016, 95, 735-741. [CrossRef]

258. Sheng, N.; Dong, K.; Zhu, C.; Akiyama, T.; Nomura, T. Thermal conductivity enhancement of erythritol phase change material with percolated aluminum filler. Mater. Chem. Phys. 2019, 229, 87-91. [CrossRef] 
259. Zhang, L.; Zhou, K.; Wei, Q.; Ma, L.; Ye, W.; Li, H.; Zhou, B.; Yu, Z.; Lin, C.; Luo, J.; et al. Thermal conductivity enhancement of phase change materials with 3D porous diamond foam for thermal energy storage. Appl. Energy 2019, 233, 208-219. [CrossRef]

260. Darkwa, J.; Zhou, T. Enhanced laminated composite phase change material for energy storage. Energy Convers. Manag. 2011, 52, 810-815. [CrossRef]

261. Hasse, C.; Grenet, M.; Bontemps, A.; Dendievel, R.; Sallée, H. Realization, test and modelling of honeycomb wallboards containing a Phase Change Material. Energy Build. 2011, 43, 232-238. [CrossRef]

262. Yang, Y.; Pang, Y.; Liu, Y.; Guo, H. Preparation and thermal properties of polyethylene glycol/expanded graphite as novel form-stable phase change material for indoor energy saving. Mater. Lett. 2018, 216, 220-223. [CrossRef]

263. Ling, Z.; Wang, F.; Fang, X.; Gao, X.; Zhang, Z. A hybrid thermal management system for lithium ion batteries combining phase change materials with forced-air cooling. Appl. Energy 2015, 148, 403-409. [CrossRef]

264. Fathabadi, H. High thermal performance lithium-ion battery pack including hybrid active-passive thermal management system for using in hybrid/electric vehicles. Energy 2014, 70, 529-538. [CrossRef]

265. Xie, Y.; Tang, J.; Shi, S.; Xing, Y.; Wu, H.; Hu, Z.; Wen, D. Experimental and numerical investigation on integrated thermal management for lithium-ion battery pack with composite phase change materials. Energy Convers. Manag. 2017, 154, 562-575. [CrossRef]

266. Song, L.; Zhang, H.; Yang, C. Thermal analysis of conjugated cooling configurations using phase change material and liquid cooling techniques for a battery module. Int. J. Heat Mass Transf. 2019, 133, 827-841. [CrossRef]

267. Ling, Z.; Cao, J.; Zhang, W.; Fang, X.; Gao, X. Compact liquid cooling strategy with phase change materials for Li-ion batteries optimized using response surface methodology. Appl. Energy 2018, 228, 777-788. [CrossRef]

268. Zheng, Y.; Shi, Y.; Huang, Y. Optimisation with adiabatic interlayers for liquid-dominated cooling system on fast charging battery packs. Appl. Therm. Eng. 2019, 147, 636-646. [CrossRef]

269. Xie, J.; Chen, J. Battery Early Warning and Monitoring System. U.S. Patent 8,952,823, 10 February 2015.

270. Hermann, W.A. Method for Detecting Battery Thermal Events Via Battery Pack Isolation Monitoring. U.S. Patent 8,168,315, 1 May 2012.

271. Hill, D.; Gully, B.; Agarwal, A.; Nourai, A.; Thrun, L.; Swartz, S.; Koslowske, M.; Cumming, S.; Butkowski, J.; Moore, B. Detection of off gassing from Li-ion batteries. In Proceedings of the 2013 IEEE Energytech, Cleveland, OH, USA, 21-23 May 2013; pp. 1-7.

272. Somov, A.; Spirjakin, D.; Ivanov, M.; Khromushin, I.; Passerone, R.; Baranov, A.; Savkin, A. Combustible gases and early fire detection: An autonomous system for wireless sensor networks. In Proceedings of the 1st International Conference on Energy-Efficient Computing and Networking; ACM: New York, NY, USA, 2010; pp. 85-93.

273. Lecocq, A.; Eshetu, G.G.; Grugeon, S.; Martin, N.; Laruelle, S.; Marlair, G. Scenario-based prediction of Li-ion batteries fire-induced toxicity. J. Power Sources 2016, 316, 197-206. [CrossRef]

274. Larsson, F.; Andersson, P.; Blomqvist, P.; Mellander, B.E. Toxic fluoride gas emissions from lithium-ion battery fires. Sci. Rep. 2017, 7, 10018. [CrossRef]

275. Andersson, P.; Blomqvist, P.; Lorén, A.; Larsson, F. Using Fourier transform infrared spectroscopy to determine toxic gases in fires with lithium-ion batteries. Fire Mater. 2016, 40, 999-1015. [CrossRef]

276. Keane, R.E.; Cary, G.J.; Davies, I.D.; Flannigan, M.D.; Gardner, R.H.; Lavorel, S.; Lenihan, J.M.; Li, C.; Rupp, T.S. A classification of landscape fire succession models: Spatial simulations of fire and vegetation dynamics. Ecol. Model. 2004, 179, 3-27. [CrossRef]

277. Summer, S.M. Flammability Assessment of Lithium-Ion and Lithium-Ion Polymer Battery Cells Designed for Aircraft Power Usage, US Department of Transportation; Federal Aviation Administration: Washington, DC, USA, 2010.

278. Ditch, B.; de Vries, J. Flammability Characterization of Lithium-Ion Batteries in Bulk Storage; FM Global: Johnston, RI, USA, 2013.

279. Egelhaaf, M.; Kress, D.; Wolpert, D.; Lange, T.; Justen, R.; Wilstermann, H. Fire Fighting of Li-Ion Traction Batteries. Sae Int. J. Altern. Powertrains 2013, 2, 37-48. [CrossRef]

280. Long, R.T.; Blum, A.F.; Bress, T.J.; Cotts, B.R. Best Practices for Emergency Response to Incidents Involving Electric Vehicles Battery Hazards: A Report on Full-Scale Testing Results; National Fire Protection Research Foundation: Quincy, MA, USA, 2013. 
281. Maloney, T. Extinguishment of Lithium-Ion and Lithium-Metal Battery Fires, US Department of Transportation; Federal Aviation Administration: Washington, DC, USA, 2014; pp. 46-51.

282. Edison, C. Considerations for ESS Fire Safety; DNV GL: Oslo, Norway, 2017.

283. Rao, H.; Huang, Z.; Zhang, H.; Xiao, S. Study of fire tests and fire safety measures on lithiumion battery used on ships. In Proceedings of the 2015 International Conference on Transportation Information and Safety (ICTIS), Wuhan, China, 25-28 June 2015; pp. 865-870.

284. Wang, Q.; Shao, G.; Duan, Q.; Chen, M.; Li, Y.; Wu, K.; Liu, B.; Peng, P.; Sun, J. The efficiency of heptafluoropropane fire extinguishing agent on suppressing the lithium titanate battery fire. Fire Technol. 2016, 52, 387-396. [CrossRef]

285. Luo, W.; Zhu, S.; Gong, J.; Zhou, Z. Research and Development of Fire Extinguishing Technology for Power Lithium Batteries. Procedia Eng. 2018, 211, 531-537. [CrossRef]

(C) 2019 by the authors. Licensee MDPI, Basel, Switzerland. This article is an open access article distributed under the terms and conditions of the Creative Commons Attribution (CC BY) license (http://creativecommons.org/licenses/by/4.0/). 